\title{
S3-Leitlinie Chronische Pankreatitis: Definition, Ätiologie, Diagnostik, konservative, interventionell endoskopische und operative Therapie der chronischen Pankreatitis. Leitlinie der Deutschen Gesellschaft für Verdauungs- und Stoffwechselkrankheiten (DGVS) ${ }^{1}$
}

S3-Consensus Guidelines on Definition, Etiology, Diagnosis and Medical, Endoscopic and Surgical Management of Chronic Pancreatitis German Society of Digestive and Metabolic Diseases (DGVS)

Autoren

Institute
A. Hoffmeister ${ }^{1 *}$, J. Mayerle ${ }^{2 *}$, C. Beglinger ${ }^{3}$, M. W. Büchler ${ }^{4}$, P. Bufler ${ }^{5}$, K. Dathe ${ }^{6}$, U. R. Fölsch ${ }^{7}$, H. Friess ${ }^{8}$, J. Izbicki ${ }^{9}$, S. Kahl ${ }^{10}$, E. Klar ${ }^{11}$, J. Keller ${ }^{12}$, W. T. Knoefe ${ }^{13}$, P. Layer ${ }^{12}$, M. Loehr ${ }^{14}$, R. Meier ${ }^{15}$, J. F. Riemann ${ }^{16}$, M. Rünzi ${ }^{17}$, R. M. Schmid ${ }^{18}$, A. Schreyer ${ }^{19}$, B. Tribl ${ }^{20}$, J. Werner ${ }^{4}$, H. Witt ${ }^{21}$, J. Mössner ${ }^{1 *}$, M. M. Lerch ${ }^{2^{* *}}$

Die Institutsangaben sind am Ende des Beitrags gelistet. eingereicht 11.7 .2012

akzeptiert 24.9.2012

Bibliografie

DOI http://dx.doi.org/

$10.1055 / \mathrm{s}-0032-1325479$

Z Gastroenterol 2012; 50:

1176-1224 ๑ Georg Thieme

Verlag KG Stuttgart · New York . ISSN 0044-2771

Korrespondenzadresse

Prof. Dr. Markus M. Lerch Klinik für Innere Medizin A, Universitätsmedizin, ErnstMoritz-Arndt-Universität Greifswald

Ferdinand-Sauerbruch-Straße 17475 Greifswald

Tel.: ++49/3834/867230

Fax: ++49/3834/867234

lerch@uni-greifswald.de

\begin{tabular}{|c|c|c|}
\hline \multicolumn{3}{|c|}{ Inhaltsverzeichnis } \\
\hline & Definition und Epidemiologie & 1178 \\
\hline & Ätiologie & 1179 \\
\hline & Diagnostik der exokrinen Insuffizienz & 1181 \\
\hline & Bildgebende Diagnostik & 1184 \\
\hline & Therapie des akuten Schubes & 1187 \\
\hline & $\begin{array}{l}\text { Indikationsstellung zur interventionellen } \\
\text { oder operativen Therapie }\end{array}$ & 1190 \\
\hline 7. & $\begin{array}{l}\text { Endoskopische und interventionelle } \\
\text { Therapie der chronischen Pankreatitis }\end{array}$ & 1192 \\
\hline & Schmerztherapie & 1198 \\
\hline & $\begin{array}{l}\text { Enzymsubstitution und Ernährung bei } \\
\text { chronischer Pankreatitis }\end{array}$ & 1201 \\
\hline & Operative Verfahren und ihre Indikation & 1205 \\
\hline & $\begin{array}{l}\text { Überwachung und Verlaufskontrolle der } \\
\text { chronischen Pankreatitis }\end{array}$ & 1208 \\
\hline & $\begin{array}{l}\text { Diagnostik und Therapie der chronischen } \\
\text { Pankreatitis im Kindesalter }\end{array}$ & 1210 \\
\hline
\end{tabular}

Die vorliegende Leitlinie wurde erstellt durch die Deutsche Gesellschaft für Verdauungs- und Stoffwechselkrankheiten (Leitung: Prof. Dr. med. M. M. Lerch, Klinik und Poliklinik für Innere Medizin A, Universitätsmedizin Greifswald; Prof. Dr. med. J. Mössner, Klinik und Poliklinik für Gastroenterologie und Rheumatologie, Universitätsklinikum Leipzig).

Folgende Fachgesellschaften/Organisationen waren darüber hinaus an der Leitlinienerstellung beteiligt:

- Deutsche Gesellschaft für Allgemein- und Viszeralchirurgie (DGAV)

- Deutsche Gesellschaft für Innere Medizin (DGIM)

- Deutsche Gesellschaft für Pathologie (DGP)

- Deutsche Gesellschaft für pädiatrische Gastroenterologie (DPGE)

- Österreichische Gesellschaft für Gastroenterologie und Hepatologie (ÖGGH)

- Schweizerische Gesellschaft für Gastroenterologie (SGG)

- Schweizerische Gesellschaft für Viszeralchirurgie (SGVC)

- Arbeitskreis der Pankreatektomierten e.V.
- Deutsche Pankreashilfe e.V.

- Deutschen Röntgengesellschaft

- bng Berufsverband der niedergelassenen Gastroenterologen

\section{Geltungsbereich und Gültigkeitsdauer der Leitlinie}

Die Empfehlungen der Leitlinie richten sich in erster Linie an alle an der Diagnostik und Therapie beteiligten Facharztgruppen im ambulanten und stationären Bereich. Die Leitlinie soll im Rahmen der Fort- und Weiterbildung Wissen vermitteln und dazu dienen, eine optimale medizinische Betreuung der Patienten zu erreichen. Den Betroffenen selbst soll die Möglichkeit gegeben werden, sich durch die Leitlinie über das Krankheitsbild „Chronische Pankreatitis“ zu informieren. Die Leitlinie soll bei der Entscheidungsfindung hinsichtlich diagnostischer und therapeutischer Maßnahmen dienen. Jedoch muss grundsätzlich bei jedem Patienten die Situation der Erkrankung individuell betrachtet werden und unter Berücksichtigung des Allgemeinzustands die weitere Vorgehensweise festgelegt werden. Ein Abweichen von den Empfehlungen der Leitlinie ist im konkreten Fall möglich. Die Leitlinie hat eine Gültigkeitsdauer von 5 Jahren.

\footnotetext{
* Gleichberechtigte Erstautoren.

** Gleichberechtigte Seniorautoren.

${ }^{1}$ In Zusammenarbeit mit der Deutschen Gesellschaft für Innere Medizin (DGIM), Berufsverband niedergelassener Gastroenterologen Deutschlands (bng), Gesellschaft für Pädiatrische Gastroenterologie und Ernährung (GPGE), Deutsche Gesellschaft für Ernährungsmedizin (DGEM), Deutsche Gesellschaft für Allgemein- und Viszeralchirurgie (DGAV), Österreichische Gesellschaft für Gastroenterologie und Hepatologie (OGGH), Schweizerische Gesellschaft für Gastroenterologie (SGG), Schweizerische Gesellschaft für Viszeralchirurgie (SGVC), Deutsche Röntgengesellschaft, Deutsche Pankreashilfe, Arbeitskreis der Pankreatektomierten, Deutsche Gesellschaft für Pathologie.
} 


\section{Arbeitsgruppenmitglieder}

$\nabla$

Die Bearbeitung der verschiedenen Themenbereiche erfolgte in verschiedenen Arbeitsgruppen. Die einzelnen Arbeitsgruppen und ihre Mitglieder sind in $\bullet$ Tab. 1 aufgeführt. Die Leiter der Arbeitsgruppen sind durch Fettdruck des Namens hervorgehoben.

Tab. 1 Personelle Besetzung der Arbeitsgruppen.

\begin{tabular}{|c|}
\hline $\begin{array}{l}\text { Arbeitsgruppe } 1 \text { „Funktionstests“ } \\
\text { Leitung: PD Dr. Jutta Keller, Hamburg }\end{array}$ \\
\hline Leitung: Prof. Dr. Matthias Löhr, Stockholm/Schweden \\
\hline Prof. Dr. Philip Hardt, Gießen \\
\hline Prof. Dr. Joachim Mössner, Leipzig \\
\hline Arbeitsgruppe 2 „Bildgebende Verfahren“ \\
\hline Leitung: Prof. Dr. Jürgen Riemann, Ludwigshafen \\
\hline Leitung: PD Dr. Andreas Schreyer, Regensburg \\
\hline Prof. Dr. Christoph F. Dietrich, Bad Mergentheim \\
\hline Prof. Dr. Michael Gebel, Hannover \\
\hline Prof. Dr. Michael Jung, Mainz \\
\hline PD Dr. Uwe Will, Gera \\
\hline Arbeitsgruppe 3 „Ätiologie und Verlaufskontrolle/Überwachung“ \\
\hline Leitung: Prof. Dr. Helmut Michael Friess, München \\
\hline Leitung: Prof. Dr. Julia Mayerle, Greifswald \\
\hline Jürgen Kleeberg, Berlin \\
\hline Prof. Dr. Jörg Kleeff, München \\
\hline PD Dr. Niels Teich, Leipzig \\
\hline Arbeitsgruppe 4 „Therapie des akuten Schubes“ \\
\hline Leitung: Prof. Dr. Ulrich R. Fölsch, Kiel \\
\hline Leitung: Prof. Dr. Michael Rünzi, Essen \\
\hline Prof. Dr. Jürgen Freise, Mülheim an der Ruhr \\
\hline Prof. Dr. Bernhard Glasbrenner, Münster \\
\hline Prof. Dr. Peter Malfertheiner, Magdeburg \\
\hline Prof. Dr. Claus Niederau, Oberhausen \\
\hline PD Dr. Alexander Schneider, Mannheim \\
\hline Prof. Dr. Emre F. Yekebas, Hamburg \\
\hline $\begin{array}{l}\text { Arbeitsgruppen } 5 \text { „Indikationsstellung zur Operation und interven- } \\
\text { tionellen endoskopischen Therapie \& Therapie des Rezidivs“" }\end{array}$ \\
\hline Leitung: Prof. Dr. Ernst Klar, Rostock \\
\hline Leitung: Prof. Dr. Markus Lerch, Greifswald \\
\hline Prof. Dr. Beat Gloor, Bern/Schweiz \\
\hline PD Dr. Stefan Kahl, Berlin \\
\hline Dr. Steffen Klabunde, Otterberg \\
\hline Prof. Dr. Jutta Lüttges, Saarbrücken \\
\hline Prof. Dr. Horst Neuhaus, Düsseldorf \\
\hline Prof. Dr. Bettina Rau, Rostock \\
\hline Arbeitsgruppe 6 „Operative Therapie der chronischen Pankreatitis“ \\
\hline Leitung: Prof. Dr. Jakob Izbicki, Hamburg \\
\hline Leitung: Prof. Dr. Jens Werner, Heidelberg \\
\hline Prof. Dr. Ulrich Adam, Berlin \\
\hline Prof. Dr. Markus Büchler, Heidelberg \\
\hline PD Dr. Thilo Hackert, Heidelberg \\
\hline Prof. Dr. Claus-Dieter Heidecke, Greifswald \\
\hline Prof. Dr. Dr. h. c. Ulrich Hopt, Freiburg \\
\hline Prof. Dr. Michael Schoenberg, München \\
\hline Prof. Dr. Christian Wittekind, Leipzig \\
\hline Prof. Dr. Helmut Witzigmann, Dresden \\
\hline $\begin{array}{l}\text { Arbeitsgruppe } 7 \text { „Endoskopische und interventionelle Therapie der } \\
\text { chronischen Pankreatitis“ }\end{array}$ \\
\hline Leitung: PD Dr. Albrecht Hoffmeister, Leipzig \\
\hline Leitung: Prof. Dr. Okka Hamer, Regensburg \\
\hline Prof. Dr. Hans-Joachim Schulz, Berlin \\
\hline Prof. Dr. Jörg Emmrich, Rostock \\
\hline Prof. Dr. Hans Seifert, Oldenburg \\
\hline
\end{tabular}

Tab. 1 (Fortsetzung)

\begin{tabular}{|l|}
\hline Arbeitsgruppe 8 „Schmerztherapie“ \\
\hline Leitung: Prof. Dr. Wolfram Trudo Knoefel, Düsseldorf \\
\hline Leitung: Prof. Dr. Roland Schmid, München \\
\hline Dr. Andrea Alexander, Düsseldorf \\
\hline PD Dr. Roland Pfützer, Köln \\
\hline Prof. Dr. Tim Strate, Reinbek \\
\hline Dr. Matthias Treiber, München \\
\hline Arbeitsgruppe 9 „Enzymsubstitution, Ernährung“ \\
\hline Leitung: Prof. Dr. Peter Layer, Hamburg \\
\hline Prof. Dr. Christian Löser, Kassel \\
\hline Prof. Dr. Paul Georg Lankisch, Lüneburg \\
\hline PD Dr. Jutta Keller, Hamburg \\
\hline Prof. Dr. Remy Meier, Liestal, Schweiz \\
\hline Prof. Dr. Johann Ockenga, Bremen \\
\hline Arbeitsgruppe 10 „Pädiatrie“ \\
\hline Leitung: PD Dr. Philip Bufler, München \\
\hline Dr. Dirk Grothues, Regensburg \\
\hline Prof. Dr. Jobst Henker, Dresden \\
\hline Prof. Dr. Klaus-Michael Keller, Wiesbaden \\
\hline Prof. Dr. Dietrich von Schweinitz, München \\
\hline Prof. Dr. Heiko Witt, München \\
\hline
\end{tabular}

\section{Methodik}

In dieser Leitlinie sind die Evidenzgrade nach dem Oxford-Schema angegeben ( $\bullet$ Tab.2). Die Empfehlungen sind so formuliert, dass sie die Stärke der Empfehlungen widerspiegeln ( $\bullet$ Abb.1). Eine Ausnahme stellen Empfehlungen dar, die als sog. „Klinischer Konsens-Punkt“ (KKP) die gute klinische Praxis in der Behandlung beschreiben.

Die Definition der Konsensusstärke erfolgte über die prozentuale Zustimmung der Konsensuskonferenzteilnehmer: Starker Konsens $>95 \%$, Konsens 75 - 95\%, Mehrheitliche Zustimmung 50 $75 \%$, kein Konsens $<50 \%$.

Hinsichtlich der weiteren, ausführlichen Details zum organisatorischen Ablauf sowie zu den methodischen Grundlagen der S3Leitlinienerstellung (Literaturrecherche, Klassifikation der Evidenz- und Empfehlungsgrade, Konsensusprozess etc.) wird auf den Leitlinienmethodenreport verwiesen.

Tab. 2 Klassifikation der Evidenz nach dem Oxford-Schema. ${ }^{1}$

\begin{tabular}{|c|c|}
\hline $\begin{array}{l}\text { Evidenz- } \\
\text { grad }\end{array}$ & Beschreibung \\
\hline la & $\begin{array}{l}\text { „Evidenz“ durch systematisches Review randomisierter } \\
\text { kontrollierter Studien (RCT) }\end{array}$ \\
\hline Ib & „Evidenz“ durch eine geeignet geplante RCT \\
\hline IC & Alle-oder-Keiner-Prinzip \\
\hline Ila & $\begin{array}{l}\text { „Evidenz“ durch systematisches Review gut geplanter } \\
\text { Kohortenstudien }\end{array}$ \\
\hline IIb & $\begin{array}{l}\text { „Evidenz“ durch eine gut geplante Kohortenstudie/RCT } \\
\text { mäßiger Qualität (z. B. < } 80 \text { \% Follow-up) }\end{array}$ \\
\hline Ilc & „Evidenz“ durch Outcome-Research-Studien \\
\hline IIla & $\begin{array}{l}\text { „Evidenz“ durch systematisches Review gut geplanter Fall- } \\
\text { kontrollstudien }\end{array}$ \\
\hline IIIb & „Evidenz“ durch eine Fallkontrollstudie \\
\hline IV & $\begin{array}{l}\text { „Evidenz“ durch Fallserien/Kohorten- und Fallkontroll- } \\
\text { studien mäßiger Qualität }\end{array}$ \\
\hline V & $\begin{array}{l}\text { Expertenmeinung ohne explizite kritische Bewertung oder } \\
\text { basierend auf physiologischen Modellen, Laborforschungs- } \\
\text { resultaten oder „first principles“ }\end{array}$ \\
\hline
\end{tabular}

${ }^{1}$ Nach „Oxford Centre of Evidence Based Medicine”, www.cebm.net. 


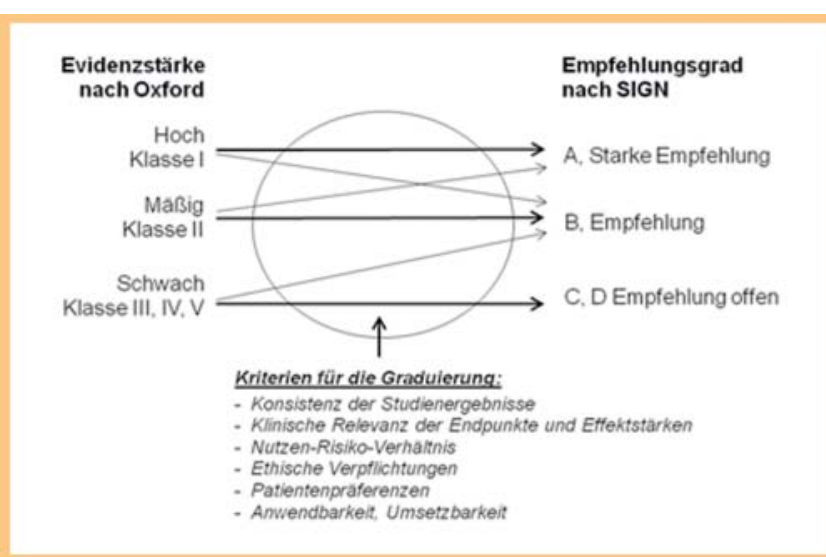

Abb. 1 Überleitung der Evidenzstärke in Empfehlungsgrade (modifizierte Abbildung aus "Lehrbuch Evidenzbasierte Medizin in Klinik und Praxis“, Hrsg. Kunz et al., Deutscher Ärzte-Verlag, 2007, Seite 367).

\section{Grundlagen \\ $\nabla$}

Kapitel 1 - Definition und Epidemiologie

1-1: Definition (AG1-AG10)

\section{Statement 1-1-1: Definition}

Die chronische Pankreatitis ist eine Erkrankung der Bauchspeicheldrüse, bei der durch rezidivierende Entzündungsschübe das Pankreasparenchym durch fibrotisches Bindegewebe ersetzt wird.

Folge des bindegewebigen Umbaus der Bauchspeicheldrüse ist ein fortschreitender Verlust der exokrinen und endokrinen Pankreasfunktion. Daneben kommt es zu charakteristischen Komplikationen wie z. B. Pseudozysten, Pankreasgangstenosen, Duodenalstenosen, Gefäßkomplikationen, Kompression der Gallenwege, eine Mangelernährung sowie einem Schmerzsyndrom. Schmerzen stellen das Hauptsymptom von Patienten mit chronischer Pankreatitis dar. Die chronische Pankreatitis stellt einen Risikofaktor für ein Pankreaskarzinom dar. Eine chronische Pankreatitis reduziert die Lebensqualität und die Lebenserwartung betroffener Patienten deutlich. [starker Konsens]

\section{Erläuterung}

Für Jahrhunderte war das Pankreas eine „terra incognita“ versteckt hinter dem Magen und ebenso blieb die pathophysiologische Bedeutung dieses Organs im Verborgenen. Erst 1761 beschrieb Jean-Baptista Morgagni den ersten Autopsiefall einer chronischen Pankreatitis und es dauerte weitere 60 Jahre, bis Kuntzmann eine Verbindung zwischen Fettstühlen und einer Erkrankung der Bauchspeicheldrüse herstellte. Selbst im 21. Jahrhundert ist der Zeitraum vom Symptombeginn bis zur Diagnosestellung einer chronischen Pankreatitis unverhältnismäßig lang. Grund hierfür sind das Fehlen spezifischer Laborparameter sowie die unspezifischen klinischen Symptome, die dieses Krankheitsbild charakterisieren. Die erste moderne Methode zur Diagnosestellung von Pankreaserkrankungen entstand 1929, als Elman die Amylasemessung im Serum in die klinische Routine einführte. Im Anschluss an diese Entdeckung gelang es Comfort und Mitarbeitern, aus klinischen Beobachtungen, Erkenntnissen aus Operationen und Autopsiestudien den natürlichen Verlauf der chronischen Pankreatitis zu beschreiben. Sie berichteten erstmals über eine Assoziation mit langjährigem Alkoholkonsum, das häufige Auftreten der Erkrankung in der 3. und 4. Lebensdekade und typische Komplikationen wie den Verlust der endokrinen oder exokrinen Funktion der Bauchspeicheldrüse.

Die Inzidenz der chronischen Pankreatitis steigt in Abhängigkeit vom Alkoholkonsum der Bevölkerung. Weltweit wird die Inzidenz zwischen 1,6-23/100 000 mit einer steigenden Prävalenz [1] angegeben. Obwohl die meisten Patienten mit chronischer Pankreatitis ambulant behandelt werden, erfolgten allein in Deutschland im Jahr 200810267 (ICD-10: K86) Krankenhausaufnahmen wegen chronischer Pankreatitis (stat. Bundesamt). Darin nicht enthalten sind die Patienten, die mit einem akuten Schub einer chronischen Pankreatitis als akute Pankreatitis kodiert wurden (50673 Fälle). Dies belegt die hohe sozioökonomische Bedeutung der Erkrankung. Die Letalität infolge einer chronischen Pankreatitis wird bei einer mittleren Beobachtungszeit von 6,3-9,8 Jahren mit 12,8$19,8 \%$ angegeben [2 - 4]. Die Gesamtletalität wurde in den gleichen Studien mit 28,8 - 35\% angegeben. Ein fortgesetzter Alkoholkonsum führt zu einem signifikant verkürzten Überleben. 33 \% der Patienten, die an einer chronischen Pankreatitis leiden, können ihren erlernten Beruf nicht mehr ausüben [5]. Die Anzahl der Patienten, die arbeitslos werden aufgrund längerer Krankheitsphasen oder fortgesetzten Alkoholkonsums oder im Verlauf der Erkrankung entweder arbeitsunfähig und berentet werden, liegt bei $40 \%$ [3]. Die Sterblichkeit der Erkrankung ist 3,6-fach erhöht im Vergleich zur Normalbevölkerung. Die 10-Jahres-Überlebensrate beträgt $70 \%$, die 20-Jahres-Überlebensrate $45 \%$ im Vergleich zu $93 \%$ und $65 \%$ in einer altersadjustierten Kohorte. Fortgesetzter Alkoholabusus hat mit einer Hazard Ratio von 1,6, Rauchen mit einer HR von 1,4, eine Leberzirrhose mit einer HR von 2,5 einen negativen Einfluss auf die Prognose der Erkrankung [6].

Die Pathogenese der chronischen Pankreatitis ist in vielen Punkten noch unklar. Alkohol ist der wichtigste Risikofaktor und die häufigste Ursache im Erwachsenenalter. Wenn Kinder von einer chronischen Pankreatitis betroffen sind, so liegt häufig eine genetische Komponente vor. Beim Fortschreiten der chronischen Pankreatitis scheint Rauchen ein wichtiger Faktor zu sein $[7,8]$. Seit der Formulierung der ersten deutschen Konsensus-Empfehlungen [9] hat sich das Verständnis der chronischen Pankreatitis von seinen Grundlagen bis hin zur Behandlung wesentlich verbessert. Verantwortlich hierfür sind bedeutende Fortschritte in der Aufklärung der Pathomechanismen sowie eine größere Anzahl von validen epidemiologischen Beobachtungen und prospektiven, zum Teil randomisierten Therapiestudien.

Ziel dieser Leitlinie ist es, den aktuellen Kenntnisstand zu Definition, Ätiologie, Diagnostik und Therapie aller Formen der chronischen Pankreatitis bei Erwachsenen und Kindern zusammenzufassen, zu bewerten und in praxisrelevante Empfehlungen zu übertragen. Die Leitlinie soll der evidenzbasierten Fort- und Weiterbildung dienen und auf dieser Basis eine Verbesserung der medizinischen Versorgung der betroffenen Patienten im ambulanten und stationären Sektor erreichen.

Hierbei war es eine grundlegende Vorbedingung, die Leitlinie auf das Krankheitsbild der chronischen Pankreatitis zu beschränken und auf den Einschluss der akuten Pankreatitis zu verzichten. Die chronische Pankreatitis erfordert durch ihre Schwere, Häufigkeit und Chronizität und ihre Beeinträchtigung der Lebensqualität und Lebenserwartung eine angemessene diagnostische Abklärung und eine systematische Behandlung. 


\section{Kapitel 2 - Ätiologie (AG3)}

$\nabla$

\section{2-1: Ursachen einer chronischen Pankreatitis}

Statement 2-1-1

Alkohol kann als gesicherte Ursache für eine chronische Pankreatitis angesehen werden.

[Evidenzgrad 3b, starker Konsens]

Fallkontrollstudien schließen einen linearen Zusammenhang zwischen Menge und Dauer des Alkoholabusus und dem Auftreten einer chronischen Pankreatitis aus und legen einen logarithmischen Zusammenhang nahe.

[Evidenzgrad 4, starker Konsens]

\section{Kommentar}

Es gibt retrospektive Fall-Kontrollstudien mit einer ausreichenden Fallzahl, die einen kausalen Zusammenhang eines Alkoholabusus und einer chronischen Pankreatitis nahelegen. [10 - 16]. Levy und Mitarbeiter konnten 1995 in einer Studie aus Marseille einen logarithmischen Zusammenhang zwischen dem relativen Risiko, an einer Pankreatitis zu erkranken, und der Menge an konsumiertem Alkohol und Protein belegen. Als Risiko für die Entwicklung einer chronischen Pankreatitis wird von einem Minimum von $80 \mathrm{~g}$ Alkohol pro Tag über einen Zeitraum von 6 12 Jahren ausgegangen. Ein Schwellenwert kann nicht festgelegt werden. Die Art des konsumierten Alkohols hat keinen Einfluss auf das erhöhte Risiko. Patienten mit chronischer Pankreatitis oder Leberzirrhose unterscheiden sich nicht signifikant hinsichtlich der Menge des konsumierten Alkohols. Die Zeit zwischen Beginn eines exzessiven Alkoholkonsums bis zum Auftreten einer Pankreatitis beträgt im Mittel $18 \pm 11$ Jahre. Die Prävalenz der chronischen Pankreatitis korreliert mit der Menge des Alkoholkonsums in der Gesellschaft $[12,17,18]$.

Eine chronische Pankreatitis wird nicht durch eine Cholzystolithiasis bzw. Choledocholithiasis ausgelöst. Weder klinische Studien noch tierexperimentelle Daten belegen einen kausalen Zusammenhang für eine biliäre Genese der chronischen Pankreatitis (belegt ist die biliäre Genese einer akuten Pankreatitis oder unbehandelt auch für die rezidivierende akute Pankreatitis) [Evidenzgrad 4]. Nach nationalen und internationalen Leitlinien besteht bei Patienten mit Cholezystolithiasis und nach einer Episode einer akuten Pankreatitis ohne sichere Ursache und mit Cholezystolithiasis die Indikation zur Cholezystektomie [19, 20]. Aus pathophysiologischen Überlegungen könnte eine Chronifizierung bei rezidivierenden Schüben eintreten, sollte aber bei rechtzeitiger Gallengangssanierung nicht vorkommen. Eine Mikrolithiasis/Sludge im Ductus hepaticus communis (DHC) kann unbehandelt zu rezidivierenden Pankreatitis-Schüben führen. Zeichen einer chronischen Pankreatitis wie Kalzifikationen oder höhergradige Gangveränderungen wurden in diesem Zusammenhang bisher nicht beschrieben [21, 22].

Ein primärer Hyperparathyreodismus kann zu einer chronischen Pankreatitis mit oder ohne Kalzifikationen führen [Evidenzgrad 4]. Es liegen Fallserien von Patienten mit einem primären Hyperparathyreodismus (pHTP) vor, die eine erhöhte Rate an Pankreatitiden (akut und chronisch) belegen. Eine kausale Assoziation wird über erhöhte Serumkalziumspiegel vermutet [23]. Etwa 1\% der Patienten mit einer Pankreatitis hat zusätzlich einen pHPT und $12 \%$ der Patienten mit pHPT haben zusätzlich eine Pankreatitis [24]. Somit haben Patienten mit einem pHPT ein 28-fach er- höhtes Risiko, eine Pankreatitis zu entwickeln. Kontrollierte Studien existieren nicht $[23,24]$.

Der Diabetes mellitus Typ 1 oder 2 ist kein unabhängiger Risikofaktor für eine chronische Pankreatitis. Der Diabetes mellitus Typ 3c (pankreopriv) kann Folge einer chronischen Pankreatitis sein [Evidenzgrad 4]. Es liegen einzelne Fallserien vor, die eine Assoziation zwischen einem Diabetes mellitus und einer chronischen Pankreatitis ausschließen. Unbestritten ist die Assoziation der chronischen Pankreatitis mit dem Diabetes mellitus Typ 3c. Die Destruktion der Langerhanschen Inseln durch die progrediente Entzündungsreaktion führt zum Verlust der Expression und Sekretion von Insulin, Glukagon und Somatostatin. Hier ist der Diabetes eine Folge der chronischen Pankreatitis, aber nicht die Ursache [25].

Die Diskussion, ob ein Pancreas divisum einen Risikofaktor für das Auftreten einer chronischen Pankreatitis darstellt, wird weiterhin kontrovers geführt. Im Rahmen der abgehaltenen Konsensuskonferenz wurde diese Diskussion mit folgender Formulierung abgestimmt: Das Vorliegen eines Pancreas divisum ohne weitere Risikofaktoren führt eher nicht zu einer chronischen Pankreatitis [Evidenzgrad 3b]. Ein Pankreas divisum entsteht durch eine inkomplette Verschmelzung des dorsalen (Ductus Santorini) mit dem ventralen (Ductus Wirsungianus) Ausführungsgang des Pankreas während der Embryonalentwicklung. Somit münden beiden Gänge über getrennte Papillen (Papilla duodeni major und minor) in das Duodenum. Das Pankreas divisum ist die häufigste angeborene Fehlbildung des Pankreas.

Die Häufigkeit eines Pankreas divisum liegt in Autopsiestudien bei $5-10 \%$ und wird in $6-26 \%$ der Patienten mit idiopathischer chronischer Pankreatitis gefunden [26-35]. Bei Vorliegen eines weiteren Risikofaktors (z. B. Alkohol, SPINK-1-Mutationen) tritt gehäuft eine chronische Pankreatitis auf. Die Kohorten, die ein erhöhtes Risiko für eine chronische Pankreatitis bei alleinigem Vorliegen eines Pancreas divisum belegen, wurden häufig nicht auf weitere, z. B. genetische Risikofaktoren untersucht. In Einzelfällen kann eine endoskopische Intervention sinnvoll sein. Im Kindesalter sollte bei Auftreten einer akuten idiopathischen Pankreatitis ätiologisch an Anomalien des hepatopankreatikobiliären Systems gedacht werden [30].

Es gibt keinen sicheren Anhalt dafür, dass ein Papillentumor zu einer chronischen Pankreatitis führen kann [Evidenzgrad 4]. Einzelne Fallberichte zeigen eine Assoziation zwischen einem Papillentumor und wiederkehrenden Pankreatitisschüben, eine Chronifizierung wird jedoch nicht beschrieben. Bei Papillentumoren, die pankreatitischen Schübe auslösen, dürfte in der Regel deren Resektion eine Chronifizierung verhindern [36].

\section{Statement 2-1-2}

Patienten mit chronischer Pankreatitis, die rauchen, soll dringend empfohlen werden, sich einem Nikotinentwöhnungsprogramm zu unterziehen, da Zigarettenrauchen die Progression der Erkrankung beschleunigt.

[Evidenzgrad 3b, Empfehlungsgrad A, starker Konsens]

\section{Kommentar}

Rauchen beschleunigt die Krankheitsprogression bei chronischer Pankreatitis, kann aber zurzeit nicht als gesicherter alleiniger Auslöser für die Krankheitsentstehung angesehen werden. Größere, z. T. prospektive Kohortenstudien mit bis zu 695 Patienten zeigen, dass Rauchen zu einer Exazerbation des pankreatischen Schmerzes und zu Kalzifikationen führt [2, 6, 7, 16, 37 - 42]. Fort- 
gesetztes Rauchen führt auch unter Alkoholabstinenz zu einer rascheren Progression der chronischen Pankreatitis [39, 40]. Die Studie von Yadav et al. [38] zeigt, dass Patienten ohne Alkoholanamnese, aber mit 21-35 pack years ein erhöhtes Risiko für eine chronische Pankreatitis haben $(p<0,05$, Odds Ratio, OR, 3,26 ) [38]. Es ist durchaus wahrscheinlich, dass Rauchen in zukünftigen Studien als unabhängiger Risikofaktor etabliert werden wird.

\section{Statement 2-1-3}

Mutationen im kationischen Trypsinogen-Gen führen mit einer Penetranz von bis zu $80 \%$ in einem autosomal dominanten Erbgang zu einer chronischen Pankreatitis.

[Evidenzgrad 1c, starker Konsens]

\section{Kommentar}

Die drei 1996 publizierten Linkage-Analysen zeigten für die hereditäre Pankreatitis eine Kopplung mit einem Locus auf Chromosom 7q35 [43, 44]. Weitere genetische Analysen zeigten eine Assoziation der Erkrankung mit Mutationen im Trypsinogen-Gen (PRSS1) (initial p.N29I und p.R112H) [43]. Klinische Daten des EUROPAC-1 Registers belegen bei Patienten einen Zusammenhang zwischen Trypsinogen-Mutationen und dem Auftreten der Erkrankung [45]. Trypsinogen ist ein Schlüsselmolekül der Pathogenese der Pankreatitis. Bis zu 66\% der Patienten mit hereditärer Pankreatitis haben eine Mutation im PRSS1-Gen. Die Prävalenz der hereditären Pankreatitis beträgt 0,3/100 000 ([Auswahl: [43-52]).

\section{Statement 2-1-4}

Mutationen im SPINK1-Gen prädisponieren für eine idiopathische (sporadische) chronische Pankreatitis.

[Evidenzgrad 1a, starker Konsens]

\section{Kommentar}

Die 2008 publizierte Metaanalyse an 2431 Patienten und 4857 Kontrollen belegte mit einer Odds Ratio (OR) von 11,0, dass die N34S-Mutation im Serinprotease-Inhibitor, Kazal-Typ-1(SPINK1)Gen mit einer chronischen Pankreatitis assoziiert ist. Die OR für eine idiopathische Pankreatitis wird mit 14,97 angegeben. Weitere, seltenere Mutationen im SPINK1-Gen sind ebenfalls assoziiert mit dem Auftreten einer chronischen Pankreatitis. In der Gruppe der alkoholinduzierten Pankreatitiden errechnet sich eine OR von 4,98 für die N34S-Mutation. Insgesamt finden sich Mutationen im SPINK1-Gen bei bis zu $30 \%$ aller Patienten mit idiopathischer chronischer Pankreatitis [53, 54], aber nur in 1-2\% der Bevölkerung.

\section{Statement 2-1-5}

Patienten mit idiopathischer Pankreatitis tragen zu 25-30\% molekulare Veränderungen im CFTR-Gen, im Vergleich zu ca. $15 \%$ in der gesunden Bevölkerung. Somit stellen CFTR-Mutationen einen Risikofaktor für die chronische idiopathische Pankreatitis dar.

[Evidenzgrad 3b, starker Konsens]

\section{Kommentar}

In allen bisher publizierten Fallserien findet sich ein erhöhtes Risiko für eine idiopathische Pankreatitis bei Vorliegen einer Mutation im Cystic-Fibrosis-Transmembrane-Conductance-Regula-
tor(CFTR)-Gen ohne klinische Zeichen einer zystischen Fibrose. Die zystische Fibrose (synonym auch Mukoviszidose), eine autosomal-rezessiv vererbte Erkrankung mit einer geschätzten Inzidenz von 1:2500, ist u.a. durch eine Pankreasinsuffizienz und durch eine chronische Lungenerkrankung charakterisiert. Die Pankreasbeteiligung variiert von einem kompletten Verlust der exokrinen und endokrinen Funktion bis zu einer nahezu normalen Pankreasfunktion. Rezidivierende Pankreatitiden werden bei $1-2 \%$ der pankreassuffizienten und nur extrem selten auch bei pankreasinsuffizienten Patienten beobachtet [55]. Im Vergleich zur Normalbevölkerung weisen Patienten mit idiopathischer Pankreatitis etwa doppelt so häufig molekulare Veränderungen im CFTR-Gen auf [56-60].

\section{Statement 2-1-6}

Patienten mit einer Chymotrypsin-C-Mutation haben ein erhöhtes Risiko, an einer chronischen Pankreatitis zu erkranken. [Evidenzgrad 3b, starker Konsens]

\section{Kommentar}

Seit der Erstbeschreibung von Mutationen im Chymotrypsin-C (CTRC)-Gen im Jahr 2008 [61] konnte die Assoziation dieser Mutation mit der idiopathischen chronischen Pankreatitis sowie der alkoholischen chronischen und hereditären Pankreatitis in mindestens 3 unabhängigen Kohorten reproduziert werden [62, 63]. Mutationen im CTRC-Gen finden sich bei 3,3\% der Patienten mit idiopathischer Pankreatitis. CTRC-Genmutationen führen unter experimentellen Bedingungen zum Endoplasmatischen-Reticulum-Stress (ER-Stress) in Azinuszellen, der als Ursache des Zellschadens angenommen wird [61-64].

\section{Zusammenfassung zur Ätiologie der chronischen Pan- kreatitis}

Es liegen keine populationsbasierten Daten zur Ätiologie der chronischen Pankreatitis aus Europa vor. Alkoholabusus ist die überwiegende prädisponierende Ursache mit je nach Studienlage 50-84\% im Erwachsenenalter. Die zweithäufigste Gruppe ist die idiopathische Pankreatitis mit bis zu $28 \%$. Hierbei finden sich in bis zu 45 \% genetische (Suszeptibilitäts-)Faktoren. Eine hereditäre Pankreatitis nach Definition von Comfort und Steinberg liegt bei bis zu 1 - 4\% der Patienten vor. Anatomische Varianten führen nicht sicher zur chronischen Pankreatitis. Der primäre Hyperparathyreoidismus kann zu einer chronischen Pankreatitis führen. Die vorliegenden Zahlen zur Inzidenz und Prävalenz sind hier nicht belastbar [Evidenzgrad 4].

Neben den obengenannten Ätiologien wurde zuletzt die Autoimmunpankreatitis beschrieben. Hierbei handelt es sich um eine systemische fibrosierende entzündliche Erkrankung, bei der das Pankreas eines der betroffenen Organe ist. Die Autoimmunpankreatitis wurde 1961 erstmalig von Henri Sarles erwähnt [65]; das Konzept zur Entität „Autoimmunpankreatitis“ erstmals von Yoshida et al. 1995 [66]. Die größte vergleichende Studie hat 731 Fälle rekrutiert [67]. Männer erkranken häufiger als Frauen (2:1) [68]. In Asien wird davon ausgegangen, dass die Prävalenz der Autoimmunpankreatitis $5-6 \%$ in einer Patientenkohorte mit chronischer Pankreatitis beträgt. Etwa $5 \%$ der Patienten, die bei V.a. auf ein Pankreaskarzinom operiert werden, leiden histologisch an einer Autoimmunpankreatitis [69] Klinische Symptome sind diskrete Abdominalschmerzen, Ikterus (50\%) und wiederkehrende Episoden einer Pankreatitis. Radiologische Befunde sind eine diffuse oder segmentale Stenosierung des Pankreas- 
gangs, häufig ohne prästenotische Dilatation, „Sausage shaped pancreas" und selten Kalzifikationen. Im Serum vor allem der asiatischen Patienten werden erhöhte Immunglobulin(Ig)-GSpiegel und IgG-4-Spiegel gefunden. Selten und mit fraglicher diagnostischer Relevanz werden auch Lactoferrin und Carboanhydrase-II-Antikörper gefunden. Erhöhte IgG-4-Spiegel finden sich nur in etwa $50 \%$ der Betroffenen mit autoimmuner Pankreatitis in der europäischen Bevölkerung. Histologisch ist die Autoimmunpankreatitis durch eine dichte kragenartige lymphoplasmazytäre Infiltration mit obliterativer Phlebitis und periduktulärer Fibrose (Typ-1-Autoimmunpankreatitis) oder „Granulocytic epithelial lesions“ (GELs) bei $45 \%$ der Patienten (Typ-2-Autoimmunpankreatitis, eher weiblich, mit chronisch entzündlichen Darmerkrankungen, CED, assoziiert, kein IgG4, seltener Rezidive) sowie gleichartigen Veränderungen in anderen Organen charakterisiert. Die Diagnosestellung der Autoimmunpankreatitis erfolgt nach den HiSORT-Kriterien, einer Kombination von Kriterien, die die Histologie, Serologie, die Beteiligung anderer Organsysteme und das Ansprechen auf eine Steroidtherapie einschließen [68, 70]. Diagnostisch beweisend ist ein rasches Ansprechen auf Steroide. Da die Autoimmunpankreatitis nicht Teil dieser Leitlinie ist, möchten wir auf unten aufgeführte Literatur verweisen [65, 66, 6878].

\section{2 - 2: Genetische Diagnostik bei chronischer Pankreatitis}

\section{Statement 2-2-1}

Patienten mit einer chronischen Pankreatitis und mit erkrankten Verwandten ersten oder zweiten Grades sollte eine molekular-genetische Testung auf Mutationen in PRSS1-Gen, die mit dem Auftreten einer hereditären Pankreatitis assoziiert sind, angeboten werden. Dies trifft insbesondere dann zu, wenn das Erstmanifestationsalter der Betroffenen in der Familie im Kindes- und jungen Erwachsenenalter liegt.

[Evidenzgrad 3b, Empfehlungsgrad B, Konsens]

\section{Kommentar}

Bereits 1952 wurde von Comfort und Steinberg eine erbliche Form der Pankreatitis mit einem autosomal-dominanten Erbgang beschrieben [79]. Diese Patienten werden in den Patienten-Registern EUROPAC und CAPER rekrutiert. Für Patienten mit Trypsinogen(PRSS1)-Mutationen ist ein erhöhtes Risiko für die Entwicklung eines Pankreaskarzinoms belegt [80]. An effizienten Tumorvorsorgestrategien für diese Patientengruppe wird aktuell gearbeitet. Für Mutationen im SPINK1-, CFTR- und CTRC-Gen konnte ein erhöhtes Krebsrisiko bisher nicht belegt werden. Eine klinische Konsequenz im Hinblick auf die Behandlung des Patienten ergibt aus der Kenntnis der genetischen Ursache nicht. Aspekte des Versicherungswesens müssen mit dem Patienten oder seinen Erziehungsberechtigten vor dem genetischen Test erörtert werden. Eine genetische Testung nicht erkrankter Familienmitglieder sollte außerhalb von Forschungsprojekten nicht erfolgen [79, 81].

\section{Statement 2-2-2}

Eine Mutationsanalyse im PRSS1-Gen sollte bei Patienten mit einer positiven Familienanamnese (ein oder zwei Verwandte ersten Grades mit idiopathischer chronischer Pankreatitis), zwei oder mehr Schüben einer akuten Pankreatitis ohne identifizierbare Ursache vor dem 25. Lebensjahr oder einer idiopa- thischen chronischen Pankreatitis mit ersten Symptomen vor dem 25. Lebensjahr erfolgen.

[Evidenzgrad 3b, Empfehlungsgrad B, Konsens]

\section{Kommentar}

Träger einer PRSS1-Mutation haben beim Vorliegen einer chronischen Pankreatitis ein kumulatives Risiko von bis zu 49\%, bis zum 75. Lebensjahr an einem Pankreaskarzinom zu erkranken. Dieses Risiko ist signifikant höher als für alle anderen bekannten Ätiologien der chronischen Pankreatitis. Der autosomale Erbgang legt trotz seiner reduzierten Penetranz einen kausalen Zusammenhang zwischen der PRSS1-Mutation und dem Auftreten der chronischen Pankreatitis nahe [45, 46, 48, 49, 80 - 82]. Welches Verfahren zur Tumorvorsorgeuntersuchung bei dieser Hochrisikogruppe das bestgeeignete ist, wird zurzeit noch untersucht.

\section{Statement 2-2-3}

Eine Mutationsanalyse auf Veränderungen im SPINK1-Gen, CFTR-Gen, CTRC-Gen oder einer anderen assoziierten Genveränderungen kann im Rahmen von Forschungsprojekten oder zur vertieften Ursachenabklärung erfolgen.

[Evidenzgrad 3b, Empfehlungsgrad C, Konsens]

\section{Kommentar}

Es gibt kein belegbares erhöhtes Risiko für eine Tumorentwicklung bei Patienten mit Mutationen in diesen Suszeptibilitätsgenen gegenüber anderen Ätiologien der chronischen Pankreatitis. Es kann davon ausgegangen werden, dass es sich um Suszeptibilitätsfaktoren handelt, die für die Erkrankung prädisponieren, sie aber alleine nicht auslösen. Auch der Nachweis von Mutationen in diesen Genen lässt eine sichere ätiologische Einordnung der chronischen Pankreatitis nicht zu und eröffnet in der Regel keine alternativen Therapieoptionen [45, 46, 53, 60, 61].

\section{Kapitel 3 - Diagnostik der exokrinen Insuffizienz (AG1)} $\nabla$

\section{3 - 1: Definition der exokrinen Insuffizienz}

Unter exokriner Pankreasinsuffizienz versteht man die funktionelle Einschränkung der Pankreasenzym- und Bikarbonatsekretion - unabhängig von ihrer Genese. Als Hauptursachen einer exokrinen Pankreasinsuffizienz gelten beim Erwachsenen die chronische Pankreatitis, das Pankreaskarzinom und eine durchgeführte Pankreasresektion [83]. Auch nach (sub-)totaler Gastrektomie sowie bei ausgeprägtem Proteinmangel oder bei Fortschreiten einer Mukoviszidose (zystischen Fibrose) muss mit einer Einschränkung der Pankreasfunktion gerechnet werden. Zu den seltenen Ursachen zählen das Shwachman-Diamond-Syndrom, das Johanson-Blizzard-Syndrom und angeborene Enzymdefekte wie der Mangel an Trypsinogen, Enteropeptidase (Enterokinase) oder $\alpha 1$-Antitrypsin sowie das Fehlen von Amylase, Lipase oder anderer Proteasen. Typische Symptome einer exokrinen Insuffizienz sind abdominelle Beschwerden, eine Steatorrhö und Zeichen der Malnutrition.

\section{Entwicklung und klinische Symptomatik der exokrinen Pankreasinsuffizienz}

Prinzipiell ist bereits bei Diagnosestellung einer chronischen Pankreatitis, verstärkt aber ab ca. 10 Jahren nach Auftreten von Symptomen der chronischen Pankreatitis mit der Entwicklung 
einer Steatorrhö und anderen Symptomen der exokrinen Pankreasinsuffizienz zu rechnen [Evidenzgrad $1 b-2 b$ ].

Der Zeitpunkt des Auftretens einer exokrinen Pankreasinsuffizienz bei chronischer Pankreatitis hängt u.a. von der Ursache der Erkrankung ab. Bei Patienten mit alkoholischer chronischer Pankreatitis kommt es meist ca. 10 - 15 Jahre nach Auftreten erster Symptome zur klinisch manifesten exokrinen Pankreasinsuffizienz. Bei Patienten mit frühem Beginn einer idiopathischen bzw. mit einer hereditären chronischen Pankreatitis oft erst nach noch längeren Krankheitsverläufen [84] [Evidenzgrad 2b]. Die meist späte Manifestation der exokrinen Insuffizienz trotz Untergangs von Pankreasgewebe bereits in frühen Stadien der Erkrankung wird durch die große funktionelle Reservekapazität des Pankreas erklärt. Es ist allgemein akzeptiert, dass eine Dekompensation mit Steatorrhö und Kreatorrhö erst auftritt, wenn die Sekretion der entsprechenden Enzyme um mehr als 90 - 95\% reduziert ist [85, 86] [Evidenzgrad $1 b / 2 b]$. Es gibt aber auch Patienten, die sich primär mit Zeichen der exokrinen Insuffizienz wie Malnutrition und/oder abdominellen Symptomen (Diarrhö/Steatorrhö, abdominelle Distension/Meteorismus, Schmerzen) vorstellen.

Typisches Symptom einer hochgradigen exokrinen Pankreasinsuffizienz ist eine Steatorrhö. Diese kann aber auch fehlen oder andere Ursachen haben. Insgesamt gibt es kein klinisches Symptom, das eine exokrine Pankreasinsuffizienz eindeutig belegt bzw. dessen Fehlen eine solche ausschließt [Evidenzgrad $1 b-2 b$ ]. Eine Steatorrhö kann klinisch nicht sicher erfasst werden. Auch die Stuhlvisite ist hier unzuverlässig, selbst wenn sie vom Erfahrenen durchgeführt wird $[87,88$ ] [Evidenzgrad $2 b$ ]. Die fehlende Angabe klinischer Symptome einer Steatorrhö ist noch viel weniger aussagekräftig, der negative prädiktive Wert liegt hier nur bei $31 \%$ [89] [Evidenzgrad 2b].

Zudem sind die möglichen Ursachen für eine Diarrhö und sonstige abdominelle Symptome auch bei Patienten mit chronischer Pankreatitis mannigfaltig und die exokrine Pankreasinsuffizienz bei Patienten mit chronischer Pankreatitis ist nicht die einzige Ursache einer Malnutrition, sondern diese kann bspw. auch auf einer schmerzbedingten Reduktion der Nahrungszufuhr oder dem fortgesetzten Alkoholkonsum beruhen sowie auf einem erhöhten Grundumsatz [90].

Andererseits kann sich auch eine exokrine Pankreasinsuffizienz, die nicht mit einer symptomatischen Steatorrhö einhergeht, negativ auf Ernährungsparameter wie das Gewicht auswirken [89] [Evidenzgrad 2b]. Zudem gibt es Studien, die eine verminderte Absorption fettlöslicher Vitamine bei Patienten mit leichter bis mäßiger exokriner Insuffizienz belegen ([91], 1b/2b, [92] 2b, [93]) und auch neue Daten, die bei Patienten mit osteoporotischer Fraktur deutlich erniedrigte Stuhlelastase Konzentrationen nachgewiesen haben, die mit niedrigen Vitamin- $\mathrm{D}_{3}$-Spiegeln korrelieren [94] [Evidenzgrad 3b]. Patienten mit Steatorrhö waren bei dieser Untersuchung ausgeschlossen. Bereits bei subklinischer bzw. milder bis mäßiger exokriner Insuffizienz scheint also ein deutlich erhöhtes Osteoporose- und Frakturrisiko zu bestehen.

\section{Zusammenhang zwischen exokriner Insuffizienz und morphologischen Veränderungen bei chronischer Pankreatitis}

Exokrine Pankreasfunktion und morphologische Zeichen der chronischen Pankreatitis verhalten sich meistens, aber nicht immer parallel. Eine exokrine Pankreasinsuffizienz ist auch bei Fehlen morphologischer Zeichen einer chronischen Pankreatitis möglich [Evidenzgrad 1b-2b].
Einzelne ältere Untersuchungen haben eine praktisch vollständige Übereinstimmung zwischen normaler Morphologie und normaler exokriner Funktion bzw. schweren Veränderungen in Bezug auf beide Parameter gezeigt [95] [Evidenzgrad 1b]. Es ist auch gut belegt, dass bei den meisten Patienten mit chronischer Pankreatitis eine Korrelation zwischen dem Ausmaß morphologischer und funktioneller Störungen besteht. Diskordante Befunde mit unterschiedlichem Ausmaß morphologischer und funktioneller Veränderungen finden sich nach den Ergebnissen mehrerer anderer Untersuchungen aber bei etwa einem Viertel der Patienten [87] [Evidenzgrad 2b] [96, 97] [Evidenzgrad 1b-2b], [98] [Evidenzgrad $1 b-2 b]$, und das Fehlen morphologischer Zeichen der chronischen Pankreatitis ist nicht gleichzusetzen mit einer normalen Pankreasfunktion. Dies gilt selbst bei Einsatz hoch sensitiver Untersuchungsmethoden wie der Endosonografie, wie mehrere Untersuchungen jüngeren Datums zeigen [98] [Evidenzgrad 1b-2b], [97] [Evidenzgrad 1b-2b], [99] [Evidenzgrad 2b]. Selbst bei normalem morphologischem Befund hatten 28\% der untersuchten Patienten eine durch Enzymmessung im Duodenum messbare exokrine Pankreasinsuffizienz $[100,101]$ [Evidenzgrad 2b]. In einer anderen Untersuchung, in der Endosonografie und Sekretin-Test mit histologischen Befunden als Referenz verglichen wurden, lag die Sensitivität der Endosonografie für die Diagnose „chronische Pankreatitis“ bei $84 \%$, die des Sekretintests bei $86 \%$. Die Spezifität der Endosonografie war höher als die des Sekretin-Tests (100 vs. $67 \%$ ). Wurden aber beide Untersuchungsmethoden kombiniert, ergab sich eine Sensitivität von 100\% [102] [Evidenzgrad 2b]. Eine exokrine Pankreasinsuffizienz trotz normaler morphologischer Befunde scheint bei Patienten mit chronischer Pankreatitis v.a. bei einer „small duct disease“ vorliegen zu können [97] [Evidenzgrad 1b-2b].

\section{Statement 3-1-1}

Der Sekretin-Test ist das in Deutschland verfügbare Referenzverfahren zur direkten Messung der exokrinen Pankreasfunktion. Er soll zur Etablierung neuer Funktionstests durchgeführt werden und kann im Rahmen von Gutachten sinnvoll sein.

[Evidenzgrad 1b, Empfehlungsgrad A (1. Teilstatement), starker Konsens]

\section{Statement 3-1-2}

Unter klinischen Fragestellungen sollte ein nicht invasiver Pankreasfunktionstest durchgeführt werden. Hierfür bietet sich wegen der leichten Durchführbarkeit der fäkale ElastaseTest (mit spezifischen Antikörpern) an. Alternativ kommen Atemtests mit ${ }^{13} \mathrm{C}$-markierten Lipiden infrage.

[Evidenzgrad 5, Empfehlungsgrad B, Konsens, klinischer Konsenspunkt für die Bevorzugung nicht invasiver Tests]

\section{Kommentar zu Statements 3-1-1 und 3-1-2}

Die Messung der fäkalen Elastase-Konzentration in einer beliebigen Stuhlprobe ist aktuell der in Deutschland am besten klinisch verfügbare und am weitesten verbreitete Pankreasfunktionstest. Darüber hinaus sind die folgenden Pankreasfunktionstests klinisch verfügbar: Messung der Stuhlfettausscheidung, Messung der Chymotrypsinaktivität im Stuhl, Atemtests mit ${ }^{13} \mathrm{C}$-markierten Substraten (bevorzugt ${ }^{13} \mathrm{C}$-markierte gemischte Triglyceride), Sekretin-Test. 
Tab. 3 Sensitivität und Spezifität der verfügbaren Pankreasfunktionstests. ${ }^{1}$

\begin{tabular}{|c|c|c|c|c|c|}
\hline Test & $\begin{array}{l}\text { leichte exokrine } \\
\text { Insuffizienz }\end{array}$ & $\begin{array}{l}\text { moderate exokrine } \\
\text { Insuffizienz }\end{array}$ & $\begin{array}{l}\text { schwere exokrine } \\
\text { Insuffizienz }\end{array}$ & & Evidenzgrad \\
\hline & Sensitivität (\%) & Sensitivität (\%) & Sensitivität (\%) & Spezifität (\%) & \\
\hline f-Elastase-1 (Stuhlelastase) & $54 \%$ & $75 \%$ & $95 \%$ & $85 \%(96 \% / 79 \%)^{2}$ & $1 a / b$ \\
\hline qualitative Stuhlfettbestimmung & $0 \%$ & $0 \%$ & $78 \%^{3}$ & $70 \%^{3}$ & \\
\hline Chymotrypsinaktivität im Stuhl & $<50 \%$ & ca. $60 \%$ & $80-90 \%$ & $80-90 \%$ & $1 a / b$ \\
\hline${ }^{13} \mathrm{C}$-Atemtests (gem. Triglyceride) & $62-100 \%$ & & $90-100 \%$ & $80-90 \%$ & $1 \mathrm{~b} / 2 \mathrm{~b}$ \\
\hline
\end{tabular}

${ }^{1}$ Die direkten invasiven Pankreasfunktionstests (Sekretin- bzw. Sekretin-Pankreozymin-Test) wurden als Referenzverfahren benutzt. Für diese wird deshalb keine Sensitivität und Spezifität angegeben.

${ }^{2}$ Mittlere Spezifität, in Klammern: Spezifität bei unterschiedlichen Kontrollen (Gesunde/Patienten).

${ }^{3}$ Bezogen auf quantitative Stuhlfettbestimmung.

Die Messung der quantitativen Stuhlfettausscheidung wird wegen des hohen Aufwands und der unangenehmen Prozedur des Stuhlsammelns und -aufarbeitens in Deutschland kaum noch durchgeführt. Die qualitative Stuhlfettbestimmung ist demgegenüber in den meisten großen Laboratorien möglich. Atemtests mit ${ }^{13} \mathrm{C}$-markierten Substraten (bevorzugt ${ }^{13} \mathrm{C}$-markierte gemischte Triglyzeride) sind ebenfalls verfügbar, aber weniger etabliert.

Die Chymotrypsinaktivität im Stuhl wird nur noch vereinzelt gemessen.

Der Pankreolaury ${ }^{\circledR}{ }^{-}$-Test ist in Deutschland nicht mehr verfügbar. Der Sekretin-Pankreozymin-Test (bzw. Sekretin-Caerulein-Test) als exaktestes Verfahren zur Quantifizierung der exokrinen Pankreasfunktion ist in dieser Form nicht mehr durchführbar, weil das einzige verfügbare Cholezystokinin-Analogon Takus ${ }^{\circledR}$ vom Markt genommen wurde. Somit bleibt die Möglichkeit, einen Sondentest unter alleiniger Sekretinstimulation durchzuführen. Hierunter kommt es normalerweise zu einem starken Anstieg der pankreatischen Bikarbonatsekretion, die als wichtigster Messparameter gilt, aber auch die Enzymsekretion wird stimuliert. Allerdings ist diese Untersuchung aufwendig, mit der Notwendigkeit der nasoduodenalen Intubation verbunden und teuer. Sie ist somit spezialisierten Zentren und streng selektierten Fragestellungen vorbehalten. Die in den USA zunehmend favorisierte endoskopische Variante des Sekretintests mit wiederholter endoskopischer Aspiration von Duodenalsekret nach Sekretinstimulation ist prinzipiell in jeder normal ausgestatteten Endoskopie durchführbar. Wegen der langen Untersuchungsdauer (bis $60 \mathrm{~min}$ ) wird das Verfahren aber kaum eingesetzt.

Bislang werden MRT-basierte Verfahren nur im Rahmen von Studien zur Messung der exokrinen Pankreasfunktion eingesetzt. Andererseits kann bereits jetzt beispielsweise bei Durchführung einer Sekretin-verstärkten MRCP zur Darstellung des pankreaticobiliären Gangsystems über die Erfassung der Flüssigkeitssekretion in das Duodenum ein zusätzlicher, semiquantitativer Parameter zur Beurteilung der exokrinen Pankreasfunktion gewonnen werden [103, 104] [Evidenzgrad 2b], [105].

Sensitivität und Spezifität der verfügbaren Pankreasfunktionstests sind in $\odot$ Tab. 3 angegeben [Evidenzgrad ๑ Tab. 3] s. [106].

\section{Statement 3-1-3}

Bei Diagnosestellung einer chronischen Pankreatitis sollte ein Pankreasfunktionstest durchgeführt werden.

[Evidenzgrad 1b-2b, Empfehlungsgrad B, starker Konsens]

\section{Kommentar}

Das Statement ist folgendermaßen begründet (s. auch Abschnitt 3-2 und 3-3):

1. Der initiale Pankreasfunktionstest ist im Einzelfall Grundlage der Diagnosestellung, weil es selten Patienten mit chronischer Pankreatitis und unauffälligen Befunden in der morphologischen Diagnostik gibt.

2. Auch bei eindeutigen morphologischen Befunden, die die Diagnose der chronischen Pankreatitis begründen, ist die klinische Symptomatik (Anamnese und Stuhlvisite) unzuverlässig für die Erfassung einer exokrinen Insuffizienz, selbst wenn diese schwer ist und mit einer Steatorrhö einhergeht. Diese schweren Formen werden aber von allen klinisch verfügbaren Funktionstests zuverlässig erfasst. Der initiale Ausschluss einer schweren exokrinen Insuffizienz erscheint sinnvoll.

3. Umgekehrt sind die möglichen Ursachen für eine Diarrhö und sonstige abdominelle Symptome auch bei Patienten mit chronischer Pankreatitis vielfältig, und die exokrine Pankreasinsuffizienz bei Patienten mit chronischer Pankreatitis ist nicht die einzige Ursache einer Malnutrition, sondern diese kann beispielsweise auch auf einer schmerzbedingten Reduktion der Nahrungszufuhr oder dem fortgesetzten Alkoholkonsum beruhen sowie auf einem erhöhten Grundumsatz [90].

\section{Statement 3-1-4}

Bei neu aufgetretenen oder zunehmenden Symptomen, die auf einer exokrinen Pankreasinsuffizienz beruhen können, sollte die Pankreasfunktionsdiagnostik bei zuvor unauffälligen Befunden wiederholt werden.

[Evidenzgrad 2b, Empfehlungsgrad B, Konsens]

\section{Kommentar}

Die Entwicklung von Symptomen einer exokrinen Pankreasinsuffizienz bei bekannter chronischer Pankreatitis ist jederzeit möglich, auch wenn es meist erst mehrere Jahre nach Auftreten erster Symptome zur Steatorrhö kommt. Leichte exokrine Pankreasfunktionseinschränkungen können eine klinische Bedeutung haben. Diese erschließt sich aus dem klinischen Kontext [Evidenzgrad 2b].

\section{Statement 3-1-5}

Diabetiker haben ein erhöhtes Risiko für eine exokrine Pankreasinsuffizienz. Deshalb sollten Pankreasfunktionstests bei klinischen Symptomen einer exokrinen Pankreasinsuffizienz durchgeführt werden.

[Evidenzgrad 2b, Empfehlungsgrad B, Konsens] 


\begin{tabular}{|lllll|l}
\hline Untersuchung & Sensitivität & Spezifität & Evidenz & Literatur & $\begin{array}{l}\text { Tab. } 4 \text { Sensitivität und Spezifität } \\
\text { für die einzelnen bildgebenden }\end{array}$ \\
\hline CT & $\mathrm{n} / \mathrm{a}$ & $\mathrm{n} / \mathrm{a}$ & $2 \mathrm{~b}$ & {$[124]$} & Verfahren. \\
\hline ERCP & $70-80 \%$ & $80-100 \%$ & $2 \mathrm{a}$ & {$[98,120,124-127]$} & \\
\hline MRCP & $88 \%$ & $98 \%$ & $2 \mathrm{~b}$ & {$[121,122]$} & \\
\hline US & $60-81 \%$ & $70-97 \%$ & $2 \mathrm{a}$ & {$[124,128,129]$} & \\
\hline EUS & $80-100 \%$ & $80-100 \%$ & $2 \mathrm{a}$ & {$[113,120,130-132]$} \\
\hline
\end{tabular}

\section{Kommentar}

Ein signifikanter Anteil der Patienten mit Typ-1- und Typ-2-Diabetes mellitus hat eine exokrine Pankreasinsuffizienz [107110]. Dies wird u.a. durch eine gestörte insulo-azinäre Achse [111] und durch eine signifikante exokrine Atrophie [112] erklärt. Deshalb ist bei entsprechenden Beschwerden die Durchführung eines Pankreasfunktionstests sinnvoll.

\section{Kapitel 4 - Bildgebende Diagnostik (AG2)}

Die Diagnose einer chronischen Pankreatitis basiert auf klinischen, morphologischen und funktionellen Parametern. Aufgrund der nur unzureichenden Korrelation der drei diagnostischen Säulen mit der klinischen Symptomatik sind diese komplementär einzusetzen. Als morphologische Basisdiagnostik wird die transabdominelle Ultraschalluntersuchung angesehen.

\section{Statement 4-1-1}

Nach Anamnese und klinischer Untersuchung hat die Sonografie des Pankreas die erste Präferenz. Bei unsicheren Zeichen einer Pankreatitis (inhomogenes Organ, normal weiter Pankreasgang) und klinischem Verdacht sollte eine Endosonografie (EUS) erfolgen. Mit der endosonografisch gestützten Feinnadelpunktion (EUS-FNP) gelingt die zytologische resp. histologische Diagnose fokaler Herde. Die Computertomografie (CT) und MRT sowie MRCP sind ergänzende diagnostische Methoden bei unklaren Pankreasveränderungen im Ultraschall und in der Endosonografie. Insbesondere sollte die MRCP erfolgen, um nähere Informationen zum Pankreasgangsystem zu erhalten, wenn dies erforderlich ist. [Evidenzgrad 2a, Empfehlungsgrad B, Konsens]

\section{Kommentar}

Die Endosonografie hat in der Diagnostik der chronischen Pankreatitis die höchste Trennschärfe [113-116]. In Vergleichsstudien zur endoskopisch retrograden Cholangiografie (ERC) hat die Endosonografie vergleichbare Ergebnisse erbracht [117, 118]. Die MRCP konnte in einer prospektiven Studie im Vergleich mit der endoskopisch retrograden Cholangiopankreatikografie (ERCP) zur Diagnostik eines Malignoms eine höhere Sensitivität (84\%) im Vergleich zur ERCP (70\%) bei gleicher Spezifität (94\%) zeigen. Bei höherer Morbidität und Mortalität sollte auf eine diagnostische ERCP verzichtet werden. Vergleichsstudien zwischen MRCP und EUS konnten insbesondere bei frühen Formen der chronischen Pankreatitis eine bessere Trennschärfe für die Endosonografie zeigen [119]. Die diagnostische ERCP sollte nur in Ausnahmefällen zum Einsatz kommen [120 - 123].

\section{Statement 4-1-2}

Sensitivität und Spezifität für die einzelnen bildgebenden Verfahren für die Diagnose einer chronischen Pankreatitis werden wie in $\bullet$ Tab. 4 angegeben.

[Evidenzgrad $2 b$ ]

\section{Kommentar}

Es gibt keine prospektiven randomisierten Arbeiten die EUS, Ultraschall (US) und CT in der Diagnostik einer chronischen Pankreatitis vergleichen. Prospektive vergleichende Studien existieren nur für die ERCP mit EUS und MRCP mit EUS [120, 124] und für US mit ERCP [133]. Es konnte gezeigt werden, dass der EUS der ERCP insbesondere in der Beurteilung früher Formen der Pankreatitis überlegen ist. In der einzigen Ultraschallstudie konnte eine Sensitivität von 81 \% für den US im Vergleich zu 53 \% für die ERCP gezeigt werden. Es gibt Arbeiten, die belegen, dass Patienten mit Veränderungen im EUS bei initial unauffälligem Duktogramm in der ERP im weiteren Verlauf pathologische Veränderungen am Gangsystem im Sinne einer chronischen Pankreatitis zeigen bzw. histologische Veränderungen einer chronischen Pankreatitis aufweisen [131, 134]. In einer Vergleichsstudie mit dem Sekretintest zeigten EUS vs. ERP vergleichbare Ergebnisse (Sensitivität 72 vs. $68 \%$, Spezifität 76 vs. $79 \%$ ) [125, 126]. Bei Verdacht auf eine chronische Pankreatitis sollte primär eine Sonografie erfolgen, bei unauffälligem Befund kann der EUS durch die höhere Ortsauflösung frühe Parenchymveränderungen erkennen, die auf eine chronische Pankreatitis hinweisen. Für die Operationsplanung hat die CT-Diagnostik nach wie vor einen hohen Stellenwert [113, 128, 129, 131 -134].

\section{Statement $4-1-3$}

Die unterschiedlichen Kriterien der verschiedenen bildgebenden Verfahren sollten für Erwachsene modifiziert und nach der Cambridge Klassifikation verwendet werden. [Evidenzgrad 2a, Empfehlungsgrad B, starker Konsens]

\section{ERCP:}

Cambridge 0: keine pathologischen Veränderungen bei kompletter Darstellung des Pankreasgangs

Cambridge 1: weniger als 3 pathol. Seitenäste, Hauptgang regelrecht

Cambridge 2: mehr als 3 pathol. Seitenäste, Hauptgang regelrecht Cambridge 3: $>3$ pathol. Seitenäste plus pathol. Hauptgang Cambridge 4: wie 3 plus Zyste, Gangsteine, Strikturen, Einbeziehung von Nachbarorganen.

\section{Transabdominelle Sonografie:}

Cambridge 0: normales Organ, Gang < 2 mm, glatte Kontur Cambridge 1: echodichte Organkontur, Organ vergrößert (bis 1,5-fach), Gang < $3 \mathrm{~mm}$, Textur wabig lobuliert

Cambridge 2: irreguläre Kontur, irregulärer echoverstärkter Hauptgang $>3 \mathrm{~mm}$, lobulierte Textur mit echodichten Septen Cambridge 3: wie 2 und Zysten, fokale Verkalkungen 
Cambridge 4: wie 3 und Gangsteine, Obstruktionen des Ganges, tumoröse Auftreibung des Organs > 2-fach, Thrombose Milzvene

\section{Endosonografie:}

Cambridge 0: keine

Cambridge 1: wabig lobulierte Textur - honigwabenartig, Gang $<3 \mathrm{~mm}$,

Cambridge 2: hyperechogener Gang, hyperechogene Foci, echodichte Kontur, Gang < $3 \mathrm{~mm}$

Cambridge 3: wabig lobuliert, septiert, hyperechogene Foci, Gang $>3 \mathrm{~mm}$, irregulärer Gang, keine Gangsteine,

Cambridge 4: wie 3 und Verkalkungen, Gangsteine, Zysten

\section{CT/MRCP:}

Cambridge 0: keine

Cambridge 1: mit den heutigen Methoden im CT/MRCP nicht abgrenzbar

Cambridge 2: Zwei oder mehr der folgenden Veränderungen:

Pankreasgang zw. 2 und $4 \mathrm{~mm}$ im Corpus pancreatis,

leichte Pankreasvergrößerung,

heterogene Parenchymstruktur

kleine zystische Veränderungen $(<10 \mathrm{~mm})$

Gangunregelmäßigkeiten

pathologische Nebengänge $>3$

Cambridge 3: Alle bei 2 genannten Veränderungen plus patholo-

gischer Hauptgang ( $>4 \mathrm{~mm}$ )

Cambridge 4: Eine der bei 2 und 3 genannten Veränderungen

plus eine oder mehr der folgenden:

zystische Strukturen $>10 \mathrm{~mm}$

Parenchymverkalkungen

intraduktale Füllungsdefekte (Kalksteine)

Gangobstruktion (Strikturen)

schwere Gangunregelmäßigkeiten

\section{Kommentar}

Goldstandard zur Beurteilung der chronischen Pankreatitis war bisher die ERP mit der Cambridge-Klassifikation [135]. Die Cambridge-Klassifikation und ihre Adaptation für Schnittbildverfahren (US, EUS, CT/MRCP) sollte bei Erwachsenen zur Diagnose einer chronischen Pankreatitis eingesetzt werden. Sie entspricht weiterhin dem Stand der Wissenschaft [Evidenzgrad 3a].

Die Cambridge-Kriterien zur Beurteilung des Pankreasgangsystems kommt in der ERCP noch zur Anwendung, allerdings nur bei Patienten, die zur Interventionellen ERP vorgestellt wurden. Bei Patienten mit Verdacht auf chronische Pankreatitis kommen primär nicht invasive Verfahren (Sono, CT, MRCP, EUS) zum Einsatz. Während die Cambridge-Kriterien nur das Pankreasgangsystem beschreiben, gelingt es mit den erwähnten bildgebenden Verfahren sowohl das Gangsystem als auch angrenzende Parenchymstrukturen mit einzubeziehen. In der Beschreibung des Gangsystems bedienen sich diese Methoden der Kriterien der Cambridge-Klassifikation. Insbesondere die MRCP setzt die Nomenklatur der Cambridge-Klassifikation komplett um [113, 117, $135,136]$.

Die ERP als invasives Verfahren in der Diagnostik sollte aufgrund ihrer höheren Morbidität durch andere bildgebende Verfahren mit identischer Aussagekraft ersetzt werden [115, 117, 188 137]. Randomisierte Vergleichsstudien der ERP mit den bildgebenden Verfahren existieren nur für EUS und MRCP. Es ist aufgrund des Vergleichs der einzelnen bildgebenden Verfahren sinnvoll, die Cambridge-Klassifikation für Sonografie, CT und MRCP zu über- nehmen, um eine Vereinheitlichung der Nomenklatur herbeizuführen $[121,122]$.

Frühe Veränderungen der chronischen Pankreatitis werden nur im EUS erkannt. In Vergleichsstudien wurden pathognomonische Befundkriterien erarbeitet, die bei gleichzeitigem Vorliegen direkt mit der Wahrscheinlichkeit einer chronischen Pankreatitis korrelieren [113]. Prospektive histopathologische Studien konnten mit einer Spezifität von $100 \%$ zeigen, dass beim Vorliegen von $>4$ Kriterien die EUS sensitiver als die MRCP war $[113,114$, $116-122]$.

\section{Statement $4-1-4$}

Die Elastografie kann zum jetzigen Zeitpunkt nicht zur Diagnostik einer chronischen Pankreatitis empfohlen werden.

[Evidenzgrad 4, Empfehlungsgrad C, starker Konsens]

Sie kann aber hilfreich bei der Differenzialdiagnose von Herdbefunden sein.

[Evidenzgrad 3b, Empfehlungsgrad C, starker Konsens]

\section{Kommentar}

Bisherige monozentrische Studien haben sich mit der Elastografie bei Patienten mit Raumforderungen am Pankreas beschäftigt [138]. In zwei Studien konnte bisher gezeigt werden, dass man mit der Elastografie gut zwischen benignen und malignen Herdbefunden unterscheiden kann (Sensitivität 91,4\%, Spezifität 87,9\% [139]; Sensitivität 100\%, Spezifität 92,9\% [140]). In der Studie von Saftiou et al. an 68 Patienten wurden allerdings nur 11 Patienten mit chronischer Pankreatitis eingeschlossen. In der Studie von Iglesia et al. wurden 27 Patienten mit inflammatorischen Pankreasveränderungen beschrieben, wobei diese nicht zwischen akuter und chronischer Pankreatitis unterschieden haben. In einer Arbeit von Janssen et al. wurde gezeigt, dass die Elastografie bei der chronischen Pankreatitis vergleichbare Bilder wie beim duktalen Karzinom generiert. Für die Diagnose der chronischen Pankreatitis hat die EUS-Elastografie derzeit keinen Stellenwert. Patienten mit chronisch kalzifizierender Pankreatitis sollten prospektiv mit der Elastografie untersucht werden, um den Stellenwert der Methode in der Differenzierung einer fokal chronischen Pankreatitis und eines Pankreaskarzinoms in der chronischen Pankreatitis zu erhärten. Es gibt erste Hinweise, dass die Elastografie in der Diagnostik einer autoimmunen Pankreatitis hilfreich sein kann [141].

Anhand nachfolgender Klassifikationssysteme können die morphologischen Befunde der chronischen Pankreatitis (c.P.) beurteilt werden:

1. Manchester-Klassifikation [142]:

* Milde c.P.: ERP, CT, US, EUS - Kriterium positiv, keine Komplikationen, keine endokrine oder exokrine Insuffizienz; Schmerzen ohne Analgetika

* Moderate c.P.: ERP, MRT, CT, US, EUS positiv, Schmerzen mit Analgetika, gestörte endokrine oder exokrine Funktion

* Schwere c.P.: wie moderat (auch ohne Schmerzen) plus: biliäre Striktur, portale Hypertension, duodenale Stenose, plus exokrine oder endokrine Insuffizienz

2. ABC-System (Ramesh, modifiziert nach Büchler) [143, 144]:

* Stadium A: Schmerzen, positive Bildgebung US, ERP, MRT, EUS keine exokrine oder endokrine Insuffizienz

* Stadium B: Schmerzen, positive Bildgebung, keine exokrine oder endokrine Insuffizienz, plus Komplikation: (Obstruktion 
DHC, Duodenum, Pseudozyste, Fistel etc.), aber ohne exokrine und endokrine Insuffizienz

* Stadium C: Schmerzen, positive Bildgebung, mit endokriner (C1) oder exokriner Funktionsstörung (C2) mit oder ohne Komplikationen

3. Rosemont-Klassifikation mithilfe der Endosonografie [113]:

* Neben Parenchymveränderungen (hyperechogene Foci mit und ohne Schatten, honigwabenartige Lobulierung, Zysten, echodichte Septen) wurden duktale Veränderungen (Steine im Gang, irregulärer Gang, erweiterte Nebengänge, erweiterter Hauptgang, echogene Begrenzung des Hauptganges) beschrieben. Prospektive histopathologische Studien konnten zeigen, dass beim Vorliegen von > 4 Kriterien die EUS sensitiver als die MRP war mit einer Spezifität von $100 \%[116,119]$.

4. M-ANNHEIM-Klassifikation [145]:

Schmerzen, Schmerzkontrolle, chirurgische Eingriffe, exokrine Insuffizienz, endokrine Insuffizienz, Morphologie (entsprechend Cambridge), Organkomplikationen und Bildgebung basierend auf CT oder US oder MRT oder EUS.

\section{Kommentar}

In der Manchester-Klassifikation werden bildgebende Befunde der chronischen Pankreatitis konklusiv mit klinischen Befunden kombiniert und in ein einfaches Schema der Einteilung der chronischen Pankreatitis überführt [142]. In diesem System ist dominierend für den Schweregrad der Pankreatitis der Nachweis einer exokrinen oder endokrinen Insuffizienz bzw. der Nachweis von Komplikationen. Die differenten bildgebenden Veränderungen spielen für den Schweregrad eher eine untergeordnete Rolle. Eine vergleichbare Klassifikation stellt das ABC-System nach Ramesh und Büchler dar $[143,144]$. In allen Stadien wird eine positive Bildgebung gefordert, für den Schweregrad der chronischen Pankreatitis ist allein das Vorliegen einer exokrinen oder endokrinen Insuffizienz und/oder von Komplikationen entscheidend. Die Rosemont-Klassifikation beschreibt anhand von EUS-Kriterien das Vorliegen einer chronischen Pankreatitis [113]. Die Anzahl der vorliegenden Parameter korreliert mit dem Schweregrad der chronischen Pankreatitis. Dies konnte in histopathologischen Studien gezeigt werden. In dieses System gehen keine klinischen Befunde zur Beurteilung ein. Die M-ANNHEIM-Klassifikation versucht eine Charakterisierung der Patienten nach Ätiologie, klinischem Stadium und Schweregrad [145]. Der Schweregrad der Entzündungsreaktion wird durch klinische Symptome und therapeutische Interventionen evaluiert. Am Ende eines komplexen Klassifikationssystems steht ein Punktesystem (0 25 Punkte), das den Schweregrad der chronischen Pankreatitis beschreibt [145].

Alle Klassifikationssysteme müssen in prospektiv randomisierten Studien auf ihre Aussagekraft untersucht werden. Zielkriterium muss das Erfassen der Morbidität und Mortalität sein, um Therapieeffekte messen zu können.

Die Entscheidung, welches bildgebende Verfahren gewählt wird, hängt von der erwarteten Komplikation ab [Evidenzgrade: Ultraschall 3a; EUS 2a, CT 4, MRT 3a].

\section{Nekrosen}

Der kontrastmittelverstärkte Ultraschall (CEUS) kann Nekrosen in gleichem Umfang wie die das kontrastgestützte CT erfassen. Dies ist insbesondere bei Patienten mit eingeschränkter Nierenfunktion von Vorteil. Allerdings ist eine Quantifizierung, wie sie für die Einschätzung des Schweregrades nach Balthazar und Moertele erforderlich ist, nicht möglich [146, 147]. Bei Verdacht auf eine infizierte Nekrose kann sich eine US- oder CT-gestützte Punktion anschließen. Die kontrastgestützte MRT kann ebenso nekrotische Pankreasanteile nachweisen [148, 149].

\section{Zysten}

Zysten sind gut mit dem Ultraschall detektierbar [150, 151], ihre Kriterien klar definiert (echofrei, Tangentialphänomen, dorsale Schallverstärkung). Bei abweichenden Befunden spricht man von atypischen Zysten. Hier müssen differenzialdiagnostisch zystische Neoplasien bedacht werden und andere bildgebende Befunde herangezogen werden.

Die höchsten Trefferraten in der Differenzierung zystischer Pankreasläsionen kommen der EUS und der MRT/MRCP zu. Zystische Neoplasien sind mit EUS und MRT/MRCP gut von Pseudozysten oder peri-intestinalen Flüssigkeitsansammlungen zu unterscheiden.

Im Zweifelsfall kann sich eine EUS-FNP mit Asservierung von Zystenflüssigkeit (Zytologie, Lipase und Carcino-Embryonales Antigen [CEA]-Bestimmung) anschließen. Vergleichende Literatur existiert nicht.

\section{Pseudoaneurysmen}

Beim Nachweis zystischer Veränderungen im Pankreas sollte der Ultraschall kombiniert mit dem Farbdoppler durchgeführt werden, um Perfusionen in der Zyste i.S. eines Pseudoaneurysmas sicher erkennen zu können. Dies sollte vor Interventionen obligat sein.

Die CT-Angiografie sowie die MR-Angiografie können ebenso Pseudoaneurysmen exzellent nachweisen. Es existieren keine vergleichenden bildgebenden Studien.

\section{Karzinom}

Der perkutane Ultraschall und der endoskopische Ultraschall können bei Nachweis einer chronischen Pankreatitis nur begrenzt zwischen Karzinom und Entzündung unterscheiden. Im Zweifelsfall sollte sich eine EUS-FNP anschließen; dies kann die Sensitivität auf über $85 \%$ bei guter Spezifität erhöhen [152, 153]. Die Wahrscheinlichkeit falsch negativer Befunde wird mit 5$10 \%$ angegeben, sodass bei operablen Befunden in der Bildgebung und Tumorverdacht eine Operation auch ohne vorherige Feinnadelpunktion (FNP) empfohlen wird (siehe Adler et al. [154]).

Für die MRT mit MRCP wurde eine Sensitivität von $84 \%$ mit einer Spezifität von $97 \%$ festgestellt. Zur Differenzierung zwischen einer chronischen Pankreatitis und einem Pankreaskarzinom wurde eine Sensitivität von 93\% mit einer Spezifität von $75 \%$ ermittelt [155]. Dies gilt nicht, wenn ein Karzinom in einer chronischen Pankreatitis entsteht. Hier ist auch unter Ausschöpfung aller diagnostischer Verfahren die Sensitivität zur Detektion eines Tumors bei $67 \%$ und die Spezifität bei $45 \%$.

\section{Erläuterung}

Neuere Arbeiten der CEUS und Endosonografie konnten zeigen [156], dass sich Nekrosen als auch Pankreaskarzinome als hypoperfundierte Herdbefunde demarkieren [139, 140, 157 - 159]. Im Zusammenhang mit der Klinik und dem Labor kann bei einer akuten Pankreatitis das Vorliegen einer Nekrose vermutet werden. Bei einer chronischen Pankreatitis kann es sich um eine fokale Nekrose oder ein Karzinom handeln [160]. Bei operativer Konsequenz ist eine EUS-FNP dieser Herdbefunde sinnvoll, wobei mit einer beträchtlichen Rate falsch negativer Befunde zu rechnen ist [161]. 


\section{Statement 4-1-5}

Die zytologische oder histologische Feinnadelpunktion kann zur Differenzierung zwischen einer Autoimmunpankreatitis und anderen Pankreaserkrankungen empfohlen werden. [Evidenzgrad 2c, Empfehlungsgrad B, Konsens]

\section{Kommentar}

$40 \%$ der Patienten mit einer Autoimmunpankreatitis präsentieren sich mit einer fokalen Läsion. Die diagnostische Trennschärfe des endoskopischen Ultraschalls zur diagnostischen Einordnung einer Pankreasläsion mittels endosonografischer Feinnadelaspiration wird mit 95 \% für Läsionen $<10$ mm und mit $100 \%$ für Läsionen $>3 \mathrm{~cm}$ angegeben. Für die Diagnose einer Autoimmunpankreatitis nach den HiSORt-Kriterien ist die zytologische/ histologische Diagnose der Goldstandard. Bei bildgebendem oder klinischem Verdacht auf eine Autoimmunpankreatitis kann deshalb eine endosonografisch gestützte FNP erfolgen [68, 162, 163].

\section{Statement 4-1-6}

Bei Durchführbarkeit des EUS und der MRT/MRCP kann die ERP nicht als primäres diagnostisches Verfahren empfohlen werden. In Einzelfällen (z. B. unzureichende Aussage von EUS und MRT/MRCP) kann eine ERP erfolgen. Bei V.a. auf eine Autoimmunpankreatitis kann die diagnostische ERP eingesetzt werden.

[Evidenzgrad 4, Empfehlungsgrad C, starker Konsens]

\section{Kommentar}

Für die Diagnostik der chronischen Pankreatitis ist die Kombination aus der EUS oder der MRCP oder beider Untersuchungen meist ausreichend. Die ERP birgt gerade in den frühen Stadien der chronischen Pankreatitis ein zu hohes Risiko für eine PostERCP-Pankreatitis. Die Rate an Post-ERCP-Pankreatitiden in einem unselektierten Krankengut beträgt 3,5\%. In den meisten Fällen verläuft die Post-ERCP-Pankreatitis mild, jedoch kommt es in $10 \%$ der Fälle zu einem schweren Verlauf mit möglicher Todesfolge. Ihr Einsatz zur Diagnostik ist deshalb im Regelfall nicht gerechtfertigt.

Zur Diagnose einer Autoimmunpankreatitis und zur Unterscheidung von einem Pankreaskarzinom mittels ERP wurden 4 Kriterien mit hoher Sensitivität und Spezifität entwickelt: (1) Langstreckige Stenosen $>1 / 3$ der Pankreasganglänge, (2) ohne nachgeschaltete Dilatation des Pankreasgangs, (3) Dilatation der Seitenäste, (4) multifokale Strikturen im Verlauf des Pankreasgangs deuten auf das Vorliegen einer Autoimmunpankreatitis hin. In der japanischen Leitlinie [164] wird die ERCP als Diagnostik gefordert; vergleichende Untersuchungen für die MRCP liegen nicht vor. Da die serologischen Parameter ( $\operatorname{IgG} 4$, $\operatorname{IgG})$ in der westlichen Bevölkerung eine geringe Aussagekraft haben, kann die diagnostische ERP zur Diagnose einer Autoimmunpankreatitis in Europa eine größere Rolle als in Japan spielen [165].

\section{Kapitel 5 - Therapie des akuten Schubes \\ $\nabla$}

\section{Einleitung}

Für die Therapie akuter Schübe v.a. rezidivierender Pankreatitiden, weniger der typischen chronischen kalzifizierenden Pankreatitis, gelten die gleichen Prinzipien wie für die akute Pankreatitis allgemein. Daher werden die klinisch wichtigen Aspekte in der Behandlung der akuten Pankreatitis und ihrer Komplikationen im Folgenden behandelt. Der akute Schub einer chronischen Pankreatitis zählt zu den häufigsten gastroenterologischen Erkrankungen. Die Inzidenz der Neuerkrankungen einer akuten Pankreatitis liegt zwischen 10-79/100000 Einwohner. In Deutschland erfolgten im Jahr 200850673 Krankenhausentlassungen wegen akuter Pankreatitis. Somit sind ca. 1,2\% des klinischen Krankenguts betroffen [19]. In den letzten Jahren wurde eine steigende Inzidenz beobachtet. Klinische Symptome wie gürtelförmige Oberbauchbeschwerden und Erbrechen zusammen mit einem über das 3-Fache der Norm erhöhten Serumspiegel für Amylase oder Lipase führen zur Diagnosestellung der akuten Pankreatitis. Bei einem Serumlipasewert unterhalb des Dreifachen der Norm sollte nach den revidierten Kriterien der Atlanta-Klassifikation von 1994 (Publikation steht aus) ein bildgebendes Verfahren zur Diagnosesicherung (z. B. kontrastmittelunterstützte CT) durchgeführt werden. Die häufigsten Ursachen des akuten Schubes sind ein fortgesetzter Alkoholabusus oder Diätfehler. Im klinischen Verlauf lassen sich für den akuten Schub einer chronischen Pankreatitis 2 Formen unterscheiden, deren Auftreten unabhängig von der Ätiologie der Erkrankung ist: die akute interstitiell-ödematöse Pankreatitis (75-85\%) mit einer Letalität unter $1 \%$ und die akute hämorrhagisch-nekrotisierende Pankreatitis (15 - 25\%) mit einer Letalität zwischen 10 und 24\%. Um eine adäquate Therapie der akuten Pankreatitis zu gewährleisten, ist es notwendig, Patienten stationär im Krankenhaus zu betreuen. Häufige Verlaufskontrollen des klinischen Befunds, der laborchemischen Verlaufsparameter sowie der bildgebenden Befunde machen eine optimale ambulante Patientenbetreuung nahezu unmöglich. Zum Zeitpunkt der Aufnahme ins Krankenhaus ist es meist schwierig, zwischen der Mehrzahl der Patienten mit leichtem und unkompliziertem Verlauf (etwa 80\%) und denjenigen Patienten mit einem schweren, meist durch zahlreiche Organkomplikationen belasteten Verlauf (etwa 20\%) zu unterscheiden. Neben der klinischen Untersuchung durch einen erfahrenen Arzt ließen sich in der Vergangenheit verschiedene Parameter zur Beurteilung der Prognose identifizieren: Bei Patienten mit drei oder mehr Hinweisen auf Organkomplikationen, z. B. im Ranson- oder Imrie-Score, oder beim klinischen Vorliegen einer systemischen Komplikation (z.B. respiratorische oder Niereninsuffizienz), oder beim Nachweis von Pankreasnekrosen im kontrastmittelverstärkten CT kann meist von einem komplizierten Verlauf ausgegangen werden. Als Parameter von hoher prognostischer Bedeutung für die Vorhersage des Schweregrads der akuten Pankreatitis gelten heute das C-reaktive Protein (CRP), der Hämatokrit sowie ein persistierendes (> 48 Stunden) Organversagen.

\section{Therapie}

Statement 5-1-1

Eine rasche und adäquate Flüssigkeitssubstitution soll erfolgen, da sie für die Prognose entscheidend ist.

[Evidenzgrad 2b, Empfehlungsgrad A, starker Konsens] 


\section{Kommentar}

Die entscheidende therapeutische Maßnahme bei der Behandlung der akuten Pankreatitis (und ebenso der häufigste Behandlungsfehler, wenn sie nicht erfolgt) ist die ausreichende Substitution des Flüssigkeitsverlusts. In einer japanischen retrospektiven Analyse konnte gezeigt werden, dass die Letalität einer Patientengruppe mit akuter Pankreatitis 61,2\% betrug, wenn weniger als 3,5 Liter Flüssigkeit in den ersten 24 Stunden des Krankenhausaufenthalts infundiert wurden [166 - 168]. Das akute prärenale Nierenversagen innerhalb der ersten 48 Stunden nach Aufnahme in ein Krankenhaus korreliert mit einer erhöhten Letalität. Jeder Anstieg des Serumharnstoffs um $5 \mathrm{mg} / \mathrm{dl}$ erhöht die Mortalität um einen Faktor von 2,2 [169, 170]. Allerdings führt die exzessive Gabe von Flüssigkeit zu lokalen Komplikationen und respiratorischem Globalversagen. Um eine adäquate Flüssigkeitssubstitution zu etablieren, wurde in einer prospektiv randomisierten Studie an Patienten mit schwerer akuter Pankreatitis (APACHE-II-Score > 14) der klinische Verlauf mit zwei Schemata der Flüssigkeitssubstitution untersucht. Die eine Gruppe erhielt $10-15 \mathrm{ml} / \mathrm{kg} / \mathrm{h}$ bis zum Ausgleich des Flüssigkeitsdefizits gemessen am Erreichen von 2 oder mehr der folgenden Kriterien: Herzfrequenz< $120 / \mathrm{min}$, mittlerer arterieller Druck 65 $85 \mathrm{mmHg}$, Urinausscheidung $>1 \mathrm{ml} / \mathrm{kg} / \mathrm{h}$, Hämatokrit < 35\%. Die zweite Gruppe erhielt eine geringere Substitution von $5-10 \mathrm{ml} /$ $\mathrm{kg} / \mathrm{h}$. In der Gruppe, die $10-15 \mathrm{ml} / \mathrm{kg} / \mathrm{h}$ erhielt, mussten $94,4 \%$ der Patienten im Verlauf künstlich beatmet werden gegenüber $65 \%$ in der Gruppe mit 5-10 ml $/ \mathrm{kg} / \mathrm{h}$. Die Letalität in der Gruppe, der aggressivere Volumen zugeführt wurde, war signifikant erhöht, ebenso wie lokale Komplikationen wie ein abdominelles Kompartment-Syndrom oder eine Sepsis [164]. Wenn eine invasive Messung des Flüssigkeitsdefizits nicht möglich ist, kann eine Therapie mit $5-10 \mathrm{ml} / \mathrm{kg} / \mathrm{h}$ empfohlen werden [Evidenzgrad $1 \mathrm{~b}$, Empfehlungsgrad A]. Die Volumengabe sollte, wenn möglich, durch ein Thermodilutionssystem gesteuert werden. Der Hämatokrit hat sich ebenso wie der ZVD als nicht ausreichend zur Abschätzung des Volumendefizits erwiesen. Abgeleitet aus der VISEP-Studie zur Sepsistherapie sollten überwiegend kristalloide Lösungen und nicht kolloidale Lösungen zur Flüssigkeitssubstitution verwendet werden [171]. Es ist allgemeiner Konsens (internationale Guidelines), dass eine rasche und adäquate Flüssigkeitssubstitution prognostisch bedeutsam ist. [19, 166, 167, 172, 173].

\section{Statement 5-1-2}

Bei Fehlen einer Subileus- oder Ileussymptomatik mit Erbrechen kann auf das Einlegen einer Magensonde verzichtet werden.

[Evidenzgrad 4, Empfehlungsgrad C, starker Konsens]

\section{Kommentar}

Die Platzierung einer drainierenden Magensonde ist nur zur Prophylaxe und Therapie eines paralytischen Ileus indiziert. Demgegenüber ist die Vorstellung, die Bauchspeicheldrüse durch Absaugen des Magensafts ruhig zu stellen, heute überholt [174177].

\section{Statement 5-1-3}

Die Säureblockade zur Stressulkusprophylaxe kann bei schwerer Verlaufsform empfohlen werden.

[Evidenzgrad 3a, Empfehlungsgrad C, Konsens]

\section{Kommentar}

Kontrollierte Studien zur Stressulkusprophylaxe liegen nicht vor. Es wird allgemein zu einer Prophylaxe geraten.

\section{Statement 5-1-4}

Eine adäquate Schmerztherapie ist erforderlich. [Evidenzgrad 2b, Empfehlungsgrad A, starker Konsens]

\section{Kommentar}

Patienten mit akuten Schüben einer Pankreatitis leiden oft unter stärksten viszeralen Schmerzen. Deshalb ist eine ausreichende Analgesie eines der wichtigsten und oft dringlichsten Behandlungsziele. Das Argument einer möglichen Kontraktion der Duodenalpapille durch Morphine und damit die Schaffung einer zusätzlichen Obstruktion für die Pankreassekretion ist nach heutigem Wissensstand obsolet [Evidenzgrad 2b]. Wir wissen heute, dass dieser Effekt bei den meisten Analgetika dieser Gruppe nicht auftritt oder so gering ausgeprägt ist, dass er klinisch keine Rolle spielt. Einige morphinanaloge Analgetika werden mit Erfolg zur Schmerztherapie bei akuter Pankreatitis eingesetzt. Das in Deutschland aus betäubungsrechtlichen Gründen sehr gerne verordnete Tramadol führt bei Patienten mit akuter Pankreatitis häufig zu Übelkeit und Erbrechen, sodass sein Einsatz bei diesem Krankheitsbild nicht zu empfehlen ist. Einige Zentren haben inzwischen gute Ergebnisse mit dem Einsatz der thorakalen Periduralanalgesie (PDA) erzielt. Diese führt nicht nur zur raschen Schmerzfreiheit der Patienten, sondern verhindert oder therapiert zusätzlich einen paralytischen Ileus. Voraussetzung für den Einsatz der PDA ist, dass der Patient wach und ansprechbar ist und keine manifeste Gerinnungsstörung vorliegt [178-182].

\section{Statement 5-1-5}

Eine initiale orale Nahrungskarenz kann aufgrund der klinischen Symptomatik erforderlich sein. [Evidenzgrad 4, Empfehlungsgrad D, starker Konsens]

\section{Kommentar}

Eine Nahrungskarenz hat einen positiven Einfluss auf den Verlauf des paralytischen Ileus, der als Folge einer akuten Pankreatitis auftreten kann. Zudem empfinden viele Patienten die orale Nahrungskarenz subjektiv als Erleichterung für ihre Übelkeit, ihr Erbrechen und ihre Schmerzen. Auf den klinischen Verlauf oder die Prognose der akuten Pankreatitis selbst hat die Nahrungskarenz nach neueren Studien keinen positiven Einfluss. Vor allem die Vorstellung, dass durch Nahrungskarenz die Bauchspeicheldrüse 'ruhig gestellt' werden muss, gilt heute als obsolet. Sowohl in experimentellen als auch in klinischen Studien wurde überzeugend belegt, dass im Verlauf einer Pankreatitis die exokrine Sekretion blockiert ist und dass somit eine Hemmung der Sekretion als therapeutisches Prinzip sinnlos ist [183]. Eine therapeutische Aufhebung der Sekretionsblockade bei der Pankreatitis wäre, zumindest aus pathophysiologischen Überlegungen, ein vielversprechenderer Behandlungsansatz. Die enterale Sondenernährung ist der parenteralen Ernährung bei akuter Pankreatitis überlegen.

In 10 prospektiv randomisierten klinischen Studien [184-193] konnte inzwischen gezeigt werden, dass eine enterale Ernährung der parenteralen Ernährung bei akuter Pankreatitis überlegen ist. Die Gründe hierfür liegen nicht nur in den Kosten der parenteralen Ernährung (6-mal so teuer wie die enterale Sondenernährung), sondern vor allem in den Komplikationen der parenteralen 
Ernährung. Neben der Gefahr einer zusätzlichen Infektionsquelle durch den zentralvenösen Katheter kommt es in tierexperimentellen Studien bei ausschließlich parenteraler Ernährung innerhalb weniger Tage zu einer Zottenatrophie im Darm, die dann eine bakterielle Translokation in die umliegenden parenchymatösen Organe erleichtert. Bei Patienten mit nekrotisierender Pankreatitis siedeln sich die translozierten Bakterien bevorzugt in der Pankreasnekrose an und können eine der gefürchtetsten Komplikationen der Pankreatitis - die infizierte Nekrose oder den Pankreasabszess verursachen. Eine enterale Sondenernährung, die über eine tief liegende Dünndarmsonde oder, nach neuesten Studien, mit gleicher Effektivität auch über eine Magensonde verabreicht wird, wirkt der Translokation entgegen und hat sich als Alternative zur parenteralen Ernährung bewährt [194 197]. Nicht bei allen Patienten mit nekrotisierender Pankreatitis ist ein vollständiger Kalorienersatz über eine enterale Ernährungssonde möglich und eine zusätzliche intravenöse Substitution zur Verhinderung der Katabolie ist gelegentlich erforderlich. Dennoch sollten, wann immer möglich, enterale Kalorien zur Verhinderung der Zottenatrophie im Darm verabreicht werden. Alle Zweifler an diesem Paradigmenwechsel in der Behandlung der akuten Pankreatitis seien darauf hingewiesen, dass in keiner der Studien zur enteralen Ernährung bei akuter Pankreatitis ein klinisch relevanter Nachteil dieser Behandlungsmethode gegenüber der vollständig parenteralen Ernährung beschrieben wurde. Es konnte durch Imrie et al. gezeigt werden, dass die Rate an pulmonalen Komplikationen durch die enterale Ernährung signifikant reduziert wird [195].

\section{Statement 5-1-6}

Die gegebenenfalls notwendige intensivmedizinische Therapie basiert auf standardisierten Prinzipien, die insbesondere bei der Therapie der Sepsis, des Systemischen inflammatorischen Response-Syndroms (SIRS) und des Multiorganversagens zur Anwendung gelangen.

[starker Konsens, klinischer Konsenspunkt]

\section{Kommentar}

Neue Pankreatitis-spezifische prospektive Studien zum Einsatz intensivmedizinischer Verfahren existieren nicht. Eine multizentrische Studie zur Rolle des PiCCO-Katheters (Thermodilutionsmethodik) für das Volumenmonitoring bei akuter Pankreatitis wurde auf den Weg gebracht [198].

\section{Statement 5-1-7}

Ein zügiger Beginn der oralen Ernährung sollte angestrebt werden.

[Evidenzgrad 2b, Empfehlungsgrad B, starker Konsens]

\section{Kommentar}

Neuere Untersuchungen weisen darauf hin, dass bei milder akuter Pankreatitis die orale Nahrungszufuhr im Vergleich zur Nahrungskarenz den Verlauf günstig beeinflussen kann. Beim oralen Kostaufbau, der bei schmerzfreien Patienten möglichst frühzeitig erfolgen sollte, kann mit leicht verdaulicher Kost begonnen werden. Lévy et al. konnten in einer multizentrischen Kohorten-Studie über ein Wiederauftreten der Beschwerden bei akuter Pankreatitis zeigen, dass etwa $20 \%$ der Patienten im Rahmen des Kostaufbaus ein Rezidiv erleiden und dass die Wahrscheinlichkeit für ein Rezidiv vom Ausmaß der Nekrose, das heißt dem
Schweregrad der Pankreatitis, abhängig ist [199]. Eine Metaanalyse, die alle 3 der hierzu publizierten Studien einschließt (274 Patienten), bestätigt dieses Ergebnis [200]. Der Wert sog. Pankreasdiäten oder der abgestuften Pankreasschonkost ist nicht nur völlig unbewiesen - sie sind auch bei normal entwickeltem Geschmacksempfinden kaum genießbar. Eine kürzlich publizierte randomisierte Studie schlägt vor, bei leichter Pankreatitis keine Nahrungskarenz anzuordnen [201]. Dies führte zu einer Reduktion der Krankenhausverweildauer und einer schnelleren Rekonvaleszenz. Die Arbeit von Teich et al. bestätigt diesen Therapieansatz [202].

\section{Statement 5-1-8}

Bei schwerer Verlaufsform sollte vorzugsweise eine enterale Ernährung über eine gastrale oder eine jejunale Ernährungssonde erfolgen.

[Evidenzgrad 2b Empfehlungsgrad B, starker Konsens]

\section{Kommentar}

Studien konnten nicht zeigen, dass eine jejunale Sondenernährung einer gastralen Sondenernährung überlegen ist [193, 194, 201, 203, 204]. Beide Verfahren sind somit als gleichwertig zu betrachten und die Auswahl hängt von lokalen und patientenbedingten Gegebenheiten ab. Die Überlegenheit der enteralen über die parenterale Ernährung wurde weiter oben bereits ausgeführt.

\section{Statement 5-1-9}

Eine parenterale Verabreichung von immunmodulierender Supplementation sollte nicht erfolgen.

[Evidenzgrad 2b, Empfehlungsgrad B, starker Konsens]

\section{Kommentar}

Die Bedeutung der Immunonutrition ist derzeit unklar. Studien konnten keinen eindeutigen bzw. günstigen Einfluss auf den Krankheitsverlauf, bei gleichzeitig deutlich höheren Kosten, belegen [205-208].

\section{Statement 5-1-10}

Eine generelle prophylaktische Gabe von Antibiotika sollte nicht erfolgen.

[Evidenzgrad 1a, Empfehlungsgrad B, starker Konsens]

\section{Kommentar}

Die milde Verlaufsform bedarf keiner Antibiotika-Prophylaxe. Die Einstellung zur Behandlung der akuten Pankreatitis mit Antibiotika hat sich in den letzten Jahren mehrfach gewandelt. In neueren Studien wurde überzeugend gezeigt, dass eine generelle Antibiotikaprophylaxe keine Vorteile bietet und nur zur Selektion resistenter Erreger beiträgt. Demgegenüber profitieren Patienten mit nachgewiesener infizierter Pankreasnekrose von einer Antibiotikabehandlung erheblich. Die letzte Metaanalyse zur prophylaktischen Antibiotikagabe, die auch die Daten der neuesten „Meropenem-Studie“ von Dellinger et al. [209] einschließt und damit 7 Studien mit insgesamt 467 Patienten in der Analyse berücksichtigt, fand keinen Unterschied für die Rate an infizierten Nekrosen [210]. Auch die Gesamtmortalität war in der Antibiotika-Therapiegruppe nicht signifikant reduziert. 
Zahlreiche Studien und Metaanalysen konnten keinen signifikanten Vorteil der prinzipiellen Antibiotika-Prophylaxe bei der schweren Verlaufsform für die Infektion der extrapankreatischen Infektion, der Pankreas-Nekroseninfektion und der Letalität belegen. Für das Beta-Laktam-Antibiotikum Imipenem wurde ein signifikanter Vorteil für die Nekroseninfektion gezeigt, jedoch nicht für die Letalität. Sämtliche Studien weisen methodische Schwächen auf, insbesondere eine nicht adäquate StudienPower. Da die schwere nekrotisierende Verlaufsform eine hohe Mortalität hat, ist bei dieser Subgruppe eine frühzeitige Gabe nekrosegängiger Antibiotika (u. a. Beta-Laktame, Chinolone) aufgrund eines Trends zur Reduktion der Letalität vermutlich sinnvoll [209-216].

\section{Statement 5-1-11}

Probiotika sollen nicht gegeben werden. Sie haben einen eher ungünstigen Effekt auf den Verlauf der Pankreatitis. [Evidenzgrad 1b, Empfehlungsgrad A, starker Konsens]

\section{Kommentar}

Probiotika sind lebende Mikroorganismen, die eine Reihe von positiven Effekten auf die Gesundheit haben sollen. Olah und Kollegen haben in den letzten Jahren 2 randomisierte kontrollierte Studien zur Prophylaxe einer infizierten Nekrose bei Patienten mit akuter Pankreatitis durchgeführt. Beide Studien belegen, dass der Einsatz von Probiotika die Inzidenz von infektiösen Komplikationen verminderte [186, 217]. Umso mehr Aufsehen haben die Ergebnisse der PROPATRIA-Studie der Niederländischen Pankreatitis-Studien-Gruppe erregt. In einer doppelt verblindeten placebokontrollierten Studie an $298 \mathrm{~Pa}-$ tienten mit schwerer akuter Pankreatitis beobachteten die Autoren, dass die Probiotika-Gabe (Ecologic 641: Lactobacillus acidophilus, Lactobacillus casei, Lactobacillus salivarius, Lactococccus lactis, Bifidobacterium bifidum und Bifidobacterium lactis) nicht zu einer signifikanten Abnahme der infektiösen Komplikationen, sondern zu einer signifikanten Zunahme der Mortalität, überwiegend verursacht durch Darmnekrosen in der Verumgruppe, führte [218, 219]. Die Gabe von Probiotika zur Therapie der akuten Pankreatitis sollte somit unterbleiben, bis weitere Studien die Hintergründe dieses Befunds klären konnten [218, 220, 221].

\section{Statement 5-1-12}

Der klinische und/oder bildgebende Verdacht auf eine Nekroseninfektion kann durch eine Feinnadelpunktion gesichert werden.

[Evidenzgrad 2b, Empfehlungsgrad D, starker Konsens]

\section{Kommentar}

Singuläre Parameter, wie z. B. Procalcitonin, können eine Nekroseninfektion nicht sichern. Der klinische Befund, Laborparameter und das kontrastmittelgestützte CT können zusammen den Verdacht einer infizierten Nekrose begründen. Die Sicherung der Nekroseninfektion erfolgt mittels Feinnadelpunktion und mikrobiologischer Diagnostik. Bei unzureichender Sensitivität des Verfahrens wurde nur eine „Kann“-Empfehlung ausgesprochen $[19,173,222]$.

\section{Statement $5-1-13$}

Bei Vorliegen einer infizierten Nekrose soll die konservative Behandlung zunächst ausgeschöpft werden. Die endoskopische/ interventionelle Therapie soll einem offenen chirurgischen Verfahren vorgezogen werden. Kommen endoskopische /interventionelle oder chirurgische Verfahren zum Einsatz, sollen diese möglichst spät im Krankheitsverlauf eingesetzt werden.

[Evidenzgrad 1b, Empfehlungsgrad A, starker Konsens]

\section{Kommentar}

Ein operatives Vorgehen bei akuter nekrotisierender Pankreatitis ist nur bei nachgewiesener infizierter Nekrose und nicht bei einer sterilen Nekrose indiziert. Im Verlauf der letzten 2 Jahrzehnte hat sich das therapeutische Konzept von einem aggressiven operativen Vorgehen hin zu einem konservativen interventionellen Management gewandelt. Ursprünglich wurde die Indikation zur Nekrosektomie bei Auftreten eines Multiorganversagens gestellt. Dieses Vorgehen war mit einer Letalität von $65 \%$ verbunden, was den Nutzen des operativen Vorgehens in dieser Situation infrage stellte. Noch im Jahr 2003 belief sich die Letalität bei offener Nekrosektomie auf 47\% [223]. Die offene Nekrosektomie sollte deshalb, wo immer möglich, vermieden werden, da das operative Trauma ein schwer beherrschbares SIRS induziert [224]. Eine Studie von Mier et al. belegt, dass ein operatives Vorgehen innerhalb von 2 Wochen nach Krankheitsbeginn mit einer signifikant höheren Letalität behaftet ist [225]. Ein kombiniert konservatives und interventionelles Vorgehen ist auch bei infizierter Nekrose dem operativen Verfahren zumindest gleichwertig [226]. Eine Reihe von Studien hat in den letzten Jahren gezeigt, dass minimalinvasive Therapieverfahren wie die perkutane Drainageanlage oder eine laparoskopisch assistierte Nekrosektomie vielversprechende Ergebnisse liefern [227, 228]. Die minimalinvasive Therapie im „Step-up“-Ansatz führt wie in der PANTER-Studie gezeigt zu einem signifikant besseren klinischen Verlauf (kombinierter Endpunkt: Mortalität und schwere Komplikationen) [229]. Als neues und sehr wenig invasives Therapieverfahren gilt die transgastrische oder transduodenale endoskopische Nekrosektomie. Bisher wurden in der Literatur ca. 250 Behandlungsfälle beschrieben. Die Indikation war entweder eine nachgewiesene infizierte Nekrose oder ein Pankreasabszess. Die technische Erfolgsrate bei diesen hochselektionierten Patienten lag bei 92,1\%, wobei es in 19,6\% zu Komplikationen wie Kolonfisteln, Blutung, Prothesendislokation, Schmerzen nach mehr als $24 \mathrm{~h}$, Perforationen oder Senkungsabszesse beschrieben wurden. Die Letalität in dieser Patientengruppe betrug 5,6\%, der Langzeiterfolg der Therapie lag bei 81,2\% und die Anzahl der Eingriffe bei im Median 2,3 [230 - 233]. Insgesamt stellt dieses Verfahren bei richtiger Indikationsstellung und frühestens 2-3 Wochen nach Krankheitsbeginn einen vielversprechenden therapeutischen Ansatz dar [221, 226, 229, 234-241].

\section{Kapitel 6 - Indikationsstellung zur interventionellen oder operativen Therapie $\nabla$}

Als Leitsymptom der chronischen Pankreatitis imponiert der gürtelförmige Oberbauchschmerz, ein Gewichtsverlust verbunden mit einer Steatorrhö und der Diabetes mellitus. Die Therapie beschränkt sich bei fehlenden kausalen Therapieansätzen auf die Symptombekämpfung mittels Enzymsubstitution, analgetischer Therapie und optimierter Einstellung der endokrinen Insuffizienz. 30-60\% der Patienten entwickeln Komplikationen ihrer 
Erkrankung wie Strikturen des Ductus hepatocholedochus, entzündliche Raumforderungen, Pankreaspseudozysten, oder Pankreasgangsteine, die einer interventionellen oder operativen Therapie bedürfen. Im Nachfolgenden sollen die Indikationen zur Therapie behandelt werden.

\section{Statement 6-1-1}

Bei dauerhaften analgetikapflichtigen Schmerzen sollte eine interventionelle oder operative Therapie erfolgen.

[Evidenzgrad 2b, Empfehlungsgrad B, Konsens]

\section{Kommentar}

Analgetikapflichtige Schmerzen bei chronischer Pankreatitis können sowohl mittels endoskopischer, als auch mittels chirurgischer Verfahren effizient behandelt werden (Evidenzgrad $2 b / 3 b$ aus mehreren Studien [242]). Im Bezug auf eine langfristige Schmerzreduktion sind chirurgische Verfahren (Drainage) den endoskopischen überlegen, jedoch bei geringerer Morbidität mit einer höheren Letalität assoziiert. Es liegen 25 Arbeiten mit einem Evidenzgrad $2 b$ oder $3 a$ zur Schmerzbehandlung bei chronischer Pankreatitis durch Endoskopie, ESWL, thorakoskopischer Splanchniketomie, resezierende und drainierende chirurgische Verfahren vor [242]. Ein direkter Vergleich zwischen Operation und Endoskopie erfolgte nur in zwei Arbeiten auf dem Evidenzgrad $1 b$ [243, 244]. In beiden Studien wurde übereinstimmend ein Vorteil für das chirurgische Vorgehen im Langzeitverlauf gezeigt.

\section{Statement 6-1-2}

Bei Verdacht auf ein resezierbares Pankreaskarzinom soll eine chirurgische Therapie erfolgen.

[Evidenzgrad 2b, Empfehlungsgrad A, Konsens]

\section{Kommentar}

Kann bei Vorliegen einer Pankreasraumforderung der Verdacht auf ein (resektables) Pankreaskarzinom nicht ausgeräumt werden, sollt eine chirurgische Resektion erfolgen Begründung: Bei Vorliegen eines Pankreaskarzinoms liegt die Lebenserwartung ohne Operation bei unter einem Jahr, nach erfolgreicher Resektion in $20-25 \%$ bei über 5 Jahren. [Evidenzgrad 1a] [245, 246].

\section{Statement $6-1-3$}

Das alleinige Vorliegen einer exokrinen Pankreasinsuffizienz bei chronischer Pankreatitis stellt keine Indikation für eine operative oder interventionelle Therapie dar. [starker Konsens, klinischer Konsenspunkt]

\section{Kommentar}

Da eine exokrine Pankreasinsuffizienz medikamentös in der Regel gut behandelt werden kann und keine konsistenten Studien vorliegen, dass durch eine endoskopische Intervention oder eine chirurgische Operation die exokrine Pankreasfunktion nachhaltig verbessert werden, können operative oder interventionelle Verfahren nicht zur Behandlung der exokrinen Pankreasfunktion empfohlen werden.

Zur Endoskopie in diesem Zusammenhang liegen praktisch keine Studien vor. Ergebnisse zur exokrinen Pankreasfunktion nach Beger, Kausch-Whipple oder Frey'scher Operation sind sehr heterogen im Ergebnis [247].

\section{Statement 6-1-4}

Das alleinige Vorliegen einer endokrinen Pankreasinsuffizienz stellt keine Indikation für die operative oder interventionelle Therapie einer chronischen Pankreatitis dar.

[starker Konsens, klinischer Konsenspunkt]

\section{Kommentar}

Vereinzelt gibt es positive Fallserien, die nach Resektion eines Karzinoms eine Verbesserung der endokrinen Stoffwechselsituation beobachten konnten. Randomisierte Studien, die einen positiven Einfluss auf die endokrine Stoffwechselsituation nach Resektion bei chronischer Pankreatitis zeigen, liegen nicht vor [248]. Es bestand starker Konsens darüber, dass die vorliegenden Fallserien die Empfehlung zur operativen Therapie alleinig zur Verbesserung einer endokrinen Insuffizienz nicht rechtfertigen. Die Empfehlung wurde daher trotz des formalen Evidenzgrads 4 als klinischer Konsenspunkt gewertet.

\section{Statement 6-1-5}

Bei persistierenden klinischen Symptomen einer Magenausgangs- oder Duodenalstenose auf dem Boden einer chronischen Pankreatitis soll eine operative oder interventionelle Therapie erfolgen.

[starker Konsens, klinischer Konsenspunkt]

\section{Kommentar}

Eine Magenausgangstenose oder Duodenalstenose auf dem Boden einer chronischen Pankreatitis sollte interventionell oder chirurgisch behoben werden [starke Empfehlung, aber nur Expertenmeinung als klinischer Konsenspunkt]. Vergleichende Studien, ob hierbei ein resezierendes chirurgisches Verfahren, eine chirurgische Bypassoperation oder die endoskopische Einlage von selbstexpandierenden Metallgitterstents größere Vorteile bietet, liegen nicht vor [249] (siehe Chirurgische Therapie).

\section{Statement 6-1-6}

Symptomatische Pseudozysten sollten therapiert werden. Die endoskopische oder chirurgische Therapie einer symptomatischen Pseudozyste sollte unabhängig von der Größe erfolgen. [Evidenzgrad 2a, Empfehlungsgrad B, starker Konsens]

\section{Kommentar}

Pseudozysten, die zu Komplikationen wie Magenausgangstenose, Blutung, Schmerzen, Cholestase oder Gefäßstenosen geführt haben, sollten endoskopisch oder chirurgisch behandelt werden. Die chirurgischen Verfahren zur Pseudozystenbehandlung haben einen Trend zu höheren Erfolgsraten, sind aber mit einer etwas höheren Letalität behaftet als die endoskopische Pseudozystendrainage ins Duodenum oder in den Magen [Empfehlungsgrad B] [151].

\section{Statement 6-1-7}

Bei entzündlichem Pankreaskopftumor sollten eine primäre Endoskopie und Stenteinlage in den Gallengang bei Gallengangstenose mit Gangdilatation erfolgen. Besteht jedoch nach temporärer endoskopischer Therapie eine Persistenz der Symptome oder der Cholestase, so sollte die chirurgische Resektion durchgeführt werden.

[Evidenzgrad 2b, Empfehlungsgrad B, starker Konsens] 


\section{Kommentar}

In einer retrospektiven Analyse aller behandelten Patienten mit einer mittleren Beobachtungsdauer von 45 Monaten konnte gezeigt werden, dass eine Stenttherapie von Gallengangstenosen aufgrund einer chronischen Pankreatitis über ein Jahr hinaus keinen nachhaltigen Langzeiteffekt erbringt [250].

Eine prospektive Untersuchung zeigt eine deutlich schlechtere Langzweitwirkung der Stentversorgung von distalen Gallengangstenosen, wenn Kalzifikationen bei chronischer Pankreatitis vorliegen [251].

\section{Kapitel 7: Endoskopische und interventionelle Therapie der chronischen Pankreatitis \\ $\nabla$}

Der natürliche Verlauf der chronischen Pankreatitis zeigt, dass zwischen 30 und $60 \%$ aller Patienten letztlich einer Intervention bedürfen. In mindestens $30 \%$ der Fälle scheint eine konservative Therapie, erweitert durch endoskopische Interventionen, zur Therapie ausreichend. In 10 - 40\% der Fälle entwickelt sich eine interventionspflichtige Stenose des Ductus hepatocholedochus (DHC). Eine weitere Komplikation stellt die Entwicklung von Stenosen des Pankreasgangs dar. Für den letzten Fall ist die die Indikation zur Einlage von Endoprothesen bisher nicht hinreichend geklärt. Es gibt keine prospektiv kontrollierten Studien, die einen positiven Effekt der Stentdrainage einer dominanten Stenose im Ductus wirsungianus gezeigt haben. Einige Studien belegen, dass die Einlage einer Prothese in den Ductus pancreaticus sekundäre Veränderungen durch den Stent mit nachfolgender Fibrosierung und Striktur induzieren kann [252, 253]. Die Behebung der Obstruktion des Pankreasgangs zur Schmerztherapie ist kurzfristig oft effektiv, und es werden Erfolgsraten zwischen 37 und 94\% berichtet [254]. Metabolische Effekte der Stenttherapie im Pankreasgang wurden bisher nicht im Langzeitverlauf untersucht. Pankreaspseudozysten entstehen als häufige Komplikation der akuten oder chronischen Pankreatitis. Ein weiteres endoskopisches/interventionelles Verfahren zur Therapie der chronischen Pankreatitis ist die extrakorporale Stoßwellenlithotripsie (ESWL) bei Pankreasgangsteinen. Vor der Einführung der ESWL 1989 war die chirurgische Operation oft die einzige Möglichkeit zur Entfernung von Pankreasgangkonkrementen, die endoskopisch nicht entfernt werden konnten. Mehrere retrospektive Studien haben sich mit der Frage des klinischen Nutzens der ESWL für Pankreasgangsteine beschäftigt (siehe Statement 7 -2-5). Die endoskopische und interventionelle Therapie von Pseudozysten ist ein häufig in der Praxis angewandtes Verfahren.

\section{7 - 1: Therapie von Pseudoyzsten bei chronischer Pankreatitis}

Die Entscheidung, bei wem, wann und durch welches Verfahren Pankreaspseudozysten behandelt werden sollten, wurde in der Vergangenheit kontrovers diskutiert. Pankreaspseudozysten entstehen als häufige Komplikation der akuten oder chronischen Pankreatitis. Die Prävalenz von Pankreaspseudozysten bei chronischer Pankreatitis liegt bei 20 - 40\% [255]. Pankreaspseudozysten treten am häufigsten bei Patienten mit alkoholischer chronischer Pankreatitis auf (70-78\%) [2]. Die zweithäufigste Ursache ist die idiopathische chronische Pankreatitis (6-16\%), gefolgt von der biliären Pankreatitis (6-8\%) [256]. Innerhalb der ersten 6 Wochen nach akutem Schub einer Pankreatitis bilden sich $40 \%$ der Pseudozysten spontan zurück, während in $20 \%$ der Fälle Komplikationen wie Infektion, Verlagerung von angrenzendem
Gewebe oder benachbarten Organen, Zystenruptur oder eine persistierende Pankreatitis eine Intervention notwendig werden lassen. Nach 12 Wochen ist die Spontanremission von Pseudozysten sehr gering, und Komplikationen werden in bis zu 2/3 der Fälle beobachtet. Verbunden mit der Entstehung von Komplikationen durch Pseudozysten ist ihre Größenzunahme auf über $5 \mathrm{~cm}$. Treten Beschwerden durch die Pseudozystenbildung auf, kann entweder eine operative Behandlung oder eine perkutane bzw. endoskopische Drainage durchgeführt werden. Alle diese Verfahren weisen hinsichtlich des technischen Erfolgs und der Rezidivrate vergleichbare Ergebnisse auf. Es sollte bei geringerer Belastung des Patienten deshalb eine endoskopische Drainage erfolgen [151].

\section{Statement 7-1-1}

Verursacht eine Pankreaspseudozyste Komplikationen, sollte eine interventionelle oder operative Behandlung erfolgen. [Evidenzgrad 2a, Empfehlungsgrad B, starker Konsens]

\section{Kommentar}

Die Datenlage zur interventionellen Therapie von Pankreaspseudozysten als Schmerztherapie ist sehr spärlich, da derzeit keine einzige randomisierte kontrollierte Studie vorliegt. Die Mehrzahl der Daten beruht auf retrospektiven Fallserien [257 - 262]. Basierend auf dieser schlechten Datenlage gibt es 3 systematische Reviews der verfügbaren Evidenz [151, 263, 264]. In den zusammengefassten Studien konnte jeweils bei einem großen Teil der Patienten Schmerzfreiheit erreicht werden, sowohl mit chirurgischen, endoskopischen oder mit perkutanen Drainageverfahren. Da in diesen retrospektiven Serien eine hohe Rate an Schmerzfreiheit erreicht werden konnte (etwa $80 \%$ ), kamen alle 3 systematischen Reviews zu dem Ergebnis, dass zwar auch eine konservative Therapie der chronischen Pankreatitis in einem gewissen Prozentsatz der Patienten zur Schmerzfreiheit führt, jedoch die perkutane, endoskopische oder chirurgische Drainage die effektivere Schmerztherapie darstellt. Im Vergleich der 3 Verfahren lässt sich aus den publizierten Daten kein signifikanter Unterschied ableiten. Zusammenfassend ist nach derzeit geringer Datenlage dennoch davon auszugehen, dass eine Pseudozystendrainage die Schmerzen der Patienten bessert. Entsprechende randomisierte kontrollierter Studien sollten dringlich erfolgen. Noch spärlicher ist die Datenlage zur geeigneten therapeutischen Intervention bei anderen Komplikationen durch Pankreaspseudozysten. Führen Pankreaspseudozysten zu einer Stenose von Gallengang oder Pankreasgang, so sollte die Pseudozyste behandelt werden. Klingt die Cholestase durch Pseudoyzstendrainage alleine nicht ab, kann auch eine Stenteinlage in den Gallengang oder ein resezierendes Verfahren indiziert sein. Dies ist in den jeweiligen Abschnitten zur Therapie von Stenosen des DHC und Pankreasgangstenosen bei chronischer Pankreatitis dargelegt ist (s. Abschnitt 7-2 und 7-3).

Als weitere Komplikationen, die eine endoskopische oder operative Therapie der Pseudozyste veranlassen, sind folgende zu werten: die Kompression großer abdomineller Gefäße; die klinische relevante Magenausgangstenose oder Duodenalstenose; die Infektion der Pankreaspseudozyse; die pankreatico-pleurale Fistel, Völlefühl, Übelkeit und Erbrechen durch die Pankreaspseudozyste.

Die endoskopisch interventionelle Therapie der eingebluteten Pseudozyste ist mit einem hohen Blutungsrisiko verbunden. Sie sollten daher chirurgisch therapiert werden. 


\section{Statement 7-1-2}

Bei symptomatischen Pankreaspseudozysten kann die initiale Therapie eine endoskopische Drainage der Pseudozysten darstellen und eine operative Therapie kann bei Rezidiv der Pseudozyste erfolgen.

[Evidenzgrad 3a, Empfehlungsgrad C, starker Konsens]

\section{Statement 7-1-3}

Die Wahl zwischen endoskopischer und operativer Pseudozystendrainage soll aufgrund der Zystenlokalisation und der Art zusätzlicher pathomorphologischer Veränderungen getroffen werden.

[Evidenzgrad 3b, Empfehlungsgrad A, starker Konsens]

\section{Kommentar}

Endoskopische Verfahren zur Drainage von Pankreaspseudozysten sind komplikationsärmer als operative Verfahren. Nicht alle Pseudozysten lassen sich dauerhaft erfolgreich durch eine alleinige endoskopische Pseudozystendrainage drainieren und erfordern dann ein operatives Vorgehen. Studien, die beide Verfahren vergleichen, liegen nicht vor. Angestrebt wird ein interdisziplinäres Therapiekonzept [151, 265].

\section{Statement 7-1-4}

Asymptomatische Pankreaspseudozysten, die eine Größe von mehr als $5 \mathrm{~cm}$ Durchmesser haben und sich innerhalb von 6 Wochen nicht zurückbilden, können behandelt werden. [Evidenzgrad 2a, Empfehlungsgrad C, mehrheitliche Zustimmung]

\section{Kommentar}

Pankreaspseudozysten, die in bildgebenden Verfahren von einer bindegewebigen Wand von mehr als $5 \mathrm{~mm}$ umgeben sind, eignen sich besonders für eine endoskopische oder operative Drainage. Gouyon konnte in einer multivariaten Analyse zeigen, dass eine Pseudozystengröße $<4 \mathrm{~cm}$ der einzig prognostisch günstige Faktor für eine spontane Rückbildung ist [266]. Bradley et al. konnten zeigen, dass unbehandelte Zysten größer als $5 \mathrm{~cm}$ in $41 \%$ der Fälle zu Komplikationen (Ruptur, Infektion, Ikterus, oder Einblutung) führen [267].

\section{Statement 7-1-5}

Die Drainage von Pseudozysten kann transgastral, transduodenal oder transpapillär durchgeführt werden. Eine perkutane Drainage ist ebenfalls möglich, jedoch mit dem Risiko einer externen Fistelbildung verbunden und für die Patienten beschwerlich.

[Evidenzgrad 4, Empfehlungsgrad D, starker Konsens]

\section{Kommentar}

Für die endoskopisch transmurale Drainage von Pseudozysten sollte der Untersucher den Zugangsweg wählen, der ihm bei der Beurteilung durch den endoskopischen Ultraschall am sichersten erscheint. Dies hängt von der Größe, der Gefäßnachbarschaft und Lokalisation der Pseudozyste ab. Vergleichende Untersuchungen, die eine Überlegenheit des endoskopischen Zugangswegs entweder durch die Magen oder Duodenalwand zeigen würden, liegen nicht vor. Transkutane Drainagen beinhalten erfahrungsgemäß das Risiko persistierender kutaner Fistelbildung. Darüber hinaus kann die liegende transkutane Drainage die Lebensqualität des Patienten beeinträchtigen. Ist die Drainage von Pseudozysten indiziert, ist daher die endoskopische transmurale Drainage zu bevorzugen [151, 265].

\section{Statement 7-1-6}

Transmurale Punktionen sollten mit endosonografischer Kontrolle erfolgen.

[Evidenzgrad 3, Empfehlungsgrad B, starker Konsens]

\section{Kommentar}

Die Endosonografie stellt ein Verfahren dar, mit dem die Wandbeschaffenheit, der Inhalt, die Lokalisation und die Beziehung zu benachbarten Blutgefäßen am besten beurteilt werden kann. Zur Verringerung der Rate an Fehlpunktionen und Komplikationen sollte daher die endoskopische transmurale Punktion unter endosonografischer Kontrolle erfolgen [268]. Ein direkter Vergleich der Komplikationsrate bei transmuraler Punktion der Drainage ohne Ultraschallkontrolle liegt nicht vor. Es muss aber von einer höheren Rate an Komplikationen ausgegangen werden. Aus diesem Grund wurde der Empfehlungsgrad auf „B“ aufgewertet. Die Erfolgsrate wird bei den 1126 publizierten Patienten mit transmuraler Drainage einer Pankreaspseudozyste mit 79,2\% angegeben, wobei die neueren Studien Erfolgsraten von deutlich über 85\% berichten, was den chirurgischen Ergebnissen entspricht. Die Letalitätsrate in größeren Serien mit über 30 Patienten liegt bei 0,2\%. Die Rezidivrate wird mit 7,6\% und die Komplikationsrate wird mit 12,8\% angegeben [151].

\section{Statement 7-1-7}

Eine diagnostische Zystenpunktion kann bei Verdacht auf infizierten Zysteninhalt oder bei Neoplasieverdacht erfolgen. [Evidenzgrad 4, Empfehlungsgrad D, starker Konsens]

\section{Kommentar}

Führt die diagnostische Zystenpunktion zum Nachweis einer Infektion des Zysteninhalts, so ist die Drainage der Pseudozyste indiziert. Bei Nachweis von Malignität sollte eine operative Therapie erfolgen. Die diagnostische Punktion einer Pseudozyste mittels EUS hilft bei der Unterscheidung zwischen zystischen Malignomen und Pseudozysten. Kurz zusammengefasst: Ergibt die EUS-gestützte Punktion einer Zyste ein CEA $>400 \mathrm{ng} / \mathrm{ml}$, eine variable erhöhte oder niedrige Amylase (Lipase), eine hohe Viskosität, Muzin oder epitheliale Zellen im Zysteninhalt, so muss vom Vorliegen einer muzinösen Neoplasie ausgegangen werden. Es handelt sich dann meist um eine muzinös zystische Neoplasie (MCN), die gehäuft bei Frauen im Alter von 30 - 50 Jahren auftritt, meist im Pankreasschwanz lokalisiert ist und bildgebend wandständige Knoten aufweist. Typisch ist hierbei das sogenannte „Eierschalen-Muster“. Bei nicht invasivem Wachstum ist die Prognose nach einer Operation gut. Wird jedoch ein invasives Wachstum nachgewiesen, so beträgt das mittlere Überleben 45 Monate. Bei einem CEA-Wert > $6000 \mathrm{ng} / \mathrm{ml}$ ist von einer malignen Läsion auszugehen. Das Zystenpunktat einer MCN unterscheidet sich wenig von einer intraduktal papillär-muzinösen Neoplasie (IPMN). Die IMPN ist als präkanzeröse Läsion zu werten. Das maligne Potenzial hängt von der Lokalisation (Hauptgang oder Seitengang) und der Größe der Läsion sowie der soli- 
den Anteile ab. Eine IMPN, die von Hauptgang ausgeht, sollte immer reseziert werden, da in 52 - 92 \% der Fälle sich in einem Zeitraum von 8 Jahren ein Karzinom aus dieser Läsion entwickelt. Für Läsionen des Seitengangs gilt dies für 6 - 46\% [269]. Läsionen die $<1 \mathrm{~cm}$ im MRT oder EUS sind und von einem Seitengang ausgehen, können nach einem Jahr bildgebend kontrolliert werden. Seitengang-Läsionen die zwischen 1 und $3 \mathrm{~cm}$ groß sind und keine soliden Anteile aufweisen, sollten nach 6 Monaten erneut kontrolliert werden. Hingegen müssen Läsionen, die $>3 \mathrm{~cm}$ sind oder wandständige Knoten oder eine Zytologie mit höhergradigen Dysplasien aufweisen, reseziert werden. Die IPMN kann multifokal auftreten und verhält sich in diesem Fall eher aggressiver [270]. Das seröse Zystadenom wird in 30\% der zystischen Läsionen ohne Anamnese für eine Pankreatitis diagnostiziert und entartet praktisch nie maligne. Das Zystenpunktat ist hier negativ für Muzin, CEA oder Amylase. Es findet sich ein glykogenreiches Epithel in der Zytologie.

\section{Statement 7-1-8}

Bei Verdacht auf einen malignen zystischen Prozess soll ein chirurgisches Vorgehen gewählt werden.

[Evidenzgrad 4, Empfehlungsgrad A, starker Konsens]

\section{Kommentar}

In $1 \%$ aller CT-Untersuchungen des Abdomens findet sich eine zystische Läsion des Pankreas als Zufallsbefund [271]. Mehr als zwei Drittel dieser Läsionen sind dysontogentische Zysten oder Pankreaspseudozysten. Die Prävalenz von Pankreaspseudozysten bei der chronischen Pankreatitis liegt bei 20-40\%. Von den zystischen Läsionen, die keine Pankreaspseudozyste darstellen, sondern echte zystische Neoplasien sind, sind 30\% benigne seröse Zystadenome, $45 \%$ der resezierten Läsionen sind muzinös-zystische Tumore und $25 \%$ intraduktale papillär muzinöse Neoplasien. Seltener finden sich solide pseudopapilläre Neoplasien oder zystische Azinuszellkarzinome. Zur Einordnung der Artdiagnose mit zystischen Tumoren bei symptomlosen Patienten ist die Frage des Ganganschlusses (IPMN und Pankreaspseudoyzste) und der Größe der zystischen Läsion (Indikation zur Resektion bei IPMN oder Therapieindikation bei Pseudozyste) wesentlich. Die diagnostische Punktion einer zystischen Läsion mittels EUS hilft bei der Unterscheidung zwischen Prämalignom, Malignom und Pseudozyste.

Eine dringliche Indikation zum operativen Vorgehen besteht immer bei Verdacht auf ein Malignom oder eine Vorstufe eines Malignoms, da hier Heilung erzielt werden kann und bei malignen Befunden nach Resektion das 5-Jahres-Überleben bei $63 \%$ liegt [151, $272-274]$.

\section{Statement 7-1-9}

Vor endoskopischer oder chirurgischer Pseudozystendrainage kann eine Darstellung des Pankreasgangs erfolgen. [Evidenzgrad 3b, Empfehlungsgrad C, starker Konsens]

\section{Kommentar}

Ob vor einer transgastralen oder transduodenalen Zystendrainage eine ERCP mit dem Versuch einer Ableitung der Pseudozyste über die Papille durchgeführt werden soll, wird noch kontrovers diskutiert. Einerseits ist die Ableitung der Pseudozyste über einen Stent im Pankreasgang die ,physiologischste' Drainage. Je nach Studie haben 22 - 57\% der Pankreaspseudozysten eine Ver- bindung mit dem Pankreasgangsystem ([259]). Eine ERP kann nach heutigem Stand zum Nachweis einer Gangverbindung oder zum Ausschluss einer Pankreasgangruptur (8\% nach akuter nekrotisierender Pankreatitis) einer endoskopischen transmuralen Drainage vorausgehen. Eine transmurale Drainage bei nicht erkannter Pankreasgangruptur oder bei Anschluss der Pankreaspseudozyste an einen stenosierten Pankreasgang ist im Bezug auf einen langfristigen Therapieerfolg weniger Erfolg versprechend. Anderseits liegt die Erfolgsquote der versuchten transpapillären Drainagen bei maximal $60 \%$. Ein solcher Versuch setzt den Patienten dem Risiko einer ERCP-induzierten Pankreatitis aus, wohingegen die direkte transgastrale oder transduodenale Zystendrainage sehr effektiv und komplikationsarm ist [151, 265]. Unabdingbar ist eine periinterventionelle Antibiotikatherapie vor der ERCP, wenn der Verdacht auf Pankreaspseudozysten besteht oder diese die Indikation zur ERCP oder ERP darstellen. Bei Kommunikation mit dem Pankreasgangsystem besteht sonst die Gefahr einer Retention von infiziertem Kontrastmittel. Ohne Antibiotikaprophylaxe steigt die untersuchungsbedingte Inzidenz von infizierten Pseudozysten und Pankreasabszessen nach ERCP an [275].

\section{Statement 7-1-10}

Bei chronischer Pankreatitis mit fortgeschrittenen Pankreasgangveränderungen, insbesondere mit Pankreatikolithiasis, sollte eine Pseudozyste als Teil eines therapeutischen Gesamtkonzepts behandelt werden.

[Evidenzgrad 2b, Empfehlungsgrad B, Konsens].

\section{Kommentar}

Eine relative Indikation zur Behandlung von Pankreaszysten ist das Vorliegen einer chronischen Pankreatitis mit Pankreasganganomalien oder Pankreasgangsteinen, weil hier durch den ständigen Entzündungsreiz die Rate an spontanen Rückbildungen auch bei kleinen Zysten nur bei maximal 10 - 26\% liegt [151, 265].

\section{Statement 7-1-11}

Eine Therapie von Pankreasgangstenosen kann bei Pankreaspseudozyste, prästenotischer Gangdilatation oder Fistel erfolgen.

[Evidenzgrad 4, Empfehlungsgrad D, starker Konsens]

\section{Kommentar}

Pankreaspseudozysten werden bei Vorliegen von prästenotischen Gangdilatationen oder Fisteln durch Pankreasgangstenosen unterhalten, wenn diese Stenosen ein Abflusshindernis darstellen. Eine Therapie von Pankreasgangstenosen wird daher in diesen Fällen empfohlen.

\section{Statement 7-1-12}

Vaskuläre Pseudoaneurysmen bei chronischer Pankreatitis sollten behandelt werden.

[starker Konsens, klinischer Konsenspunkt]

\section{Kommentar}

Es liegen keine vergleichenden Untersuchungen vor, die eine Therapie von vaskulären Pseudoaneurysmen mit einem abwartenden Verhalten vergleichen. Auch Untersuchungen zum besten 
Zeitpunkt der Therapie bei vaskulären Pseudoaneurysmen zu verschiedenen Zeitpunkten existieren nicht.

Die operative oder radiologisch interventionelle Therapie von Pseudoaneurysmen entspricht der klinischen Praxis.

\section{Statement 7-1-13}

Bei blutenden Pseudoaneurysmen des Pankreas ist die angiografische Embolisation Methode der ersten Wahl. [Evidenzgrad 3a, Empfehlungsgrad B, starker Konsens]

\section{Kommentar}

Es liegt zu dieser Fragestellung ein systematischer Review von Fallserien und Fallberichten vor [276]. In dieser Untersuchung lag die Erfolgsrate der angiografischen Therapie bei 66\%. Die Komplikationsrate ist geringer als bei einer operativen Therapie und mit einem kürzeren Krankenhausaufenthalt verbunden. Die Operation sollte Patienten mit gutem Allgemeinzustand vorbehalten bleiben, bei denen eine Operation auch aufgrund anderer Komplikationen der chronischen Pankreatitis indiziert ist.

\section{7 - 2: Therapie von Pankreasgangveränderungen und Pankreasgangsteinen bei chronischer Pankreatitis} Der Druck im Pankreasgang ist bei Patienten mit chronischer Pankreatitis unabhängig von der Ätiologie und einer Dilatation des Ductus wirsungianus anfänglich erhöht [277]. Einer duktalen und interstitiellen Hypertension und möglichen relativen Pankreasischämie wird eine wichtige Rolle bei der Pathogenese der Schmerzen zugeschrieben. Ziel der endoskopischen und der operativen Dekompressionstherapie bei Patienten mit chronischer Pankreatitis und Schmerzen und/oder klinischen Episoden einer akuten Pankreatitis ist es, die Behinderung des exokrinen Sekretablaufs aufzuheben. Techniken wie die Sphinkterotomie, Dilatation, ESWL und Stenteinlage sind für den Pankreasgang modifiziert worden. Das endoskopische Vorgehen kann dem operativen Vorgehen vorgeschaltet werden. Es stellt eine Alternative zur Operation mit niedriger Morbidität und Letalität dar. Endoskopische Eingriffe behindern eine eventuell später notwendige Operation nicht. Zudem gibt der klinische Erfolg nach endoskopischer Reduktion des intraduktalen Druckes Hinweise auf das spätere operative Ergebnis eine Drainage-Operation oder eines resezierenden Verfahrens.

\section{Statement 7 - 2-1}

Pankreasgangsteine, die durch eine Abflussbehinderung des Pankreassekrets Schmerzen verursachen, rezidivierende Krankheitsschübe induzieren, eine Pseudozyste oder Fistel unterhalten oder andere Komplikationen verursachen, können endoskopisch oder operativ behandelt werden. [Evidenzgrad 4, Empfehlungsgrad D, starker Konsens]

\section{Kommentar}

Pankreasgangsteine sind Folge und nicht Ursache einer chronischen Pankreatitis oder einer Pankreasgangstenose. Sie können jedoch durch Obstruktion des Pankreasgangs zu einem konsekutiven Sekretstau führen und dadurch Pseudozysten oder Fisteln unterhalten. Sie können auch rezidivierende Krankheitsschübe verursachen oder zur Schmerzsymptomatik von Patienten mit chronischer Pankreatitis beitragen, wenn eine Obstruktion mit Sekretstau vorliegt. Die Therapie von Pankreasgangsteinen scheint unter diesen Bedingungen sinnvoll. Es liegen jedoch kei- ne Untersuchungen vor, die eine Therapie von Pankreasgangsteinen mit einer Sham-Intervention verglichen haben.

Es liegen Fallserien und eine Metaanalyse vor, die eine Besserung von Schmerzen nach Behandlung von Pankreasgangsteinen zeigen; vergleichende Studien mit dem Spontanverlauf oder randomisierte Studien liegen allerdings nicht vor.

Die endoskopische Therapie scheint insbesondere zur Therapie von solitären Steinen und proximalen Stenosen geeignet zu sein. Bei distalen Stenosen haben sich operative Drainageverfahren als überlegen gezeigt.

Weder für die endoskopischen Verfahren noch für die chirurgischen Verfahren liegen Vergleichsstudien mit unbehandelten Kohorten oder im direkten Vergleich zum natürlichen Krankheitsverlauf vor. In zwei Studien, in denen die endoskopische Behandlung mit chirurgischen Operationen (Drainage) verglichen wurde, schneidet die chirurgische Therapie im Bezug auf die langfristige Schmerzreduktion signifikant besser ab [243, 244].

\section{Statement 7-2-2}

Pankreasgangstenosen, die durch eine Abflussbehinderung des Pankreassekrets Schmerzen verursachen, rezidivierende Krankheitsschübe induzieren, eine Pseudozyste oder Fistel unterhalten oder andere Komplikationen verursachen, können mittels endoskopischer Dilatation und Stenteinlage behandelt werden.

[Evidenzgrad 4, Empfehlungsgrad D, starker Konsens]

\section{Kommentar}

Besteht nach den unter 7 - 2-1 genannten Bedingungen die Indikation zur Therapie, kann eine endoskopische Therapie mittels Dilatation und Stenteinlage erfolgen. Untersuchungen, die eine Dilatation von Pankreasgangstenosen im Vergleich mit einer Sham-Intervention durchgeführt hätten, liegen nicht vor. In einer prospektiven nicht randomisierten Studie konnte bei nicht operablen Patienten durch die Einlage eines Pankreasstents eine rasche Symptomverbesserung erreicht werden, häufig waren jedoch weitere Interventionen notwendig [278]. Einige Studien belegen jedoch, dass die Einlage einer Prothese in den Ductus pancreaticus sekundäre Veränderungen durch den Stent mit nachfolgender Fibrosierung und Striktur induzieren kann $[252,253]$. Die Behebung der Obstruktion des Pankreasgangs zur Schmerztherapie ist kurzfristig oft effektiv. Es wurden Erfolgsraten zwischen 37 - $94 \%$ berichtet. In der größten bisher untersuchten Kohorte von 1021 Patienten konnte in 84\% der Fälle eine langfristige Reduktion der pankreatogenen Schmerzen erreicht werden [279]. Allerdings musste bei $79 \%$ der Patienten innerhalb eines Jahres und bei $97 \%$ innerhalb von 2 Jahren die Stent-Therapie zur Schmerzkontrolle wiederholt werden. Metabolische Effekte wurden bisher nicht im Langzeitverlauf untersucht.

\section{Statement 7-2-3}

Eine endoskopische Stentimplantation in den Pankreasgang kann erfolgen, wenn Pankreasgangsteine oder eine papillennahe Stenose im Pankreasgang zu einer Abflussbehinderung führen. Über die notwendige Dauer einer Stenttherapie können keine generellen Empfehlungen abgegeben werden. [Evidenzgrad 4, Empfehlungsgrad C, starker Konsens] 


\section{Kommentar}

Benigne Strikturen des Ductus wirsungianus können als Komplikation eines eingeklemmten Steins oder als Konsequenz akuter entzündlicher Parenchymveränderungen mit Kompression oder Striktur des Ductus wirsungianus auftreten [280]. Vor dem Hintergrund der dadurch bedingten Druckerhöhung als Ursache für die Schmerzentstehung und für Schübe der chronischen Pankreatitis wurde die Erfolgsrate einer Stenteinlage untersucht [280 - 289]. Von 328 Patienten war die Pankreasstenteinlage bei 308 technisch erfolgreich und bei $66 \%$ wurde eine Verbesserung der Symptomatik nach Stentversorgung einer dominanten Stenose berichtet (Nachbeobachtungszeit: 8-39 Monate). Vorwiegend profitieren Patienten, bei denen durch Steine oder eine Stenose eine Pankreasfistel oder eine Pseudozyste unterhalten wurde bzw. Pankreatitisschübe induziert wurden. Die endoskopische Drainage mit Steinextraktion und Stenttherapie ist bei einigen Patienten mit dilatiertem Ductus Wirsungianus eine wirksame Maßnahme zur Schmerzkontrolle [261], die die Notwendigkeit einer Operation herauszögern oder überflüssig machen und Hinweise auf die Effektivität einer Drainage-Operation geben kann [290]. Eine bessere Schmerztherapie wurde jedoch in zwei randomisierten Kontrollstudien mit einer Pankreatikojejunostomie erreicht [243, 244]. Dabei konnte durch die endoskopische Therapie bei 32\% [244] bzw. 65\% [243] eine Schmerzreduktion oder komplette Schmerzfreiheit erreicht werden, während dies durch die Pankreatikojejunostomie bei 75\% [244] bzw. 86\% [243] erreicht wurde. Die unterschiedliche Erfolgsrate bei der endoskopischen Therapie in beiden Studien ist möglicherweise auf die längere Dauer der Stenttherapie bei Dite et al. zurückzuführen.

Bezüglich der notwendigen Dauer einer Stenttherapie liegen derzeit keine belastbaren Daten vor [243, 244, 261]. Von einigen Autoren wird die Behandlung über $1 \mathrm{Jahr}$ mit Wechseln des Stents mindestens alle 3 Monate empfohlen, jedoch liegen keine vergleichenden Daten hierzu vor.

\section{Statement $7-2-4$}

Bei Kontraindikationen für eine operative Therapie kann zur Schmerztherapie auch die Einlage eines vollständig beschichteten Metallstents in den Ductus wirsungianus erfolgen.

[Evidenzgrad 4, Empfehlungsgrad D, starker Konsens]

\section{Kommentar}

Einzelne Fallberichte und kleine Fallserien legen nahe, dass auch beschichtete Metallgitterstents in den Pankreasgang zur Behandlung von Schmerzen bei chronischer Pankreatitis eingelegt werden können. Ihr Vorteil gegenüber Kunststoffstents besteht in ihrer längeren Durchgängigkeit. Langzeitergebnisse über ihren Nutzen liegen nicht vor. Von der Verwendung unbeschichteter Metallgitterstents im Pankreasgang wird wegen der schnellen Proliferation des Gangepithels durch das Metallgitter abgeraten $[291,292]$.

\section{Statement 7-2-5}

Einzelne Pankreasgangsteine, die durch eine Abflussbehinderung des Pankreassekrets Schmerzen verursachen, rezidivierende Krankheitsschübe induzieren, eine Pseudozyste oder Fistel unterhalten oder andere Komplikationen verursachen, können mittels ESWL behandelt werden.
Es finden sich zunehmend Hinweise darauf, dass für die Effektivität des Verfahrens nicht die anschließende endoskopische Entfernung der Pankreasgangsteine oder deren Fragmente entscheidend sind. Die Behandlung von Schmerzen bei diffusen Verkalkungen mittels ESWL ist nicht durch Studien belegt. [Evidenzgrad 2b, Empfehlungsgrad C, starker Konsens]

\section{Kommentar}

Für die Entfernung obstruierender Konkremente kann die ESWL angewandt werden. In einer Metaanalyse konnte ein deutlicher Effekt auf die Schmerzreduktion gezeigt werden, jedoch bei starker Heterogenität der Ergebnisse [293]. Alle in die Metaanalyse eingeschlossenen Studien waren Fallstudien ohne unbehandelte oder scheinbehandelte Kontrollgruppen.

In einer Kohortenstudie [294] konnte ein besseres Ergebnis bezüglich der technischen Steinfreiheit bei Anwendung der ESWL mit nachfolgender endoskopischer Steinbergung im Vergleich zur alleinigen ESWL berichtet werden. Bislang wurde nur eine randomisierte kontrollierte Studie zum Vergleich der ESWL von Pankreasgangsteinen mit und ohne anschließende ERP zur Beseitigung von Fragmenten aus dem Pankreashauptgang veröffentlicht. In dieser Studie hatte die nachfolgende endoskopische Steinextraktion keinen Einfluss auf die Schmerzfreiheit nach zwei Jahren [295].

Sowohl die endoskopische Therapie als auch die ESWL alleine ermöglichen bei einigen Patienten eine gute Schmerztherapie $[243,244,261,296,297]$.

\section{7 - 3 Endoskopische Therapie von Gallengangstenosen bei chronischer Pankreatitis}

In $10-44,6 \%$ der Fälle entwickelt sich bei Patienten mit chronischer Pankreatitis eine interventionspflichtige Stenose des DHC. Dabei gelten als Indikation für eine endoskopische Intervention eine signifikante Cholestase, cholangitische Schübe, die Prävention einer sekundären biliären Zirrhose und die Differenzierung der Schmerzursache (Stenose des DHC vs. chronische Pankreatitis). Mehrere Studien haben die Wirksamkeit und Kosteneffizienz der endoskopischen Drainage des DHC untersucht. Nur 1/3 der endoskopisch behandelten Patienten profitiert langfristig, sodass die endoskopische Therapie nur als Überbrückung bis zur operativen Sanierung, als Akutintervention beim septischen Patienten oder aber bei nicht operablen oder nicht operationswilligen Patienten indiziert ist. Nach Anlage einer endoskopisch platzierten Drainage besteht grundsätzlich das Risiko einer Cholangitis. Die Gabe einer prophylaktischen Dauerantibiose verbunden mit einer Ursodesoxycholsäuregabe hat sich in verschiedenen klinischen Studien nicht als wirksam erwiesen [298 - 302]. Zu den häufig auftretenden Komplikationen zählt die Stent-Okklusion durch Zelldedritus, Mikrokolonien von Bakterien oder extrazellulärem, fibrillärem Material [303].

\section{Statement 7-3-1}

Verursacht eine chronische Pankreatitis eine distale Gallengangstenose und bestehen klinische Anhalte für eine Cholangitis, dann sollte eine zügige endoskopische Drainage der Stenose erfolgen.

[starker Konsens, klinischer Konsenspunkt] 


\section{Kommentar}

Studien, die eine endoskopische Therapie der Cholangitis infolge einer mechanischen Cholestase mit einem abwartenden Vorgehen vergleichen, sind nicht publiziert. Die Therapie der mechanischen Cholestase als Bestandteil der Behandlung einer Cholangitis ist wichtig und durch klinische Erfahrung belegt.

\section{Statement 7-3-2}

Verursacht eine chronische Pankreatitis eine distale Gallengangstenose mit Cholestase oder Ikterus, sollte eine operative Behandlung oder eine endoskopische Stentbehandlung erfolgen. Liegen Verkalkungen im Pankreas vor, sollte eine operative Behandlung vorgezogen werden.

[Evidenzgrad 4, Empfehlungsgrad B, Konsens]

\section{Kommentar}

Studien, die eine Therapie der mechanischen Cholestase bei chronischer Pankreatitis mit einem abwartenden Vorgehen vergleichen, sind nicht publiziert. Der Empfehlungsgrad wurde dennoch als „Empfehlungsgrad B“ eingestuft, da die Therapie der mechanischen Cholestase als durch klinische Erfahrung belegt erscheint.

Eine Cholestase bei chronischer Pankreatitis kann durch endoskopische oder chirurgische Verfahren behoben werden, wobei die endoskopische Stentbehandlung über 12 Monate nur in einem Drittel der Patienten von nachhaltigem Erfolg ist. Eine prospektive Untersuchung zeigt eine noch schlechtere Langzeitwirkung der Stentversorgung von distalen Gallengangstenosen bei kalzifizierender Pankreatitis (Langzeiteffekt 9\%) [251]. In diesen Fällen wird daher die operative Therapie eindeutig bevorzugt. In einer retrospektiven Analyse aller behandelter Patienten mit einer mittleren Beobachtungsdauer von 45 Monaten konnte gezeigt werden, dass eine Stenttherapie von DHC-Stenosen bei chronischer Pankreatitis über länger als ein Jahr keinen zusätzlichen Effekt hat [250]. Bei Rezidiv einer DHC-Stenose nach einjähriger Stenttherapie sollte daher eine operative Therapie angestrebt werden.

\section{Statement 7-3-3}

Eine Therapie mit Einlage von mehreren Stents bei distaler Gallenwegstenose kann empfohlen werden.

[Evidenzgrad 3b, Empfehlungsgrad C, starker Konsens]

\section{Kommentar}

Die Einlage von multiplen Kunststoffstents in den Gallengang zur Behandlung einer Gallengangstenose bei chronischer Pankreatitis ist sowohl der Einlage von solitären Kunststoffstents, als auch der von unbeschichteten Metallgitterstents überlegen. In einer prospektiven, nicht randomisierten monozentrischen Studie war die langfristige Erfolgsrate nach Implantation von 4 - 5 Stents in den DHC gegenüber einem Einzelstent höher [304].

\section{Statement 7 - 3-4}

Die Einlage von beschichteten Metallstents kann bei distaler Gallenwegstenose erfolgen.

[Evidenzgrad 4, Empfehlungsgrad C, starker Konsens]

\section{Kommentar}

Die Einlage von gecoverten Metallstents hat in Fallserien gute Ergebnisse gezeigt. Randomisierte Studien zum Vergleich von beschichteten Metallstents vs. singulären oder multiplen Kunststoffstents stehen aus [305, 306].

\section{Statement 7-3-5}

Eine endoskopische Behandlung wegen distaler Gallenwegstenose bei chronischer Pankreatitis sollte nicht länger als 12 Monate erfolgen. Ein Stentwechsel sollte spätestens alle 3 Monate erfolgen.

[Evidenzgrad 4, Empfehlungsgrad B]

\section{Kommentar}

Die Einlage von Stents in den Gallengang eignet sich zur Behandlung der durch eine chronische Pankreatitis verursachten Gallengangstenose und extrahepatischen Choleastase. Ein Langzeiterfolg, definiert als nicht mehr erforderlicher Wechsel der Stents in 3-monatigen Abständen ohne Rezidiv der Cholestase, lässt sich nur in etwa einem Drittel der Patienten erreichen [289, 307 - 310]. Ein Stentwechsel sollte mindestens alle 3 Monate erfolgen, weil sonst ein Verschluss des Stents eine Cholangitis verursachen kann. Bei Einlage multipler Stents ist das Wechselintervall weniger kritisch [311].

\section{Statement 7-3-6}

Die Therapie einer chronischen Gallengangstenose nach erfolglosem endoskopischen Therapieversuch soll operativ erfolgen.

[Evidenzgrad 1b, Empfehlungsgrad A, starker Konsens]

\section{Kommentar}

Resezierende chirurgische Verfahren zur Behandlung einer Gallengangstenose bei chronischer Pankreatitis sind effektiv und von nachhaltigem Erfolg. In den Langzeitergebnissen unterscheiden sich die unterschiedlichen chirurgischen Verfahren nach Beger, Büchler, Kausch-Whipple und Frey nicht im Bezug auf Lebensqualität, exokrine Pankreas-Insuffizienz, endokrine Pankreasinsuffizienz, Schmerzen und Häufigkeit von Rezidiven [312-314].

\section{Statement 7-3-7}

Besteht die Indikation, eine Cholestase bei chronischer Pankreatitis operativ zu beheben, dann sollte eine präoperative endoskopische Stenteinlage in den Gallengang nur erfolgen, wenn 1. keine zeitnahe Operation erfolgen kann oder 2. eine Cholangitis vorliegt.

[Evidenzgrad 2a, Empfehlungsgrad B, starker Konsens]

\section{Kommentar}

In einer multizentrisch prospektiv randomisierten Studie wurde der Einfluss der präoperativen endoskopischen Stentimplantation in den DHC bei mechanischer Cholestase infolge eines Pankreaskopfkarzinoms vor Pankreasresektion untersucht. In der Studie an Patienten mit einem Pankreastumor wurde gezeigt, dass die präoperative Drainage die Komplikationsrate deutlich erhöhte [315]. Ähnliche Daten liegen aus der Heidelberger Arbeitsgruppe vor, sind jedoch bisher nur als Abstract publiziert. 


\section{Statement 7-3-8}

Je geringer die statistische und individuelle Lebenserwartung eines Patienten, je höher die Komorbidität und je schwieriger die absehbare technische Durchführbarkeit einer Operation (z.B. ausgeprägte Umgehungskreisläufe bei portaler Hypertension), desto eher sollte eine endoskopische Behandlung der durch eine chronische Pankreatitis verursachten Gallengangstenose einem Pankreas-resezierenden Eingriff vorgezogen werden. Je wichtiger ein nachhaltiges Therapieergebnis nach einem einmaligen Eingriff, je länger die statistische und individuelle Lebenserwartung eines Patienten, je besser sein Allgemeinzustand und je niedriger die zu erwartende Morbidität und Letalität eines Pankreas-resezierenden Eingriffs, desto eher sollte ein operatives Vorgehen gewählt werden. [Konsens, klinischer Konsenspunkt]

\section{Kapitel 8: Schmerztherapie \\ $\nabla$}

Für 80 - 95\% der Patienten sind Schmerzen das führende klinische Symptom. Studien zum natürlichen Verlauf der Erkrankung zeigen, dass mit der Erkrankungsdauer die Schmerzintensität oft abnimmt ('burn-out of pain') [40]. In den meisten Fällen korreliert die Abnahme der Schmerzintensität mit dem Auftreten von Kalzifikationen und dem Verlust der exokrinen und endokrinen Funktion. Die jährlichen Kosten die durch Schmerzen bei chronischer Pankreatitis in Amerika verursacht werden belaufen sich auf 638 Millionen \$ [316]. Die Ursache der Schmerzen ist multifaktoriell. Zu den pankreatogenen Ursachen des Schmerzes zählen die entzündlichen Infiltrationen des Parenchyms und der Nervenscheiden, insbesondere sensibler Nerven. Eine Abflussbehinderung des Pankreassekrets durch Gangstenosen und Steine kann zur Druckerhöhung führen. Dennoch wird durch eine Drainage des Ganges oder die medikamentöse Reduktion der Sekretion (Somatostatin-Analoga) meist keine ausreichende Schmerzreduktion erzielt. Eine Druckerhöhung im Pankreasparenchym bedingt ähnlich wie die Pankreaspseudozystenbildung Schmerzen über eine Pankreaskapselspannung. $\mathrm{Zu}$ den extrapankreatischen Ursachen der Schmerzen zählen Begleitund Zweiterkrankungen, wie Magen- oder Duodenalulzera und Meteorismus, ausgelöst durch die bakterielle Fehlbesiedlung des Darmes bei Maldigestion.

\section{Statement 8-1-1}

Als Gradmesser für die Quantifizierung von Schmerzen bei chronischer Pankreatitis sollte ein validierter Schmerzscore wie der von Bloechle et al. 1995 publizierte oder die Visuelle Analogskala (VAS) verwendet werden.

[Evidenzgrad 1b, Empfehlungsgrad B, starker Konsens]

\section{Kommentar}

Insgesamt liegen lediglich 2 Studien $[317,318]$ vor, die die Validierung eines Schmerzscores präsentieren. Die ältere Arbeit [317] untersucht dabei einen Pankreatitis-spezifischen Schmerzscore. Bewertet mit einem Punktwert von 0-100 wird die Frequenz der Schmerzschübe (0 nie, 100 täglich), die Intensität der Schmerzen auf der VAS (1 - 100), die analgetische Medikation (100 Morphine, 1 Acetylsalicylsäure) und die schmerzbedingten Fehlzeiten im Beruf (100: dauerhaft, 0: nicht im letzten Jahr).
Die jüngere Studie [318] vergleicht den SF-12 mit dem SF-36-Lebensqualitätsbogen. Bei beiden sind auch Schmerzaspekte berücksichtigt, die eine Auswirkung auf die Lebensqualität haben. Ein dezidierter Schmerzscore, der getrennt von den Lebensqualitätsdaten erhoben wird, ist dabei nicht eingeschlossen. Dennoch sind sowohl der SF-12 als auch der SF-36 in dieser Studie, allerdings nur für die Beurteilung der Lebensqualität, als valide beurteilt worden. Es ergibt sich daher als einziger dezidiert für die Schmerzen bei chronischer Pankreatitis validierter Score der 1995 publizierter Schmerzscore. Eine weitere Verbreitung und vor allem die Verwendung in Therapiestudien sollte angestrebt werden.

\section{Statement 8-1-2}

Die Schmerztherapie bei chronischer Pankreatitis kann nach dem WHO-Stufenschema erfolgen.

[Evidenzgrad 5, Empfehlungsgrad D, starker Konsens]

\section{Kommentar}

Die Literatur zeigt 4 randomisiert kontrollierte Studien mit 10-40 Patienten. Leider ist in keiner dieser Studien das WHO-Stufenschema konsequent angewendet worden. Es wurde lediglich die Wirksamkeit unterschiedlicher Morphine überprüft. Somit ist die Frage nach der Wirksamkeit des WHO-Stufenschemas anhand der Literatur nicht zu beantworten. Dennoch ist es klinisch indiziert, Patienten mit Schmerzen bei chronischer Pankreatitis mittels Analgetika zu behandeln, um bis zu einer definitiven Therapie (z. B. endoskopisch oder chirurgisch) Schmerzfreiheit oder -reduktion zu erzielen.

\section{Statement $8-1-3$}

Über die Dauer eines medikamentösen Therapieversuchs der Schmerzen bei chronischer Pankreatitis kann im Einzelfall entschieden werden. Eine Re-Evaluation sollte jedoch bei ausbleibendem Therapieerfolg regelmäßig vorgenommen werden, um die Therapie ggf. um ein endoskopisches oder chirurgisches Verfahren zu erweitern.

[Evidenzgrad 5, Empfehlungsgrad B, starker Konsens]

\section{Kommentar}

Wie lange die Schmerztherapie konservativ durchgeführt werden kann und ab wann eine endoskopische oder operative Therapie indiziert ist, kann anhand der bisherigen Literatur nicht beantwortet werden.

Generell wird von den meisten Autoren der Aufstau des Ductus Wirsungianus als Indikation für eine endoskopische oder chirurgische Intervention gesehen. Allerdings konnte in einer retrospektiven Kohortenstudie auch bei Patienten ohne Aufstau des Ductus Wirsungianus eine gute Schmerzkontrolle nach Pankreatikojejunostomie gezeigt werden [319].

\section{Statement 8-1-4}

Die Entwöhnung von einer Schmerztherapie kann in absteigender Reihenfolge nach dem WHO-Stufenschema erfolgen. [Evidenzgrad 5, Empfehlungsgrad D, starker Konsens]

\section{Kommentar}

Die konservative Schmerztherapie der chronischen Pankreatitis folgt im Allgemeinen dem Stufenschema der WHO, wobei dieses für Patienten mit chronischer Pankreatitis nicht speziell evaluiert ist. 
Es liegen keine Studien vor, wie dieses Schema bspw. nach einer endoskopischen Intervention oder einer Operation deeskaliert werden kann. Es erscheint naheliegend, das WHO-Stufenschema in absteigender Reihenfolge zu durchlaufen und dabei jeweils die Schmerzfreiheit des Patienten zu überprüfen. Eine Über- oder Unterlegenheit gegenüber einem anderen Stufenschema oder einfachem Absetzen der Schmerzmedikation ist jedoch nicht untersucht worden.

\section{Statement $8-1-5$}

Zur reproduzierbaren Erfolgskontrolle der Schmerztherapie bei chronischer Pankreatitis sollte ein validiertes Instrument wie der von Bloechle et al. 1995 publizierte Schmerzscore oder die visuelle Analogskala (VAS) verwendet werden. [Evidenzgrad 1b, Empfehlungsgrad B, starker Konsens]

\section{Kommentar}

Die Beurteilung des Erfolgs einer Schmerztherapie richtet sich nach der Reduktion der Schmerzen unter Therapie. Hierzu ist eine Quantifizierung der Schmerzen notwendig. Dies ist bereits in Statement 8-1-1 beantwortet worden. Der Schmerzscore von Bloechle et al. [317] ist der am besten validierte, gerade auch weil eine Schmerzreduktion durch erfolgreiche Therapie nachgewiesen werden kann.

\section{Statement 8-1-6}

Octreotid soll nicht zur Therapie von Schmerzen im Rahmen einer chronischen Pankreatitis eingesetzt werden. [Evidenzgrad 1b, Empfehlungsgrad A, starker Konsens]

\section{Kommentar}

Da die Schmerzen bei der chronischen Pankreatitis durch eine parenchymatöse und duktale Druckerhöhung mit hervorgerufen werden, ist der Ansatz die Sekretionsmenge des Pankreas zu reduzieren und damit den Druck zu senken, pathophysiologisch folgerichtig. Neben zahlreichen Einzelfallberichten und retrospektiven Fallserien liegt eine doppelblinde Crossover-Studie [320] und eine unverblindete Crossover-Studie zum Vergleich von Octreotid mit Octreotid Long acting release (LAR) [321] vor. Die Schmerzen wurden bei beiden Studien im Wesentlichen mit der VAS gemessen. Die doppelblinde Crossover-Studie, die Octreotid mit Kochsalzgabe vergleicht [320], konnte keine Reduktion der Schmerzen oder des Analgetika-Bedarfs bei gleichzeitig effektiver Hemmung der Pankreassekretion nachweisen. Die ungeblindete Crossover-Studie zeigte keinen Unterschied zwischen Octreotid und Octreotid LAR im Rahmen der Schmerzreduktion. Zusammenfassend kann gesagt werden, dass die einzige Studie, die Octreotid mit Kochsalzgabe vergleicht, keine signifikante Reduktion der Schmerzen zeigen konnte und gleichzeitig eine weitere Studie keinen Vorteil von Octreotid LAR gegenüber Octreotid gezeigt hat. Damit bleibt der Stellenwert von Octreotid bei der Behandlung von mit chronischer Pankreatitis assoziierten Schmerzen ohne Beleg durch Studien.

\section{Statement 8 -1-7}

Pankreasenzyme sollen nicht zur Therapie von Schmerzen bei chronischer Pankreatitis eingesetzt werden.

[Evidenzgrad 1a, Empfehlungsgrad A, Konsens]

\section{Kommentar}

Die Rationale für eine Pankreasenzymtherapie zur Schmerzreduktion liegt in der Annahme eines negativen Feedbackmechanismus für die Freisetzung des Cholezystokinin-Releasing-Peptids. Dies wiederum führt zu einer verminderten Cholezystokininfreisetzung und damit einer verminderten exokrinen Pankreassekretion. In einem 2009 veröffentlichten systematischen Review der Cochrane Collaboration wurden 10 RCTs mit insgesamt 361 Patienten identifiziert, die unterschiedliche Aspekte der Wirksamkeit von Pankreasenzympräparaten untersuchten [322]. Sechs der Studien verglichen magensaftresistent verkapselte Präparate mit Placebo, eine verglich ein unverkapseltes Präparat mit Placebo, zwei untersuchten unterschiedliche Präparate und eine Studie untersuchte verschiedene Dosierungsschemata. Die Heterogenität der gewählten Zielgrößen bzw. die fehlenden statistischen Kenngrößen erlaubten es nicht, die Daten zu poolen. Drei von fünf Studien, die einen Schmerzscore benutzten, zeigten eine signifikante Reduktion der Schmerzen, zwei dagegen nicht. Eine von vier Studien, die den Analgetikakonsum quantifizierte, berichtete über einen verminderten Konsum von Schmerzmitteln. Keine einzige Studie untersuchte Langzeiteffekte der unterschiedlichen Therapien. Die Autoren kommen zu dem Schluss, dass der Gebrauch von Pankreasenzympräparaten keinen nachgewiesenen positiven Einfluss auf das Symptom Schmerz habe und aufgrund fehlender Daten eine Verbesserung der Lebensqualität ebenfalls nicht nachgewiesen sei [322]. Eine in der Zwischenzeit publizierten randomisiert kontrollierten Studie (25 Patienten Verum, 29 Placebo) zeigte keinen signifikanten Einfluss auf die Schmerzreduktion [323].

Aufgrund der unterschiedlichen Einschlusskriterien, die aus den Studien teils nicht klar hervorgehen, lässt sich nicht ableiten, ob die Genese der Pankreatitis, das Vorliegen einer exokrinen Pankreasinsuffizienz oder eine bestimmte Galenik der verwendeten Präparate einen Einfluss bezüglich des fehlenden Therapieerfolgs hatten.

\section{Statement $8-1-8$}

Antioxidanzien sollten derzeit nicht zur Therapie von Schmerzen bei chronischer Pankreatitis eingesetzt werden. [Evidenzgrad 2b, Empfehlungsgrad B, starker Konsens]

\section{Kommentar}

Oxidativer Stress ist ein möglicher Faktor in der Entstehung der chronischen Pankreatitis. In Serum und Pankreassaft von Patienten mit chronischer Pankreatitis konnten erhöhte Konzentrationen freier Sauerstoffradikale nachgewiesen werden. Basierend auf diesen Erkenntnissen könnte eine Therapie mit Antioxidantien zu einer Verminderung des zellulären Schadens bei der Pankreatitis beitragen und somit Schmerz verhindern. In einer ersten Studie bei Patienten mit rezidivierender akuter und chronischer Pankreatitis zeigte sich eine signifikante Besserung hinsichtlich der Anzahl akuter Schübe wie auch chronischer Schmerzen, jedoch vor allem letzteres nur in der per Protocol-Analyse. Tatsächlich wurden nur 20 von initial 28 Patienten ausgewertet [324]. In einer weiteren Studie mit 36 Patienten zeigte sich ebenfalls eine Besserung der Schmerzen wie auch der Lebensqualität, allerdings komplettierten auch hier nur 19 Patienten die Studie [325]. Die Auswertung der Studie lässt erhebliche Fragen offen, da ein einseitiger p-Wert benutzt wurde und die Items des verwendeten Fragebogens SF-36 einzeln ausgewertet wurden, ohne für multiples Testen zu korrigieren. In einer doppelt verblindeten placebokontrollierten Studie 
aus Indien wurden 71 Patienten mit Antioxidanzien behandelt und 56 mit Placebo über einen Zeitraum von 6 Monaten. Im Untersuchungszeitraum zeigte sich eine signifikante Verminderung der Tage mit pankreatogenen Schmerzen im Verumarm [326]. Die Studie wurde vor Erreichen des Rekrutierungsziels abgebrochen und wies weitere methodische Mängel auf. Der Beweis, ob Antioxidanzien einen Stellenwert zur Therapie der Schmerzen bei chronischer Pankreatitis haben, steht also noch aus.

In der Zusammenschau scheinen Antioxidanzien möglicherweise einen Stellenwert für die Schmerztherapie der CP zu haben. Da jedoch in allen der verwendeten Studien Präparate benutzt wurden, die Beta-Carotin enthalten, dessen Gabe in Kombination mit Retinol oder Alpha-Tocopherol bei Rauchern mit der Entstehung von Bronchialkarzinomen assoziiert ist und gleichzeitig die Mehrzahl aller Patienten mit chronischer Pankreatitis raucht, kann derzeit keine generelle Empfehlung für die Therapie mit Antioxidantien gegeben werden $[327,328]$.

\section{Statement $8-1-9$}

Elektroakupunktur und transkutane elektrische Nervenstimulation (TENS) sollten nicht zur Therapie von Schmerzen bei chronischer Pankreatitis eingesetzt werden. [Evidenzgrad 2b, Empfehlungsgrad B, starker Konsens]

\section{Kommentar}

Informationen über komplementäre oder andere neuartige Therapieansätze liegen oft nur in Form von Fallberichten vor. Insgesamt konnten nur drei Studien identifiziert werden, in denen eine ausreichende Patientenzahl in einer standardisierten Form untersucht wurden.

In einer randomisierten Studie wurden Elektroakupunktur und transkutane elektrische Nervenstimulation (TENS) jeweils mit Placebo verglichen. Es zeigte sich hier keine Wirksamkeit hinsichtlich Schmerzreduktion oder Analgetikagebrauch [329].

\section{Statement 8-1-10}

Montelukast sollte nicht zur Therapie von Schmerzen bei chronischer Pankreatitis eingesetzt werden.

[Evidenzgrad 2b, Empfehlungsgrad B, starker Konsens]

\section{Kommentar}

Eine 3-monatige Therapie mit dem Leukotrienrezeptorantagonisten Montelukast zeigte ebenfalls keine signifikante Reduktion der Schmerzsymptomatik [330].

\section{Statement 8-1-11}

Eine Radiotherapie kann zur Therapie von Schmerzen bei chronischer Pankreatitis nicht empfohlen werden. [Evidenzgrad 4, Empfehlungsgrad D, starker Konsens]

\section{Kommentar}

In einer Pilotstudie konnte mit einer einmaligen Radiotherapie bei 12 von 15 Patienten eine deutliche Schmerzreduktion und die Vermeidung akuter Schübe erzielt werden [331]. Vor dem Hintergrund des erhöhten Risikos für eine Malignomentwicklung bei chronischer Pankreatitis scheint ein Einsatz risikobehaftet und kann deshalb nicht empfohlen werden.

\section{Statement 8-1-12}

Eine Plexus-coeliacus-Blockade oder eine thorakoskopische Splanchnikektomie können zur Therapie von Schmerzen im Rahmen einer chronischen Pankreatitis erwogen werden.

[Evidenzgrad 4, Empfehlungsgrad C, starker Konsens]

\section{Kommentar}

Es liegen keine randomisiert kontrollierten Studien zum Vergleich einer Plexus-coeliacus-Blockade gegenüber einer Placebo-Gabe vor. Dagegen gibt es jedoch Metaanalysen [332, 333], die über ein großes Patientenkollektiv die Effektivität der Coeliacus-Blockade untersuchten und hierbei eine Schmerzreduktion bei etwa $50 \%$ der Patienten zeigen konnten. Diese Schmerzreduktion hielt jedoch nicht länger als einige Wochen an. Wenn der Schmerz das allein führende Symptom ist und bildgebend keine wesentlichen sekundären Komplikationen der chronischen Pankreatitis nachgewiesen werden, kann zur Kontrolle des Schmerzes eine thorakoskopische Splanchnikektomie durchgeführt werden. Erstmals erwähnt wurde das Konzept der pankreatischen Denervierung 1943 von Mallet-Guy. 1993 wurde das Verfahren aufgegriffen und durch die Einführung der videoskopisch assistierten Thorakoskopie zu einem minimalinvasiven Verfahren modifiziert. In einer prospektiven Langzeitstudie konnte gezeigt werden, dass bei Patienten, die auf eine peridurale Anästhesie gut ansprechen, eine ausreichende Schmerzkontrolle mit einer perioperativen Morbidität von $7 \%$ durch eine bilaterale Splanchnikektomie erreicht wird [334]. Diese Studie ist nicht randomisiert und hat damit nur einen sehr geringen Evidenzgrad.

In einer Fallkontrollstudie [335] wurde gezeigt, dass die Ergebnisse einer Splanchnikektomie nach vorherigem Gebrauch von Opioiden schlechter ist als bei therapienaiven Patienten, wobei die thorakoskopische Splanchnikektomie signifikant bessere Ergebnisse gegenüber den Kontrollpatienten mit rein symptomatischer Therapie zeigte.

Zusammenfassend kann gesagt werden, dass die Plexus-coeliacus-Blockade bei mit chronischer Pankreatitis assoziierten Schmerzen nur kurz (wenige Monate) wirksam ist und einer chirurgischen Therapie deutlich unterlegen ist. Gewissermaßen eine Modifikation der Plexus-coeliacus-Blockade ist die Splanchniketomie, die auf thorakoskopischem Wege durchgeführt werden kann. Diese zeigt bei spärlicher Datenlage in Einzelfällen gute Ergebnisse. Die Indikation zur Plexus-coeliacus-Blockade kann lediglich bei Patienten, die keiner sicheren langfristig effektiven Schmerztherapie zugeführt werden können, angestrebt werden. Dies bedeutet, dass bei Patienten, die sich in einem inoperablen Zustand oder in einer aufgrund ihres Allgemeinzustands infausten Prognose befinden, eine Plexus-coeliacus-Blockade erfolgen kann. Doch auch für diese kurze Zeit ist der Plexus-coeliacusBlock nur für wenige Wochen bis Monate effektiv.

\section{Statement 8-1-13}

Die Plexus-coeliacus-Blockade soll, wenn keine Kontraindikationen vorliegen, unter endoskopischer Ultraschallsteuerung als bilaterale Injektion erfolgen.

[Evidenzgrad 1b, Empfehlungsgrad A, starker Konsens]

\section{Kommentar}

Randomisiert kontrollierte Studien liegen zum Vergleich der endoskopisch gesteuerten mit der CT-gesteuerten Plexusblockade 
vor (Überlegenheit der endosonografischen Steuerung) [336]. Ebenso gibt es Studien zur Frage der endoskopisch ultraschallgesteuerten Plexusblockade mit 1 oder 2 Injektionen (kein signifikanter Unterschied) [337] sowie zum Vergleich der Plexus-coeliacusBlockade mit der Pankreatikogastrostomie (Überlegenheit des chirurgischen Verfahrens) [338] und der endoskopischen Ultraschallsteuerung mit der Röntgen-Durchleuchtung zur Plexus-coeliacusBlockade (Überlegenheit der endosonografischen Steuerung) [339]. Die endoskopische Ultraschallsteuerung scheint für die Plexus-coeliacus-Blockade besser geeignet als die CT-gesteuerte Plexus-Blockade zu sein, wobei $30 \%$ der Patienten nach 24 Wochen noch profitierten gegenüber $12 \%$ nach CT-gesteuerter Punktion [336]. Ob eine einmalige oder zweifache Injektion erfolgt, scheint irrelevant für die Schmerzfreiheit zu sein [337]. Die Durchleuchtung als ältestes Verfahren zur Plexus-coeliacus-Blockade ist dagegen der endoskopischen Ultraschallsteuerung deutlich unterlegen [339].

Des Weiteren wurde in einer Kohortenstudie der zentrale im Vergleich zum bilateralen endoskopischen ultraschallgesteuerten Plexus-Block untersucht [340]. Hierbei konnte gezeigt werden, dass die Schmerzreduktion nach bilateraler Injektion nach 7 Tagen besser war als nach zentraler Injektion (70 vs. $46 \%$ ). Bei institutionell größerer Erfahrung mit der CT-gesteuerten Plexuscoeliacus-Blockade kann diese eine Alternative darstellen.

\section{Statement 8-1-14}

Eine operative Therapie soll als effektivste langfristige Schmerztherapie bei chronischer Pankreatitis erfolgen. [Evidenzgrad 1a, Empfehlungsgrad A, Konsens]

\section{Kommentar}

Eine bessere Schmerztherapie der operativen Therapie mit einer Pankreatikojejunostomie im Vergleich der endoskopischen Behandlung wurde in 2 randomisierten Kontrollstudien erreicht [243, 244, 341]. Dabei konnte durch die endoskopische Therapie bei $32 \%$ [244] bzw. $65 \%$ [243] eine Schmerzreduktion oder komplette Schmerzfreiheit erreicht werden, während dies durch die Pankreatikojejunostomie bei 75\% [244] bzw. durch eine resezierende Operation in $86 \%$ [243] erreicht wurde.

\section{Kapitel 9 - Enzymsubstitution bei chronischer Pankreatitis \\ $\nabla$}

Die Indikation zur Substitution mit Pankreasenzymen ist klinisch beim Auftreten eines Gewichtsverlusts von mehr als 10\% des Körpergewichts, einer Steatorrhö mit Stuhlfettausscheidung von mehr als $15 \mathrm{~g} / \mathrm{d}$, dyspeptischen Beschwerden mit starkem Meteorismus oder Diarrhö gegeben. Die meisten Enzympräparate enthalten Pankreatin, ein pulverisiertes Extrakt aus dem Schweinepankreas mit den Hauptkomponenten: Lipase, Amylase, Trypsin und Chymotrypsin. Pankreatin wird gastrointestinal nicht resorbiert, sondern durch enterale Bakterien und Verdauungssäfte inaktiviert und fäkal eliminiert. Die Möglichkeit der säuregeschützten Darreichungsformen in Form von mikrosphärisch verkapselten Formulierungen hat die Effizienz der Pankreasfermentsubstitution deutlich gesteigert. Als Erfolgskontrolle der Therapie gilt die Besserung der Krankheitssymptome.

\section{Kapitel 9-1: Enzymsubstitution bei chronischer} Pankreatitis

\section{Statement 9-1-1}

Pankreatin soll supplementiert werden bei Patienten, bei denen eine deutliche Steatorrhö besteht bzw. anzunehmen ist (Nachweisverfahren: Stuhlfette >15g/d, sofern verfügbar, sonst: pathologische Stuhlfettausscheidung oder pathologischer Pankreasfunktionstest in Kombination mit klinischen Zeichen der Malabsorption).

[Evidenzgrad 1b, Empfehlungsgrad A, starker Konsens]

\section{Statement 9-1-2}

Auch bei geringerer pathologischer Stuhlfettausscheidung $(7-15 \mathrm{~g} / \mathrm{d})$ soll Pankreatin supplementiert werden, wenn Zeichen der Malassimilation bestehen (z. B. Gewichtsverlust) oder der Patient abdominelle Symptome hat, die auf die Maldigestion und Malabsorption zurückgeführt werden können. [Evidenzgrad 1b Empfehlungsgrad A, starker Konsens]

\section{Kommentar 9-1-1 und 9-1-2}

Die Indikation zur Substitution mit Pankreasenzymen besteht bei einer Steatorrhö mit Stuhlfettausscheidung von mehr als $15 \mathrm{~g} / \mathrm{d}$. Da die quantitative Messung der Stuhlfette vielfach nicht mehr durchgeführt wird, ist die Indikation zur Substitution auch bei pathologischem Pankreasfunktionstest in Kombination mit klinischen Zeichen der Malabsorption gegeben [90, 342-344]. Hierzu zählen Gewichtsverlust und abdominelle Beschwerden mit Dyspepsie, starkem Meteorismus oder Diarrhö. Umgekehrt ist Pankreatin auch dann zu supplementieren, wenn die Stuhlfettausscheidung pathologisch ist ( $>7 \mathrm{~g} / \mathrm{die}$ ), ohne den Grenzwert von $15 \mathrm{~g} /$ die zu erreichen, aber gleichzeitig die o.g. klinischen Zeichen der Malabsorption bestehen [90]. Auch eine rein probatorische Therapie mit Pankreatin über 4-6 Wochen kann bei uneindeutiger Symptomlage sinnvoll sein.

\section{Statement 9-1-3}

Bei der Substitutionstherapie sollen eine Verringerung der Malabsorption mit ausreichender oraler Nährstoffversorgung (sämtliche Hauptnährstoffgruppen und Vitamine) sowie ggf. eine effektive Behandlung der abdominellen Symptome angestrebt werden. Eine vollständige Normalisierung der Nährstoffdigestion und -absorption lässt sich meist nicht erreichen.

[Evidenzgrad 2b, Empfehlungsgrad A, starker Konsens]

\section{Kommentar}

Die unbehandelte schwere exokrine Pankreasinsuffizienz führt zu einem schweren Malabsorptionssyndrom, welches längerfristig nicht mit dem Leben vereinbar ist. Dieses äußert sich klinisch vorrangig mit Steatorrhö, Mangel an fettlöslichen Vitaminen samt Folgeerscheinungen und Gewichtsverlust bis zur Kachexie $[85,86,92,93,345]$. Aufgrund der Malabsorption kann es außerdem zu abdominellen Beschwerden kommen mit Diarrhö/Steatorrhö, abdomineller Distension/Meteorismus und Schmerzen. Diese können u.a. auf Motilitätsstörungen beruhen, die durch die Maldigestion und Malabsorption hervorgerufen werden [343]. 


\section{Statement 9-1-4}

Der Erfolg einer Pankreatin-Substitutionstherapie sollte in erster Linie anhand klinischer Parameter überprüft werden (Gewichtszunahme, längerfristig Normalisierung des Vitaminstatus, Sistieren abdomineller Symptome). [Evidenzgrad 2b, Empfehlungsgrad B, starker Konsens]

\section{Statement 9-1-5}

Wenn klinisch Zweifel bestehen, ob die Persistenz von Symptomen durch eine mangelnde Wirksamkeit der Enzymsubstitution zu erklären ist, sollte die Stuhlfettausscheidung oder Pankreasfunktionstests, welche die Nährstoffdigestion unter Therapie messen (z. B. Atemtests mit ${ }^{13} \mathrm{C}$-markierten Lipiden), herangezogen werden.

[Evidenzgrad 2b, Empfehlungsgrad B, Konsens]

\section{Kommentar 9-1-4 und 9-1-5}

Das Verschwinden von klinischen Zeichen der Malabsorption ist das wichtigste Kriterium für den Erfolg einer Pankreasenzymtherapie und ist mit einer Verbesserung der Lebensqualität assoziiert [346]. Wenn die Symptome nicht oder nur inkomplett ansprechen, kann dies aber auch durch andere Pathomechanismen bedingt sein. Mehrere Studien haben gezeigt, dass Atemtests mit ${ }^{13} \mathrm{C}$-markierten Lipiden ein gutes Maß für die Fettverdauung und Stuhlfettausscheidung liefern und sich deshalb zur Überprüfung der Wirksamkeit einer Pankreatintherapie eignen [347349]. Mit der Messung der Elastase-Konzentration im Stuhl lässt sich der Erfolg der Substitutionstherapie nicht beurteilen, weil nur das menschliche, körpereigene und nicht das therapeutisch zugeführte Enzym gemessen wird. Auch die Chymotrypsinausscheidung im Stuhl gibt keine Auskunft über die Wirkung der Enzymsubstitution auf die Nährstoffdigestion und -absorption; diese kann allerdings zur Überprüfung der Compliance genutzt werden (niedrige Werte bei mangelnder Einnahme).

\section{Statement 9-1-6}

Das Pankreatin soll während der Mahlzeit eingenommen werden.

[Evidenzgrad 1b, Empfehlungsgrad A, starker Konsens]

\section{Kommentar}

Die Wirksamkeit von Pankreasenzympräparaten setzt eine Durchmischung von Pankreatin und Chymus voraus. Wenn mehr als eine Kapsel/Tablette pro Mahlzeit eingenommen werden muss, kann es sinnvoll sein, einen Teil der Dosis unmittelbar mit Beginn und den Rest verteilt während der Mahlzeit einzunehmen [86, 350].

\section{Statement 9-1-7}

Wegen der Säureinstabilität von Pankreasenzymen sollen bei Patienten mit erhaltener Magensäuresekretion Präparate mit Säureschutz verwendet werden.

[Evidenzgrad 2b, Empfehlungsgrad A, starker Konsens]

\section{Kommentar}

Insbesondere die Lipaseaktivität wird bei pH-Werten unter 4 irreversibel zerstört [351]. Solch niedrige Werte liegen intragastral während der überwiegenden Zeit der postprandialen Periode und bei exokriner Insuffizienz auch intraduodenal vor, wegen der eingeschränkten Bikarbonatsekretion [86]. Ohne begleitende Säuresuppression senken Präparate mit Säureschutz die Stuhlfettausscheidung stärker als solche ohne [352].

\section{Statement 9-1-8}

Wegen der für die optimale Wirksamkeit erforderlichen Durchmischung von Chymus und Pankreatin sollten Präparate gewählt werden, die aus säuregeschützten Partikeln mit einem Durchmesser von $\leq 2 \mathrm{~mm}$ bestehen.

[Evidenzgrad 2b, Empfehlungsgrad B, starker Konsens]

\section{Kommentar}

Dieser Grenzwert ist grundsätzlich nur für Patienten mit erhaltenem Pylorus relevant [353]. Allerdings kann eine geringe Partikelgröße auch nach distaler Magenresektion die Entleerung und/oder Freisetzung der Enzyme erleichtern und/oder beschleunigen.

\section{Statement 9-1-9}

Die verabreichte Pankreatindosis soll ausreichend enzymatische Aktivität für die Verdauung einer Mahlzeit beinhalten. [Evidenzgrad 1b, Empfehlungsgrad A, starker Konsens]

\section{Statement 9-1-10}

Pankreatinpräparate werden anhand der Lipaseaktivität dosiert. Pro Hauptmahlzeiten sollten 20000 bis 40000 Einheiten (Ph. Eur.) als Einstiegsdosis verabreicht werden, für die Verdauung kleinerer Zwischenmahlzeiten ca. 10000 (bis 20000) Lipaseeinheiten.

[Evidenzgrad $1 \mathrm{~b}$ Empfehlungsgrad B, starker Konsens]

\section{Statement 9-1-11}

Bei unzureichender Wirksamkeit sollte die Enzymdosis verdoppelt, ggf. verdreifacht werden.

[starker Konsens, klinischer Konsensuspunkt]

\section{Statement 9-1-12}

Bei weiter unzureichender Wirksamkeit sollte Pankreatinpulver oder -granulat mit einem Säureinhibitor kombiniert werden.

[Evidenzgrad 2b, Empfehlungsgrad B, starker Konsens]

\section{Statement 9-1-13}

Führt dies nicht zum gewünschten Behandlungserfolg, sollte nach einer anderen Ursache der anhaltenden Symptomatik gesucht werden.

[starker Konsens, klinischer Konsensuspunkt] 


\section{Kommentar 9-1-9 bis 9-1-13}

Die klinische Wirksamkeit von Pankreatinpräparaten wird bestimmt durch die verabreichte Dosis, den Zeitpunkt der Einnahme, Säureschutz und Größe der Pankreatinpartikel, spezielle biochemische Eigenschaften des Präparats, die durch seine Herkunft bedingt werden, sowie Vor- und Begleiterkrankungen des zu behandelnden Patienten. Letzteres bezieht sich z. B. auf postoperative Zustände mit Veränderung der gastrointestinalen Anatomie (z. B. Zustand nach Magenresektion), aber auch auf die begleitende Therapie mit bestimmten Medikamenten (z. B. Therapie mit Protonenpumpeninhibitoren bei Einnahme nicht steroidaler Antirheumatika) [323, 342, 348, 350, 352 -359]. Die empfohlene Einstiegsdosis entspricht etwa 5-10\% der kumulativ nach einer normalen Mahlzeit in das Duodenum sezernierten Lipaseaktivität [360] und sollte deshalb genügen, eine Malabsorption bzw. Steatorrhö zu verhindern [85]. Die klinische Erfahrung zeigt aber, dass bei manchen Patienten eine Verdopplung oder Verdreifachung dieser Dosis erforderlich und hilfreich ist. Wenn die Magensäuresekretion unterdrückt wird, kann auch ungeschütztes Pankreatin verabreicht werden. Dies ist dann oft besonders effektiv, weil es ohne Verzögerung durch das Auflösen eines schützenden Überzugs wirksam wird.

Patienten mit chronischer Pankreatitis weisen gehäuft eine bakterielle Fehlbesiedlung auf [361]. Diese kommt neben anderen Störungen als Ursache für anhaltende Beschwerden in Frage, wenn die o.g. Maßnahmen nicht zum Erfolg führen.

\section{Statement 9-1-14}

Fast alle in Deutschland verfügbaren Pankreasenzympräparate beinhalten Schweinepankreatin. Als Medikament können diese oft auch von Patienten eingenommen werden, welche ansonsten (aus religiösen oder ethischen Gründen) Produkte von Schweinen ablehnen.

[starker Konsens, klinischer Konsenspunkt]

\section{Kommentar}

Pankreasenzymprodukte von Rindern stellen eine theoretische Alternative dar, spielen wegen geringer Lipaseaktivität aber in der Praxis keine Rolle. Präparate mit fungalen (Rhizopus oryzae, Aspergillus oryzae) Enzymen haben weniger günstige biochemische Eigenschaften (höhere Säurestabilität, aber rasche Inaktivierung in Gegenwart niedriger Gallensäurekonzentrationen) und sind deshalb klinisch nur begrenzt einsetzbar. Bakterielle Enzyme und gentechnologisch hergestellte humane Lipase spielen bislang noch keine Rolle in der Therapie der exokrinen Pankreasinsuffizienz. Auch in Religionen, die das Essen von Schweinefleisch ablehnen, ist die Einnahme porciner Pankreasenzyme häufig erlaubt (z. B. Koran, Sure 5, Vers 1). Der Patient sollte allerdings auf den Ursprung der Präparate hingewiesen werden.

\section{Statement 9-1-15}

Bei Verabreichung von Pankreasenzympräparate sollte auf abdominelle Symptome (in $<10 \%$ Bauchschmerzen, Stuhlgangveränderungen, Übelkeit/Erbrechen) und allergische Reaktionen (in < $1 \%$ der Patienten) als mögliche unerwünschte Wirkungen geachtet werden

[Evidenzgrad 3b, Empfehlungsgrad B, starker Konsens]

\section{Statement 9-1-16}

Sehr hohe Enzymdosen (>10000-20000 Einheiten Lipase pro kg Körpergewicht pro Tag) sollten möglichst gemieden werden

[starker Konsens, klinischer Konsenspunkt]

\section{Kommentar 9-1-15 und 9-1-16}

Im Wesentlichen von einer Arbeitsgruppe ist nach Gabe extrem hoher Dosen Pankreatin bei Kindern mit Mukoviszidose sehr selten $(<0,1 \%$ ) die Ausbildung einer fibrosierenden Kolonopathie mit Ileusgefahr beschrieben worden [362]. Eine Kausalität ist nicht belegt und gilt als wenig wahrscheinlich [363 - 366]. Generell sind aber derartig hohe Dosierungen bei Patienten mit exokriner Pankreasinsuffizienz auf dem Boden einer chronischen Pankreatitis ohnehin nicht erforderlich (s. o.). Insbesondere sollten bei Refraktärität auf die o. g. Standarddosierungen eine adjuvante Säurehemmung und/oder ggf. Behandlung alternativer bzw. zusätzlicher Mechanismen erfolgen.

\section{Statement 9-1-17}

Bei Patienten mit Diabetes mellitus und neu begonnener oder erhöhter Pankreatintherapie sollten die Blutzuckerspiegel vorübergehend engmaschiger kontrolliert werden, weil die verbesserte Kohlenhydrataufnahme zur Hyperglykämie führen kann.

[Evidenzgrad 2b, Empfehlungsgrad B, starker Konsens]

\section{Kommentar}

Bei Patienten mit chronischer Pankreatitis und assoziiertem Diabetes mellitus kann es zu größeren Problemen mit der Blutzuckerkontrolle kommen, wenn eine Pankreatintherapie an- oder abgesetzt wird. Dies schließt notfallmäßig behandlungsbedürftige Situationen ein: In einer Studie von O'Keefe et al. kam es zu symptomatischer Hypoglykämie unter Placebotherapie bzw. Ketoacidose nach Aufnahme der Pankreatintherapie [367].

\section{Kapitel 9-2: Ernährung bei chronischer Pankreatitis}

\section{Statement 9-2-1}

Mangelernährung bei chronischer Pankreatitis kann nicht nur auf einer exokrinen Pankreasinsuffizienz beruhen, sondern auch durch schmerzbedingte Reduktion der Nahrungszufuhr bzw. fortgesetzten Alkoholkonsum bedingt oder erschwert sein. Zudem weist ein Teil der Patienten einen erhöhten Grundumsatz auf.

[Evidenzgrad 3b, starker Konsens]

\section{Statement 9-2-2}

Patienten mit chronischer Pankreatitis und klinisch manifester exokriner Pankreasinsuffizienz (Gewichtsverlust, Mangelernährung) sollten eine Substitutionstherapie mit Pankreasenzymen zusammen mit einer individuell adäquaten ernährungsmedizinischen Intervention erhalten, um eine Verschlechterung des Ernährungszustands gezielt zu verhindern bzw. zu stoppen.

[starker Konsens, klinischer Konsenspunkt] 


\section{Statement 9-2-3}

Bei der ernährungsmedizinischen Intervention sollen eine ausreichende Versorgung mit Nährstoffen, Vitaminen und Spurenelementen sowie die individuell adäquate Deckung des Energietagesbedarfs zur Vermeidung einer Katabolie angestrebt werden.

[Evidenzgrad 5, Empfehlungsgrad A, starker Konsens]

\section{Kommentar zu 9-2-1 bis 9-2-3}

Mangelernährung bzw. Untergewicht bei chronischer Pankreatitis sind mit einer erhöhten Letalität assoziiert [368] und sind deshalb möglichst zu vermeiden. Hierzu ist bei Patienten mit exokriner Insuffizienz in aller Regel die Kombination von Enzymsubstitutionstherapie (s. o.) und adäquater ernährungsmedizinischer Intervention erforderlich. Hierbei ist zu bedenken, dass ein Teil der Patienten einen erhöhten Grundumsatz aufweist [369]. Aufgrund der gravierenden Folgen der Mangelernährung bei chronischer Pankreatitis wurde mit starkem Konsens ein Empfehlungsgrad A ausgesprochen.

\section{Statement 9-2-4}

Patienten mit chronischer Pankreatitis und klinisch manifester exokriner Pankreasinsuffizienz sollten grundsätzlich mit einer normalen isokalorischen Kost und adäquater Pankreasenzymsubstitution therapiert werden. Hierbei kann zur Verbesserung des Ansprechens die Nahrungszufuhr auf 4-6 (entsprechend kleinere) Mahlzeiten verteilt werden. [Evidenzgrad 2b, Empfehlungsgrad B, starker Konsens]

\section{Kommentar}

Primär soll eine normale ausgewogene, ausreichend isokalorische Wunschkost empfohlen werden; eine spezifische Pankreasdiät ist nicht etabliert [90]. Bei guter Verträglichkeit ist daher auf eine ausreichende Fettzufuhr zu achten. Tierexperimentelle Daten weisen aber darauf hin, dass Diäten mit hohem Fett- und Eiweißgehalt bei adäquater Enzymsubstitution die Effektivität der Fettabsorption verbessern können [370].

\section{Statement 9-2-5}

Eine fettarme Ernährung kann nicht (generell) empfohlen werden. Nur wenn es trotz adäquater oraler Enzymsubstitution bei weiterem Fortschreiten der exokrinen Pankreasinsuffizienz klinisch zu subjektiv belastenden Zeichen einer Fettmaldigestion kommt, kann die oral zugeführte Fettmenge je nach Verträglichkeit reduziert werden.

[Evidenzgrad 5, Empfehlungsgrad C, starker Konsens]

\section{Kommentar}

Fett ist als zentraler Energieträger zur Vermeidung bzw. Behandlung der Katabolie wichtig. Wenn die Fettzufuhr wegen Unverträglichkeit trotz adäquater Enzymtherapie reduziert wird, muss darauf geachtet werden, dass dann zur Gewährleistung einer isokalorischen Ernährung kompensatorisch die orale Zufuhr anderer Energieträger (Kohlenhydrate, Proteine) adäquat gesteigert wird.

\section{Statement 9-2-6}

Mittelkettige Triglyzeride können ohne Einwirken von Lipase resorbiert werden und deshalb die Fettabsorption bei Patienten mit exokriner Insuffizienz, die keine Enzymsubstitution erhalten, verbessern. Unter Enzymgabe sollten sie nicht empfohlen werden

[Evidenzgrad 2b, Empfehlungsgrad B, starker Konsens]

\section{Kommentar}

Unter Enzymgabe scheinen mittelkettige Triglyceride zu keiner weiteren Erhöhung der Fettresorption zu führen. Sie sollten deshalb unter diesen Bedingungen nicht empfohlen werden [371].

\section{Statement 9-2-7}

Zusätzliche Ernährungsmethoden (oral, enteral oder parenteral) können bei Patienten mit fortgeschrittener exokriner Pankreasinsuffizienz erforderlich werden.

[Evidenzgrad 2b, Empfehlungsgrad C, starker Konsens]

\section{Kommentar}

Orale flüssige Zusatznahrung wird von etwa 10 - $15 \%$ aller Patienten benötigt, eine Sondenernährung ist bei ca. $5 \%$, eine parenterale Ernährung in weniger als $1 \%$ der Fälle erforderlich [90]. Sie dient in aller Regel nicht zur Behandlung der exokrinen Pankreasinsuffizienz, sondern betrifft Patienten mit Komplikationen der Erkrankung, nämlich Magenausgangstenose oder komplexen Fistelsystemen. Meist handelt es sich zudem um eine passagere Maßnahme, z. B. vor operativer Sanierung.

\section{Statement 9-2-8}

Alkoholkonsum soll bei chronischer Pankreatitis grundsätzlich gemieden werden.

[Evidenzgrad 2b, Empfehlungsgrad A, starker Konsens]

\section{Kommentar}

Alkoholkonsum stellt einen wesentlichen pathogenetischen Faktor dar für die Progression einer exokrinen Pankreasinsuffizienz bei chronischer Pankreatitis [372]. Da es bisher keine Daten zur Frage gibt, ob auch bei schon bestehender chronischer Pankreatitis der Konsum geringer Alkoholmengen (z.B. Tagesmengen $<20 \mathrm{~g} / \mathrm{d}$ ) unschädlich wäre, ist es sinnvoll, eine weitgehende Alkoholkarenz zu empfehlen.

\section{Statement 9-2-9}

Ein Defizit an Vitaminen und Spurenelemente soll gezielt ausgeglichen werden.

[Evidenzgrad 2b, Empfehlungsgrad A, Konsens]

\section{Kommentar}

Patienten mit chronischer Pankreatitis und exokriner Pankreasinsuffizienz nehmen weniger an Vitaminen und Spurenelemente zu sich, als für die tägliche Zufuhr empfohlen. So wurden gehäuft Mangelzustände für die fettlöslichen Vitamine A, D, E und K sowie für Kalzium, Magnesium, Zink, Thiamin und Folsäure nachgewiesen. Eine verminderte Zufuhr wurde auch für Riboflavin, Cholin, Kupfer, Mangan, Schwefel beschrieben. Die Aufnahme von Vitamin C und Selenium lag innerhalb der empfohlenen Ta- 
geswerte, war aber geringer als bei gesunden Kontrollpersonen $[92,93,373]$.

\section{Statement 9-2-10}

Die Indikation zur Substitution von Vitaminen und Spurenelementen sollte beim Erwachsenen in erster Linie nach klinischen Mangelsymptomen gestellt werden. Die zusätzliche Bestimmung von Serumkonzentrationen sollte nur im Einzelfall erfolgen.

[starker Konsens, klinischer Konsenspunkt]

\section{Kommentar}

Eine routinemäßige Kontrolle dieser Parameter bei Erwachsenen kann mangels Daten nicht empfohlen werden.

\section{Statement 9-2-11}

Bei Kindern sollte die Indikation zur Substitution großzügig und bereits vor Auftreten klinischer Mangelsymptome gestellt werden.

[starker Konsens, klinischer Konsenspunkt]

\section{Kommentar}

Bei Kindern können auch subklinische Mangelzustände bestehen und im Verlauf eine Gedeihstörung verursachen.

\section{Kapitel 10 - Operative Verfahren und ihre Indikation}

Die chirurgische Therapie der chronischen Pankreatitis behandelt effektiv therapierefraktäre Schmerzen und/oder lokale Komplikationen [244, 374]. Da endoskopische Verfahren prinzipiell ebenfalls für diese Indikationen angewendet werden können, ist eine frühe interdisziplinäre Diskussion zur Festlegung des für den einzelnen Patienten am besten geeignete Therapiekonzept zu fordern.

Hierbei sind vor allem die langfristigen Erfolgsaussichten einer endoskopischen Therapie abzuwägen. Der richtige Zeitpunkt zur Operation ist schwer zu stellen und bleibt kontrovers diskutiert. Es mehren sich aber Hinweise, dass eine frühzeitige chirurgische Intervention die fortschreitende globale Pankreasinsuffizienz zumindest hinauszögern kann.

Neben der Erfolgsrate sind natürlich in die Entscheidungsfindung auch die Komplikationen und insbesondere die Letalität der Therapieverfahren mit einzubeziehen. Die historisch mit einer hohen Morbidität einhergehende Pankreaschirurgie hat sich in den letzten Jahrzehnten durch Verbesserungen der Operationstechnik, des perioperativen Managements und der Bildung von Pankreaszentren dramatisch verbessert [374-378].

\section{1: Operative Verfahren und ihre Indikation}

\section{Statement 10-1-1}

Eine Operation soll bei Verdacht auf ein Malignom bei bekannter Pankreatitis erfolgen.

Eine Operation sollte bei Versagen der endoskopischen oder interventionellen Therapie bei persistierenden Schmerzen, lokalen Komplikationen wie zum Beispiel der symptomatischen Pankreasgang-, Gallengang-, oder Duodenalstenose erfolgen.
Eine Operation kann bei Pseudozysten mit gleichzeitig bestehenden Gangveränderungen durchgeführt werden.

[Empfehlungsgrad B, Evidenz 3, Konsens]

\section{Kommentar}

Bei Verdacht auf Malignom ist eine therapeutische potentiell kurative Alternative zur operativen Resektion nicht gegeben. Während das mediane Überleben bei Vorliegen eines Pankreaskarzinoms lediglich bei 6 Monaten liegt, wird durch eine Resektion eine 5 JÜR von über $20 \%$ und ein medianes Überleben von ca. 24 Monate erzielt [246, 379].

Eine Pankreaskopfresektion ist zudem die effektivste Therapieoption zur Therapie des pankreatitisassoziierten Schmerzes sowie der lokalen Komplikationen [374, 380]. Das individuelle Operationsrisiko ist im Einzelfall gegenüber dem therapeutischen Nutzen abzuwägen.

\section{Statement 10-1-2}

Das operative Standardverfahren bei chronischer Pankreatitis mit entzündlichem Pseudotumor des Pankreaskopfs ist eine Pankreaskopfresektion. Hier soll eine der Varianten der duodenumerhaltenden Pankreaskopfresektionen (OP nach Beger, Frey, Bern, Hamburg) oder das Kausch-Whipple'sche-Verfahren (in klassischer oder pyloruserhaltender Variante) angewendet werden.

[Evidenzgrad 1a, Empfehlungsgrad A, starker Konsens]

\section{Kommentar}

Die Pankreaskopfresektion ist bei Vorliegen eines entzündlichen Pankreaskopftumors das effektivste operative Verfahren und ist der reinen Drainageoperationen sowie endoskopischen Interventionen überlegen. Die duodenumerhaltenden Pankreaskopfresektionen sind dabei im kurzfristig und mittelfristig über einen Nachbeobachtungszeitraum von bis zu 2 Jahren der KauschWhipple'schen-Operation überlegen [377, 378, 381, 382]. Die 3 Varianten der duodenumerhaltenden Pankreaskopfresektion sind in ihrer Behandlungseffektivität gleichwertig [383]. Das OP-Verfahren nach der Berner Modifikation ist dabei technisch das am wenigsten aufwendigste. Das langfristige Outcome nach KauschWhipple'scher-Operation und nach duodenumerhaltender Pankreaskopfresektion ist vergleichbar. Eine randomisierte DFG geförderte multizentrische Studie rekrutiert zurzeit [248, 384 - 394].

\section{Statement 10-1-3}

Eine intraoperative innere Drainage des DHC/Gallengangs ist bei präoperativ bestehender Cholestase (bildgebend, laborchemisch) indiziert. Sie sollte bei allen Verfahren der DEPKR angewendet werden. Eine T-Drainage kann eingelegt werden. [Evidenzgrad 1c, Empfehlungsgrad B, starker Konsens]

\section{Kommentar}

Während bei der klassischen und der pyloruserhaltenden Kausch-Whipple‘sche-Operation immer eine biliodigestive Anastomose zur Gallengangdrainage angelegt wird, erfolgt dieses im Rahmen der DEPKR nicht routinemäßig. Durch die Resektion des Pankreaskopfs wird der Gallengang bei allen Varianten (Beger, Frey, Bern, Hamburg) des DEPKR vom Pankreasgewebe befreit, der Gallengang wird aber in der Regel nur bei präoperativ bestehender Cholestase intraoperativ im Pankreaskopf eröffnet 
und in die Resektionshöhle drainiert. Diese innere Gallengangdrainage kann bei allen Modifikationen der DEPKR durchgeführt werden. Eine T-Drainage zur Ableitung der Galle im postoperativen Verlauf bis zur Heilung der Anastomosen kann, muss aber nicht durchgeführt werden.

Bedingungen, unter denen von der Empfehlung Statement 10 - 11 abgewichen werden sollte/kann:

\section{Statement $10-1-4$}

Bei Verdacht auf einen malignen Pankreaskopftumor soll eine Kausch-Whipple'sche-Operation (klassisch oder pyloruserhaltend) durchgeführt werden und auf eine duodenumerhaltende Pankreaskopfresektion verzichtet werden. [Evidenzgrad 1c, Empfehlungsgrad A, starker Konsens]

\section{Statement 10-1-5}

Bei fehlendem entzündlichem Pankreaskopftumor und gestautem Pankreasgang kann eine Operation nach Frey oder eine Drainageoperation durchgeführt werden.

[Evidenzgrad 3, Empfehlungsgrad C, starker Konsens]

Steht ein gestauter Pankreasgang im Vordergrund, haben reine Drainageverfahren wie die laterale Pankreatikojejunostomie (nach Partington-Rochelle) oder die Operation nach Frey mit gering ausgeprägter Pankreaskopfresektion [395, 396] eine gute primäre Erfolgsrate. Die Ergebnisse sind zwar besser als nach endoskopischer Therapie [244], jedoch zeigen sie im Vergleich zu den pankreaskopfresezierenden Verfahren weniger gute Langzeitergebnisse auf [374, 397]. Zudem sind diese Verfahren nur Erfolg versprechend, wenn ein stark erweitertes Gangsystem (> $7 \mathrm{~mm}$ ) ohne entzündlichem Pankreaskopftumor vorliegt. Deshalb kommen sie bei weniger als $10 \%$ der Fälle infrage [398].

Bei einem Großteil (> 85\%) der Patienten liegen jedoch ein entzündlich vergrößerter Pankreaskopf und eine sekundäre Obstruktion des Pankreasgangs vor. Bei diesen Patienten führt eine Drainageoperation kaum zu einer Verbesserung der klinischen Symptomatik, und resezierende Verfahren sind vorzuziehen.

\section{Statement 10-1-6}

Bei portaler Hypertension und Ausbildung venöser Kollateralkreisläufe können die verschiedenen duodenumerhaltenden Pankreaskopfresektion-Modifikationen, die keine Durchtrennung des Pankreas voraussetzen, zur Anwendung kommen. [Empfehlungsgrad C, Evidenzgrad 4, starker Konsens]

\section{Kommentar}

Beger-Operation: Bei der duodenumerhaltenden Pankreaskopfresektion nach Beger et al. [399] wird das Pankreas über der Pfortader durchtrennt und die entzündliche Raumforderung im Pankreaskopf unter Belassung einer 5 - 8 mm dicken Parenchymlamelle an der Duodenalwand reseziert. Dieses kann wie auch die Kausch-Whipple-Operation in einigen Fällen zu einer Wiederherstellung der portalvenösen Durchblutung führen, meistens gelingt dieses jedoch aufgrund des chronischen Verschlusses nicht. Allerdings konnte durch die Arbeit von Blöchle et al. gezeigt werden, dass bei der segmentalen nicht okklusiven portalen Hypertension bedingt durch die chronische Pankreatitis durch die dekomprimierende Entfernung von Stenosen sehr wohl der portalvenöse Fluss wiederhergestellt werden konnte [400].

Die Rekonstruktion erfolgt mit einer nach Roux-Y ausgeschalteten Jejunalschlinge mit End-zu-Seit-Anastomose auf das Pankreaskorpus und Seit-zu-Seit-Anastomose auf den ausgeschälten Pankreaskopf. Voraussetzung für den langfristigen Erfolg dieser Technik ist ein gut nach links sondierbarer Pankreasgang ohne Stenosen. Bei fixierter Gallengangstenose kann der Gallengang eröffnet und als innere Gallenganganastomose in die Anastomose am Pankreaskopf einbezogen werden.

Frey-Operation: In den USA setzte sich die technisch aufwendigere duodenumerhaltende Pankreaskopfresektion nach Beger nicht durch. Frey et al. entwickelten in der Folge eine Modifikation, bei der eine umschriebene Ausschälung im Kopfbereich mit einer longitudinalen Pankreatikojejunostomie entsprechend der Partington-Rochelle-Drainageoperation kombiniert wird [401, 402]. Diese Technik scheint dann sinnvoll, wenn eine nicht stark ausgeprägte entzündliche Raumforderung im Pankreaskopf kombiniert mit Gangobstruktionen im linksseitigen Pankreas vorliegt. Die Hamburger und Berner Variante stellen eine technische Vereinfachung der duodenumerhaltenden Pankreaskopfresektion nach Beger dar [388, 403].

Bei Patienten mit Pfortaderthrombose und cavernöser Transformation sind ebenfalls die Verfahren ohne Durchtrennung der mesenterico-portalen Axe zu bevorzugen (Hamburg, Bern). Die Indikation zur Operation in diesem schwierigen Patientengut bedarf einer ausgedehnten interdisziplinären Kommunikation, da die Letalität und Mortalität signifikant erhöht sind. Dennoch kann auch in diesem Patientengut eine komplette Schmerzfreiheit und Wiederaufnahme der Arbeitsfähigkeit erzielt werden [244, 313, 390, 392, 401, $403-411]$.

\section{Statement 10-1-7}

Bei segmentalen entzündlichen Pankreasveränderungen (z. B. traumatische Korpusläsion) kann eine Pankreassegmentresektion oder ggf. auch eine Pankreaslinksresektion durchgeführt werden.

[Evidenzgrad 4, Empfehlungsgrad C, starker Konsens]

\section{Kommentar}

Indikationen für eine Pankreassegmentresektion stellen segmentale entzündliche Veränderungen dar, die im Pankreaskopf/Korpus-Übergang oder im Pankreaskorpus lokalisiert sind. Das wesentliche Argument für eine Pankreassegmentresektion zur Resektion von entzündlichen Veränderungen des Pankreaskorpus liegt in der mittlerweile durch zahlreiche Publikationen gezeigten geringeren postoperativen Morbidität im Vergleich zur partiellen Pankreatikoduodenektomie und Pankreaslinksresektion [412]. Da bei der Segmentresektion vergleichsweise deutlich weniger funktionsfähiges Pankreasparenchym entfernt wird, ist ein postoperativer Diabetes mellitus oder eine exokrine Pankreasinsuffizienz seltener [413 - 419]. Unter inzwischen mehr als 350 in Publikationen dokumentierten Pankreassegmentresektionen sind lediglich zwei Todesfälle zu finden [420, 421]. Die postoperative chirurgische Morbidität ist mit ca. 20 - 30\% akzeptabel. Zudem ist die Zufriedenheit und Lebensqualität der Patienten mit 97,4\% sehr gut. Wenn klinisch indiziert, kann eine Segmentresektion des pathologisch-morphologisch fassbaren Befunds erfolgen [420 - 422]. 


\section{Statement 10-1-8}

Eine das gesamte Organ betreffende „small duct disease“ kann mit einer V-Shape-Operation operativ behandelt werden. [Evidenzgrad 3,Empfehlungsgrad C, Konsens]

\section{Kommentar}

Sehr selten werden auch Fälle einer chronischen Pankreatitis beobachtet, in denen sich der Pankreasgang nicht der „HochdruckTheorie" entsprechend erweitert zeigt. Diese Fälle wurden als sogenannte „Small-duct-Erkrankung“ definiert. Die Häufigkeit dieser Krankheitsausprägung ist sehr umstritten. In den letzten Jahren werden zunehmend Patienten mit einer Autoimmunpankreatitis diagnostiziert, die morphologisch durch einen Entzündung des Parenchyms ohne Gangerweiterung charakterisiert ist. Es ist heute somit wichtig, bei einer „small duct disease“ eine Autoimmunpankreatitis differenzialdiagnostisch ausgeschlossen $\mathrm{zu}$ haben.

Die chirurgische Therapie der „Small duct disease“ durch eine Pankreaskopfresektion oder eine reine Gangdrainage führte zu keinen zufriedenstellenden Ergebnissen [423, 424], sodass für diese klinischen Situation die Technik der V-förmigen („V-Shape“) Exzision entwickelt wurde [388, 403]. In einer prospektiven Untersuchung konnte mit dieser Technik eine langjährige Schmerzfreiheit, verbunden mit einer signifikanten Verbesserung der Lebensqualität, bei mehr als $85 \%$ der Patienten erzielt werden [403]. Auch die niedrigen postoperativen Morbiditätund Letalitätsraten zeigen, dass dieses Verfahren in Zentren sicher durchgeführt werden kann.

\section{Statement $10-1-9$}

Die Modifikationen der duodenumerhaltenden Pankreaskopfresektion, die keine Transsektion des Pankreas voraussetzen, können bei portaler Hypertension als Folge eines Pfortader-/ Vena mesenterica-superior-Verschlusses als Operationsmethode der Wahl angesehen werden.

[Evidenzgrad 4, Empfehlungsgrad C, starker Konsens]

\section{Kommentar}

Weitere Erläuterung siehe Kommentar Statement 10 - 1-6.

\section{Statement 10-1-10}

Bei Stenosen der Vena mesenterica superior oder der V. portae kann eine Kausch-Whipple-Operation oder eine der verschiedenen Formen der DEPKR durchgeführt werden. [Evidenzgrad 4, Empfehlungsgrad C, starker Konsens]

\section{Kommentar}

Bei Stenosen der Pfortader und der V. mesenterica superior ist durch eine Kausch-Whipple-Operation oder eine DEPKR Typ Beger eine Verbesserung der portalvenösen Durchblutung erreichbar. Die Erfolgsrate ist u.a. von dem Stenosegrad und der Zeitdauer, die seit der Stenose besteht, abhängig. Die technische Durchführbarkeit ist von der Kollateralbildung und den entzündlichen Adhäsionen abhängig [248].

\section{Statement 10-1-11}

Der Verdacht auf ein Malignom, das in einer chronischen Pankreatitis entsteht, kann präoperativ oft nicht mit ausreichen- der Sicherheit widerlegt werden. Bei V.a. Malignom soll deshalb eine chirurgische Therapie erfolgen.

[Evidenzgrad 1b, Empfehlungsgrad A, starker Konsens]

\section{Kommentar}

Präoperativ sollte eine sorgfältige Anamnese erhoben werden und neu auftretende Symptome wie Gewichtsverlust, B-Symptomatik erkannt werden. Schnittbildgebung (CT oder MRT) sowie die Verlaufsuntersuchungen sollen vorliegen. Laborchemisch sollte ein CA19 - 9 als Ausgangswert für die postoperative Verlaufsbeobachtung abgenommen werden. Aufgrund der besseren lokalen Auflösung sollte eine Endosonografie durchgeführt werden.

Da die Operationsindikation bei V.a. Malignom bei chronischer Pankreatitis eine absolute ist und die Operationstechnik vorgegeben wird, sollte die Diagnostik präoperativ nicht ausgedehnt werden. Es besteht die Indikation zur Durchführung einer KauschWhipple-Operation bzw. einer pyloruserhaltenden Pankreaskopfresektion [407-409].

\section{Statement 10-1-12}

Bei Malignomverdacht soll keine duodenumerhaltenden Pankreaskopfresektion durchgeführt werden, da durch Inzision des Malignoms im Rahmen der duodenumerhaltenden Pankreaskopfresektion eine Tumordissemination stattfinden würde und damit eine potenzielle Heilung verhindert würde. [starker Konsens, klinischer Konsenspunkt]

\subsection{Therapie von postoperativen Komplikationen}

Pankreasoperationen haben sich von risikoreichen, früher oft als heroisch angesehenen Eingriffen zu Eingriffen mit überschaubarem perioperativem Risiko entwickelt $[425,426]$. Auch die Mortalität konnte an hochspezialisierten Abteilungen in den letzten Jahren deutlich gesenkt werden. Dieses gilt insbesondere für Operationen bei chronischer Pankreatitis, da ein fibrotisches hartes Pankreas weniger vulnerabel ist und Rekonstruktionen besser heilen. Eine standardisierte Operationstechnik sowie ein verbessertes perioperatives Management der Patienten haben hierzu wesentlich beigetragen.

\section{Statement 10-2-1}

In den meisten Fällen kann eine Pankreasfistel konservativ oder interventionell therapiert werden. Die Wahl der Therapie ist vom klinischen Zustand des Patienten abhängig. [Evidenzgrad 3, Empfehlungsgrad C, starker Konsens]

\section{Kommentar}

Die kritischsten Operationsschritte im Rahmen einer Pankreatikoduodenektomie und Pankreaslinksresektion sind die Pankreasanastomose bzw. der Verschluss des Pankreasresektionsrands [385, 386]. Die Konsensusdefinition für die POPF (postoperative pancreatic fistula) der International Study Group for Pancreatic Fistula (ISGPF) orientiert sich an der Amylasekonzentration in der Drainageflüssigkeit: Eine 3-fach erhöhte Amylasekonzentration in der Drainageflüssigkeit im Vergleich zur Serumamylasekonzentration ab dem 3. postoperativen Tag definiert eine POPF. Drei Grade A bis $C$ spiegeln die klinischen Auswirkungen nach Auftreten einer POPF wider $(\bullet$ Tab. 5). In einer ersten Validierung und einer Multi- 
Tab.5 ISGPF-Konsensusdefinition der postoperativen Pankreasfistel (adaptiert nach [430]). ${ }^{1}$

\begin{tabular}{|llll}
\hline Grad & klinischer Zustand, CT-Befund & Anpassung der Therapie, Intervention & Krankenhausverweildauer \\
\hline A & gut, keine Flüssigkeitsansammlung & nein, ggf. CT-Diagnostik & nicht verlängert \\
\hline B & oft gut, peripankreatische Flüssigkeit & ja, keine invasive Intervention & meistens verlängert \\
\hline C & kritisch, peripankreatische Flüssigkeit & ja, perkutane Drainage oder Relaparotomie & verlängert \\
\hline Definition & Drainagenförderung mit einer im Vergleich zum Serum 3-fach erhöhten Amylasekonzentration ab dem 3. postoperativen Tag \\
\hline
\end{tabular}

1 ISGPF: International Study Group for Panreatic Fistula.

centerstudie konnte retrospektiv ermittelt werden, dass die POPFPrävalenz entsprechend der ISGPF-Definition ca. $30 \%$ beträgt, wobei meistens eine Grad-A-Fistel ohne klinische Relevanz vorliegt [427 - 429]. Im Gegensatz zu Fisteln nach Pankreaslinksresektion die nicht zu einer Aktivierung des Pankreassekrets durch das intestinale Enzym Enterokinase führt, sind die bei der chronischen Pankreatitis selten nach Pankreaskopfresektion auftretenden Pankreasfisteln potenziell gefährlicher. Die Diagnostik der Fisteln erfolgt über die Bestimmung der Amylase und Lipasekonzentrationen über einliegende intraabdominelle Drainagen, CRP-bestimmungen sowie Sonografie und Schnittbildgebung [430 - 433].

\section{3: Follow-up nach chirurgischer Therapie}

\section{Statement 10-3-1}

Bei erneuter Cholestase nach operativem Eingriff kann eine interventionelle oder operative Therapie indiziert sein. [Evidenzgrad 3, Empfehlungsgrad C, starker Konsens]

\section{Kommentar}

Eine DHC-Stenose nach Kausch-Whipple-Operation ist durch eine erneute Cholestase definiert und in der Regel Folge einer narbig stenosierend ausgeheilten Gallengangleckage. Während initial ggf. eine endoskopisch oder interventionelle Dilatation und/oder Stenttherapie sinnvoll sein kann, ist bei Persistenz der Problematik eine Reoperation notwendig [434].

\section{Statement 10-3-2}

Postoperativ persistierende Schmerzen sollten nach dem Schema der WHO behandelt werden. [Evidenzgrad 2a, Empfehlungsgrad B, starker Konsens]

\section{Kommentar}

Postoperativ sind Schmerzen in ca. 90\% aller Patienten nach Pankreaskopfresektion deutlich vermindert. Persistierende Schmerzen werden postoperativ wie die präoperativen Schmerzen mittels Analgetika nach WHO-Schema therapiert. Eine Ursache der persistierenden Schmerzen kann der pankreasunabhängige Schmerz nach Chronifizierung des Schmerzes sein. Ein Schmerzrezidiv nach initialer Schmerzfreiheit kann jedoch auch durch ein Rezidiv des entzündlichen Pankreastumors und erneuter Pankreasgangobstruktion entstehen. In diesen Fällen ist ggf. eine Re-Operation mit Durchführung einer erneuten duodenumerhaltenden Pankreaskopfresektion oder einer Whipple-Operation indiziert [435, 436].

\section{Statement 10-3-3}

Eine Restpankreatektomie bei chronischer Pankreatitis kann nur in Ausnahmefällen empfohlen werden.

[Evidenzgrad 3, Empfehlungsgrad C, starker Konsens]

\section{Kommentar}

Eine Restpankreatektomie bei persistierenden Schmerzen oder komplett atrophem oder kalzifiziertem Pankreas ist nicht indiziert [426, 437]. Eine Restpankreatektomie kann lediglich bei postoperativen septischen Komplikationen nach erfolgloser interventioneller Therapie als Ultima Ratio indiziert sein [438].

\section{Statement 10-3-4}

Bei Versagen medikamentöser oder endoskopischer Verfahren zur Therapie von Rezidiven nach einer primären Operation kann eine Re-Operation erfolgen.

[Evidenzgrad 3a, Empfehlungsgrad C, Konsens]

\section{Kommentar}

Re-Operationen gehören zu den schwierigsten abdominellen Operationen. Ist jedoch eine Persistenz von Schmerzen oder eine erneute Cholestase auch medikamentös, interventionell bzw. endoskopisch nicht zu erfolgreich zu therapieren, so ist wie bei der primären Situation die Erfolg versprechendste Therapie die Resektion. Rezidivoperationen gehen heute nicht mit einer erhöhten Letalität einher, sollten jedoch prinzipiell in erfahrenen Zentren durchgeführt werden [279, 434].

\section{Kapitel 11 - Überwachung und Verlaufskontrolle der chronischen Pankreatitis \\ $\nabla$}

\section{Statement 11-1-1}

Im Rahmen einer chronischen Pankreatitis kommt es zum Auftreten von therapierbaren Komplikationen wie der endokrinen, exokrinen Insuffizienz, akuten Schüben, Pseudozystenbildung, Cholestase und einem erhöhten Risiko für das Auftreten eines Pankreaskarzinoms. Aus diesem Grund soll eine Überwachung/Verlaufskontrolle nach Diagnosestellung erfolgen.

[Konsens, klinischer Konsensuspunkt].

\section{Kommentar}

Prospektive Studien, die den Nutzen einer Verlaufskontrolle belegen, liegen nicht vor. Die Mortalität bei Patienten mit chronischer Pankreatitis ist 20 Jahre nach Diagnosestellung um 38,4\% erhöht im Vergleich zu einer altersbereinigten Kontrollkohorte [439]. Das Risiko für ein Pankreaskarzinom ist 16-fach erhöht bei Vorliegen 
einer chronischen Pankreatitis und bei zusätzlichem Rauchen 25fach erhöht. Das relative Risiko für ein Pankreaskarzinom kalkuliert in einer aktuellen Metaanalyse für eine chronische Pankreatitis beträgt 13,3 (95\% CI 6,1-28,9\%) und 69 für die hereditäre Pankreatitis (95\% CI 56,4-84,4) [440]. Das Lebenszeitrisiko für ein Pankreaskarzinom bei chronischer Pankreatitis beträgt max. $5 \%$ [Evidenzgrad 2b] [439 - 442]. Die klinische Erfahrung sieht deshalb eine jährliche Kontrolle vor (klinischer Befund, transabdominelle Sonografie, Labor mit $\mathrm{HbA}_{1 \mathrm{c}}$ ).

\section{Statement 11-1-2}

Das Auftreten einer endokrinen Insuffizienz bedingt bei schlechter Stoffwechselkontrolle diabetesbedingte Spätfolgen. Bei pankreoprivem Diabetes ist das Risiko einer Hypoglykämie erhöht. Dies führt zu einer erhöhten Letalität. Eine Verlaufskontrolle des Glukosestoffwechsels soll deshalb erfolgen. [Evidenzgrad 3b, Empfehlungsgrad A, starker Konsens]

\section{Kommentar}

8 Jahre nach Diagnosestellung einer chronischen Pankreatitis leiden $50 \%$ der Patienten an einem therapiepflichtigen Diabetes mellitus. Episodische Hypoglykämien treten in bis zu $79 \%$ und schwere Hypoglykämie in bis zu $41 \%$ auf. Die Letalität infolge des Diabetes mellitus ist signifikant erhöht. Das mediane Überleben beträgt 8,7 Jahre nach Diagnosestellung eines pankreopriven Diabetes. Die Diagnose und Verlaufsbeobachtung des Diabetes mellitus sollen nach den Vorgaben der Deutschen Diabetes Gesellschaft erfolgen. [Leitlinie der DDG: http://www.uni-duesseldorf.de/AWMF/ll/1l_057.html] [443-449].

\section{Statement $11-1-3$}

Das Auftreten einer exokrinen Insuffizienz führt zur Mangelernährung und Folgeerkrankungen wie z.B. Osteoporose. Eine Verlaufskontrolle kann empfohlen werden. [Evidenzgrad 4, Empfehlungsgrad D, Konsens]

\section{Kommentar}

Eine exokrine Pankreas-Insuffizienz führt zur Kachexie und Folgeerkrankungen wie Vitaminmangelzuständen und der Osteoporose. Es sollte deshalb bei Patienten mit einer chronischen Pankreatitis nach den Leitlinien des Dachverbands Osteologie (DVO) eine Osteoporose-Diagnostik sowie -Therapie erfolgen. Um eine Verschlechterung des Ernährungsstatus zu verhindern, sollte eine individuell angepasste Ernährungsintervention erfolgen. Einer Verlaufskontrolle nach den Leitlinien der Deutschen Gesellschaft für Ernährungsmedizin ist indiziert [89, 450, 451].

\section{Statement $11-1-4$}

Es kann sinnvoll sein, Hochrisikogruppen in regelmäßigen Abständen auf das Auftreten eines Pankreaskarzinoms zu untersuchen. Wie kurz- oder langfristig die Untersuchungsintervalle angesetzt werden müssen, ist nicht geklärt. Belegte Untersuchungsalgorithmen existieren zum momentanen Zeitpunkt nicht.

[Evidenzgrad 3b, Empfehlungsgrad D, starker Konsens]

\section{Statement $11-1-5$}

Hochrisikogruppen für Folgeerkrankungen sind Träger einer PRSS1-Mutation sowie Raucher.

[Evidenzgrad 3b, starker Konsens]

\section{Kommentar}

Träger einer PRSS1-Mutation haben beim Vorliegen einer chronischen Pankreatitis ein kumulatives Risiko von max. 49\%, bis zum 75. Lebensjahr an einem Pankreaskarzinom zu erkranken. Dieses Risiko ist signifikant höher als für alle anderen bekannten Ätiologien der chronischen Pankreatitis. Für das Rauchen ist eine raschere Progression der Erkrankung verbunden mit einem erhöhten Risiko für ein Pankreaskarzinom gut belegt [2, 6, 7, 37 - 39, $41,42,45,46,48,49,80,452-454]$.

\section{Statement 11-1-6}

Eine Verlaufskontrolle von Patienten mit chronischer Pankreatitis kann in Intervallen von 6-12 Monate erfolgen, da so die behandelbaren Komplikationen frühzeitig erkannt werden können.

[Evidenzgrad 5, Empfehlungsgrad D, starker Konsens]

\section{Kommentar}

Die Diagnosestellung ist nicht gleichbedeutend mit der Krankheitsdauer und bereits 8 Jahre nach Diagnosestellung leiden $50 \%$ der Patienten mit chronischer Pankreatitis an einem Diabetes mellitus. Da Komplikationen wie eine exokrine oder endokrine Insuffizienz unbehandelt mit einer beträchtlichen Morbidität und einer erhöhten Mortalität verbunden sind, scheint eine Verlaufskontrolle sinnvoll. Ziel der Verlaufskontrolle ist die Diagnose und Therapie einer exokrinen oder endokrinen Insuffizienz, eine Intervention bei Kachexie oder Schmerzen sowie die Therapie lokaler Komplikationen (Magenausgangstenose, Pseudoaneurysmen, komplizierte Pseudozysten). Eine Verlaufskontrolle kann nicht nur beim Auftreten von Warnsymptomen (Schmerzen, diabetische Stoffwechsellage, Gewichtsverlust, Ikterus, Erbrechen, Inappetenz, rez. Schübe) erfolgen, da alle relevanten Komplikationen der chronischen Pankreatitis meist beim Auftreten von Warnsymptomen bereits irreversible Schäden verursacht haben $[2,6,7,37$ - 39, 41, 42, 45, 46, 48, 49, 80, 89, 443-455].

\section{Statement 11-1-7}

Neben der klinischen und laborchemischen Untersuchung kann eine Verlaufskontrolle mittels transabdominellen Ultraschalls als nicht invasives Verfahren mit weiter Verbreitung in der Praxis empfohlen werden.

[Evidenzgrad 2b, Empfehlungsgrad C, Konsens]

\section{Kommentar}

Die Sensitivität zur Diagnose einer Pankreaserkrankung mittels transabdominellen Ultraschalls liegt bei $94 \%$, die Spezifität jedoch nur bei $35 \%$. Die Sensitivität der Anamnese, der klinischen Untersuchung und des transabdominellen Ultraschalls erreicht 94\%. Durch nachgeschaltete Untersuchungsverfahren wie dem EUS, der ERCP oder dem CT erhöht sich die Spezifität, aber nicht die Sensitivität. Der transabdominelle Ultraschall scheint somit als Eingangsuntersuchung geeignet. Zur Bestätigung der Diagnose kann ein zusätzliches bildgebendes Verfahren erforderlich sein [456]. 


\section{Statement $11-1-8$}

Bei begründetem Verdacht auf eine Komplikation der chronischen Pankreatitis oder ein Pankreaskarzinom soll eine weitere Abklärung erfolgen. Dies kann bildgebend durch kontrastmittelverstärkte Sonografie, endosonografischen Ultraschall, kontrastmittelverstärkte CT, MRT/MRCP oder ERCP erfolgen. [starker Konsens, klinischer Konsensuspunkt]

\section{Kommentar}

Dies stellt die klinische Praxis dar. Der Goldstandard für die Detektion von Komplikationen der chronischen Pankreatitis ist das kontrastmittelverstärkte CT. Einschränkend muss hinzugefügt werden, dass das CT zur Diagnose eines Frühkarzinoms nicht gut geeignet ist. Vielmehr kann keines der oben genannten Verfahren mit hinreichender Sicherheit ein operables Malignom vor dem Hintergrund einer chronischen Pankreatitis ausschließen. Eine Kombination der bildgebenden Verfahren bei klinischem Verdacht kann erforderlich sein. Zum momentanen Zeitpunkt scheint die Endosonografie den anderen bildgebenden Verfahren, auch wegen Möglichkeit zur Biopsie-Entnahme, überlegen zu sein. Siehe Themenkomplex Bildgebung bei chronischer Pankreatitis (Auswahl: $[152,157])$.

\section{Statement $11-1-9$}

Zur Verlaufskontrolle sollten keine Tumormarker (Ca19.9, CEA oder andere) verwendet werden.

[Evidenzgrad 2a, Empfehlungsgrad B, starker Konsens]

\section{Kommentar}

Tumormarker sind als Suchtest (Screeningtest) für das Vorliegen eines Pankreaskarzinoms auch bei Patienten mit chronischer Pankreatitis ungeeignet. Bei Cholestase muss zudem mit falsch hohen Werten gerechnet werden. Bisher existieren keine Kosten-Nutzen-Analysen, die die Verwendung von Tumormarkern bei chronischer Pankreatitis belegen.

Die diagnostische Sensitivität und v.a. Spezifität von Tumormarkern zur Differenzierung einer Raumforderung im Pankreas sind nicht ausreichend [457].

\section{Statement 11-1-10}

Es sollte bei Auftreten eines ungewollten Gewichtsverlusts, eines neu aufgetretenen Diabetes mellitus, bei Veränderung des Schmerzcharakters, bei einer Cholestase ohne akutes Schmerzereignis, bei rezidivierenden Schüben einer Pankreatitis ohne erkennbare Ursache eine weiterführende Diagnostik durchgeführt werden.

[Evidenzgrad 4, Empfehlungsgrad B, starker Konsens]

\section{Kommentar}

Alle für die chronische Pankreatitis bekannten Komplikationen sind im symptomlosen Frühstadium kurabel, reversibel oder zumindest einer Therapie zugänglich. Eine Diagnose vor dem Auftreten von Warnsymptomen muss deshalb Ziel des behandelnden Arztes sein. Es besteht Konsens, dass aus o.g. Gründen eine Diagnostik erfolgen soll. Kontrollierte Studien, die den Wert der Frühdiagnose von Komplikationen der chronischen Pankreatitis und einer frühzeitigen Intervention untersuchen sind dringend erforderlich. Patienten mit chronischer alkoholbedingter Pankreatitis sterben häufiger an einem Hypopharynx, Ösophagus oder Magenkarzinom. Im Rahmen von Verlaufskontrollen sollte dies mitbedacht werden $[458,459]$.

\section{Statement 11-1-11}

Es soll nach einer Pankreasresektion zum Ausschluss einer latenten oder manifesten diabetischen Stoffwechsellage frühzeitig eine Testung nach den Leitlinien der DDG erfolgen, um Spätfolgen zu vermeiden.

[Evidenzgrad 3b, Empfehlungsgrad A, Konsens]

\section{Kommentar}

In bis zu 52\% der Fälle kommt es nach Pankreasresektion zu einer Einschränkung der Glukosetoleranz. 22 \% entwickeln einen insulinabhängigen Diabetes mellitus. Eine postoperative Kontrolle ist deshalb indiziert. Deshalb erfolgt eine Einstufung als Empfehlungsgrad A [313, 382, 389, 390, 460].

\section{Statement 11-1-12}

Eine prophylaktische totale Pankreatektomie bei Hochrisikopatienten für ein Karzinom (hereditärer Pankreatitis) sollte nicht durchgeführt werden.

[Evidenzgrad 4, Empfehlungsgrad B, starker Konsens]

\section{Kommentar}

Es liegen keine prospektiven Studien zur totalen Pankreatektomie vor. Eine generelle Empfehlung zur totalen Pankreatektomie kann bei hoher Morbidität und nicht zu vernachlässigender Mortalität nicht empfohlen werden. Das mediane Überleben nach totaler Pankreatektomie bei benigner Erkrankung beträgt 8,2 Jahre. Das mittlere 5-Jahres-Überleben betrug $50 \%$ in einer kürzlich publizierten japanischen Kohorte. Die Gruppe von Professor Büchler berichtet mit einer Nachbeobachtungszeit von 23,5 Monaten eine identische Mortalität im Vergleich zu Patienten nach Whipple'scher Operation bei chronischer Pankreatitis. Die Entscheidung zur totalen Pankreatektomie sollte immer in einem interdisziplinären Team getroffen werden. Eine Nachsorge in spezialisierten Zentren zur Senkung der Morbidität sollte ermöglicht werden [461 - 464]. Die Leitliniengruppe betrachtet diese Empfehlung als von hoher klinischer Relevanz. Es erfolgt deshalb eine Einstufung als Empfehlungsgrad B

\section{Kapitel 12 - Diagnostik und Therapie der chronischen Pankreatitis im Kindesalter \\ $\nabla$}

Die akute und akut rezidivierende Pankreatitis im Kindesalter ist weit häufiger, als bisher angenommen und kann in Abhängigkeit von der Ursache zu chronischer Pankreatitis führen. Die häufigsten Ursachen sind Traumen, Infektionen, Systemerkrankungen, Medikamente und strukturelle Gallenwegläsionen; ein großer Teil ist idiopathisch. Im Kindesalter verläuft die Pankreatitis überwiegend mild und mit guter Prognose. In einer retrospektiven 10-Jahres-Analyse (1991 - 2000) der Universitätskinderklinik Dresden fanden sich insgesamt 156 Kinder, die wegen einer akuten Pankreatitis stationär behandelt wurden. Das entspricht 0,29\% des gesamten Krankenguts. Nur ein Kind, ein vier Jahre altes Mädchen, hatte eine schwere, hämorrhagisch-nekrotisierende Pankreatitis mit kompliziertem, aber nicht letalem Verlauf. Bei einem weiteren Kind konnte eine hereditäre Pankreatitis mit mehrfachen Rezidiven diagnostiziert werden. Alle anderen 154 
Kinder hatten eine milde akute Pankreatitis mit Restitutio ad integrum. In einer Literaturrecherche zu 589 Kindern mit akuter Pankreatitis und einem mittleren Alter von 9,2 $\pm 2,4$ Jahren (1 Woche-21 Jahre) fanden sich folgende Pankreatitisursachen: idiopathisch $23 \%$, Trauma $22 \%$, strukturelle Anomalien $15 \%$, Multisystemerkrankungen 14\%, Medikamente $12 \%$, Infektionen $10 \%$, hereditär und Stoffwechselerkrankungen je $2 \%$ [465]. Dabei scheinen jedoch regionale Unterschiede in der Häufigkeit der einzelnen Ursachen zu bestehen, wie aus einer 1994 veröffentlichten japanischen Arbeit hervorgeht [466]. In dieser Analyse wurden 204 in der japanischen Literatur publizierte Fälle mit 304 in westlichen Ländern veröffentlichten verglichen. Fast die Hälfte der japanischen Fälle war durch angeborene Gallengangläsionen bedingt, während bei den in westlichen Ländern erkrankten Kindern neben einem Großteil idiopathischer Fälle die traumatisch bedingten dominierten.

\section{Statement 12-1-1}

Die Diagnostik und Therapie einer chronischen Pankreatitis bei Kindern und Jugendlichen sollte unter Leitung eines pädiatrischen Gastroenterologen in Zusammenarbeit mit einem erfahrenen Kinderchirurgen oder Viszeralchirurgen, pädiatrischen Radiologen und ggf. interventionellen Endoskopiker durchgeführt werden.

[Konsens, klinischer Konsenspunkt]

\section{2: Bildgebung bei chronischer Pankreatitis im Kindesalter}

\section{Statement 12-2-1}

Die transabdominelle Sonografie sollte als primäres bildgebendes Verfahren bei chronischer Pankreatitis im Kindesalter eingesetzt werden.

[starker Konsens, klinischer Konsenspunkt]

\section{Kommentar}

Die transabdominelle Sonografie ist das primäre bildgebende Verfahren zur Diagnostik der chronischen Pankreatitis bei Kindern, da die Untersuchung einfach durchführbar und mit keiner Strahlenbelastung verbunden ist. Es gibt jedoch keine vergleichenden Studien zur Wertigkeit der Sonografie bei Kindern. Der Nutzen von Ultraschallkontrastmitteln ist bei Kindern nicht evaluiert [467].

\section{Statement 12-2-2}

Die Endosonografie kann im Kindesalter durchgeführt werden.

[Evidenzgrad 4, Empfehlungsgrad C, starker Konsens]

\section{Kommentar}

Die Endosonografie ist bei Kindern technisch ab dem Alter von ca. 5 Jahren möglich und wird v. a. zur Durchführung einer Feinnadelbiopsie oder Diagnostik von Konkrementen durchgeführt [468 - 470]. Eine Röntgenuntersuchung und CT des Abdomens sollten nur in Ausnahmefällen zur Diagnostik der chronischen Pankreatitis bei Kindern durchgeführt werden.

\section{Statement 12-2-3}

Bei Kindern sollte die MRCP als Schnittbildverfahren der ersten Wahl zur Darstellung der Gallengänge und des Ductus pancreaticus eingesetzt werden. [starker Konsens, klinischer Konsenspunkt]

\section{Statement 12-2-4}

Die Aussagekraft der MRCP kann durch Gabe von Sekretin verbessert werden.

[Evidenzgrad 4, Empfehlungsgrad C, starker Konsens]

\section{Kommentar}

Die MRCP ist die Schnittbildtechnik der Wahl zur Darstellung der Gallengänge und des Ductus pancreaticus bei Kindern, da die Untersuchung wenig invasiv und mit keiner Strahlenbelastung verbunden ist. In einer Studie hat die intravenöse Applikation von Sekretin zur besseren Darstellung der verzweigten Pankreasgänge geführt [467, 471]. Bei Kindern < 6 Jahre kann die MRCP in der Regel nur in Narkose durchgeführt werden.

\section{Statement 12-2-5}

Die ERCP kann im Kindesalter vor allem bei geplanter Intervention durchgeführt werden.

[Evidenzgrad 5, Empfehlungsgrad D, starker Konsens]

\section{Kommentar}

Die ERCP ist bei Kindern < 5 Jahren technisch schwierig durchzuführen und wird ausschließlich bei geplanter Intervention eingesetzt [472]. Die Endosonografie wird nur bei spezieller Indikation im Kindesalter angewandt und hat dabei eine höhere Sensitivität als die MRCP in der Diagnostik einer CP.

\section{Statement 12-2-6}

Im ersten Lebensjahr nimmt die Pankreasgröße proportional am meisten zu. Die sonografisch bestimmte Größe des Pankreas lässt im Kindesalter keinen verlässlichen Rückschluss auf das vorliegen einer chronischen Pankreatitis zu. [Evidenzgrad 2b, Empfehlungsgrad B, starker Konsens]

\section{Kommentar}

In einer älteren Studie wurden bei 300 Kindern und Jugendlichen im Alter von 0-19 Jahren sonografisch die Größennormwerte für das Pankreas erhoben. Der Pankreaskopf hat in anterio-posteriorer Ausrichtung einen Durchmesser von 1,0 $\pm 0,4$ bis 2,0 $\pm 0,5 \mathrm{~cm}$ (Säuglings- bis junges Erwachsenenalter), der Pankreaskörper hat einen Durchmesser von 0,6 $\pm 0,2$ bis $1,1 \pm 0,3 \mathrm{~cm}$ und der Pankreasschwanz hat einen Durchmesser von $1,0 \pm 0,4$ bis $2,0 \pm 0,4 \mathrm{~cm}$. Das Hauptwachstum des Pankreas findet im ersten Lebensjahr statt und unterliegt einer großen Streuung. Die Größenbestimmung des Pankreas lässt deshalb keinen Rückschluss auf das Vorliegen einer chronischen Pankreatitis zu [473]. 


\section{3: Ätiologie der chronischen Pankreatitis im Kindesalter}

\section{Statement 12-3-1}

Im Kindesalter sollten neben einer genetischen Abklärung der chronischen Pankreatitis eine Reihe weiterer, zugrunde liegender Erkrankungen ausgeschlossen werden, insbesondere eine zystische Fibrose, eine Hypertriglyzeridämie und eine Hyperkalzämie.

[Evidenzgrad 4, Empfehlungsgrad B, Konsens]

\section{Kommentar}

Epidemiologische Daten für die chronische Pankreatitis im Kindesalter sind spärlich. Für zahlreiche nachfolgende Ursachen gibt es aber etliche Fallberichte, die deshalb bei Kindern und Jugendlichen abgeklärt werden müssen.

- Chronisch-entzündliche Darmerkrankungen: Es gibt hierzu mehrere Fallberichte im Kindesalter [474].

- Zöliakie: Epidemiologische Daten (schwedisches Register). Keine Häufung im Kindesalter, aber bei erwachsenen Patienten [475].

- Hämolytisch urämisches Syndrom: häufige Assoziation mit akuter Pankreatitis, selten mit chronischer Pankreatitis. Andere Autoimmunerkrankungen: Es existieren Fallberichte zur Lupus erythematodes, Sjögren-Syndrom, rheumatoider Arthritis und chronischer Pankreatitis im Kindesalter.

- Hypertriglyceridämie: Fallberichte bei Patienten mit Lipoproteinlipase-Mangel und Apolipoprotein-CII-Defizienz und stark erhöhten Triglyceriden. Im Kindesalter scheint kein Zusammenhang einer chronischen Pankreatitis und Hypercholesterinämie zu bestehen.

- Ca. 2 \% der Patienten mit zystischer Fibrose zeigen die Symptome einer chronischen Pankreatitis [55].

- Kinder mit Organoazidopathien können sich als rezidivierend akute Pankreatitis präsentieren. Ebenso ist eine Hyperkalziämie ein Risikofaktor für eine Pankreatitis im Kindesalter. Kein Zusammenhang besteht mit einem alpha-1-AT-Mangel [476].

- Die Datenlage zu parasitären Infektion und chronischer Pankreatitis im Kindesalter ist unklar.

- Eine gesicherte Assoziation von Medikamenten und chronischer Pankreatitis existiert für Zytostatika wie z. B. Asparaginase oder Immunmodulatoren (Azathioprin) und Valproat, wobei die Datenlage im Kindesalter spärlich ist [477, 478].

- Der Zusammenhang zwischen Bauchtraumata und chronischer Pankreatitis im Kindesalter ist nicht gesichert. Es kann keine genaue Aussage zur Häufigkeitsverteilung der unterschiedlichen Ätiologien für die chronische Pankreatitis im Kindesalter getroffen werden.

\section{Statement 12-3-2}

Ein Schweißtest zum Ausschluss einer zystischen Fibrose soll zur ätiologischen Abklärung bei chronischer Pankreatitis im Kindesalter durchgeführt werden.

[Evidenzgrad 1c, Empfehlungsgrad A, starker Konsens]

\section{Kommentar}

Patienten mit zystischer Fibrose, die pankreassuffizient sind, leiden gehäuft an rezidivierenden Pankreatitiden [55]. Im Weiteren finden sich bei Patienten mit sog. idiopathischer chronischer Pankreatitis gehäuft Mutationen auf den CFTR-Allelen [479, 480].

\section{4: Akuter Schub einer chronischen Pankreatitis im Kindesalter}

Statement 12-4-1

Die Ernährung bei Kindern im akuten Schub einer chronischen Pankreatitis kann in Analogie zur Ernährung bei erwachsenen Patienten mit chronischer Pankreatitis durchgeführt werden.

[Evidenzgrad 5, Empfehlungsgrad D, starker Konsens]

\section{Kommentar}

Es existieren keine kontrollierten Studien zur Ernährung im akuten Schub einer chronischen Pankreatitis im Kindesalter. Prinzipiell ist wie bei Erwachsenen eine frühzeitige enterale Ernährung anzustreben, um die intestinale Barriere aufrechtzuerhalten. Aufgrund des meist milderen Verlaufs im Kindesalter ist eine orale Ernährung in fast allen Fällen möglich. Es existieren keine Studien im Kindesalter, in welchen die orale Nahrungszufuhr mit der gastralen bzw. jejunalen Zufuhr verglichen wurde. Eine voll parenterale Ernährung bei chronischer Pankreatitis im Kindesalter ist nur bei schwerem Verlauf eines akuten Schubes mit Erbrechen und (Sub-)Ileus indiziert.

\section{Statement 12-4-2}

Ein genereller Einsatz von Antibiotika bei Kindern mit akutem Schub einer chronischen Pankreatitis kann nicht empfohlen werden.

[Evidenzgrad 5, Empfehlungsgrad D, starker Konsens]

\section{Kommentar}

Es existieren keine Studien zum kontrollierten Einsatz von Antibiotika im akuten Schub einer CP im Kindesalter, ein Analogieschluss zur Therapie der akuten Pankreatitis im Erwachsenenalter scheint jedoch zulässig.

\section{Statement 12-4-3}

Nach Ausschöpfung konservativer therapeutischer Maßnahmen (Pharmakotherapie, interventionelle Therapie) kann im Kindesalter bei Vorliegen einer chronischen Pankreatitis eine operative Therapie insbesondere bei Persistenz chronischer Schmerzen indiziert sein.

[Evidenzgrad 5, Empfehlungsgrad D, starker Konsens]

\section{Kommentar}

Die Frage nach der Indikation zur operativen Therapie des Pankreas bei pädiatrischen Patienten mit chronischer Pankreatitis, der Zeitpunkt einer Operation und die Wahl der Operationstechnik ist aus der vorhandenen Literatur nicht zu beantworten.

12.5: Endoskopische, interventionelle und operative Therapie der chronischen Pankreatitis im Kindesalter

\section{Statement 12-5-1}

Eine evidenzbasierte Empfehlung zum interventionellen Vorgehen bei Kindern mit chronischer Pankreatitis kann nicht gegeben werden. Bei entsprechender Symptomatik und dem Vorliegen von Stenosen oder Steinen im Bereich des Pankreasgangs sowie einer biliären oder duodenalen Obstruktion be- 
steht mit einer ERCP die Möglichkeit der therapeutischen Intervention (Stenteinlage, Sphinkterotomie, Gangdilatation, Steinextraktion). Entsprechende randomisierte Studien dazu fehlen für das Kindesalter.

Bei Vorliegen einer symptomatischen Pankreaspseudozyste kann neben einer operativen Therapie auch eine interventionelle, nämlich eine innere Drainage nach endosonografisch gesteuerter Punktion indiziert sein.

[Evidenzgrad 4, Empfehlungsgrad D, starker Konsens]

\section{Kommentar}

Es gibt einzelne retrospektive Fallserien [470, 472, 481] und eine prospektive Fallserie [468], die nicht nur den diagnostischen Einsatz der ERCP und EUS beschreiben, sondern auch ihren Einsatz als interventionelle Therapie bei pädiatrischen Patienten mit chronischer Pankreatitis. Für die ERCP sind Sphinkterotomie, Stenteinlage, Steinextraktion und Ballondilatation und für die EUS die endosonografisch gesteuerte innere Drainage von symptomatischen Pankreaspseudozysten beschrieben.

Die Durchführung einer solchen interventionellen Therapie im Kindesalter ist an entsprechende personelle und apparative Voraussetzungen gebunden und erfordert bei den betroffenen pädiatrischen Patienten im Regelfall eine Vollnarkose.

\section{Statement 12-5-2}

Eine evidenzbasierte Empfehlung zum operativen Vorgehen bei Kindern mit chronischer Pankreatitis kann nicht gegeben werden.

[Evidenzgrad 5, Empfehlungsgrad D, starker Konsens]

\section{Kommentar}

Für das operative Vorgehen bei chronischer Pankreatitis im Kindesalter gibt es keine Vorgaben in der Literatur. Prinzipiell wird man bei Kindern besonderen Wert auf den Organerhalt von Pankreas und Milz legen, angesichts der extrem kleinen Patientenzahlen gibt es hierfür aber keine Evidenz.

\section{Statement $12-5-3$}

Es kann keine Empfehlung zur Wahl eines bestimmten Operationsverfahrens bei Kindern mit chronischer Pankreatitis abgegeben werden.

[Evidenzgrad 4, Empfehlungsgrad D, starker Konsens]

\section{Kommentar}

Bei der extrem geringen Anzahl von operativen Eingriffen bei chronischer Pankreatitis im Kindesalter gibt es zu Ergebnissen spezifischer Operationsverfahren insgesamt keine validen Ergebnisse. In einer retrospektiven Studie wurden 25 Patienten über 34 Jahre gesammelt, bei denen 6 verschiedene Operationsverfahren angewendet wurden. Deshalb ist eine Aussage zur Wertigkeit einzelner Operationsverfahren bei Kindern nicht möglich [481].

\section{6: Schmerztherapie der chronischen Pankreatitis im Kindesalter}

\section{Statement 12-6-1}

Es existiert keine spezifische Schmerztherapie bei chronischer Pankreatitis im Kindesalter. Die Therapie kann in Analogie zur Schmerztherapie bei Erwachsenen erfolgen.

[Evidenzgrad 5, Empfehlungsgrad D, starker Konsens]

\section{Kommentar}

Die Schmerztherapie bei Kindern richtet sich nach den Erfahrungen bei Erwachsenen. Untersuchungen bei Kindern zu diesem Thema fehlen. Es lassen sich die allgemeinen Prinzipien der Schmerztherapie bei Kindern auch auf den Bauchschmerz bei Pankreatitis anwenden.

\section{7: Enzymsubstitution der chronischen Pankreatitis im Kindesalter}

Vor allem im Kindesalter sollte bei exokriner Insuffizienz eine Substitutionstherapie vorgenommen werden. Bei einer exokrinen Pankreasinsuffizienz ist zwar die Sekretion aller Enzyme betroffen, die Reduktion der Fettverdauung spielt jedoch die entscheidende pathophysiologische Rolle. Folgende Mechanismen wirken zusammen: früherer und stärkerer Rückgang der Lipasesekretion im Vergleich mit anderen Enzymen; durch duodenale Azidität (Bikarbonatmangel!) bedingte Säuredenaturierung der Lipase; begleitende Störung der Fettresorption durch intraduodenale Säuredenaturierung der Gallensäuren; rascherer proteolytischer Abbau der Lipase; fehlende effektiv kompensierende Enzymsysteme. Die Verdauung von Eiweiß und Stärke ist in der Regel nicht wesentlich gestört bzw. wird von anderen Enzymen des Speichels, des Magens und des Bürstensaumes der Duodenalschleimhaut übernommen. Im Einzelfall sind Blähungen möglich.

\section{Statement 12-7-1}

Unter oraler Substitution von Pankreasenzymen können bei Kindern Nebenwirkungen auftreten. Ggf. kann die Therapie auf ein alternatives Enzympräparat umgestellt werden.

[Evidenz 4, Empfehlungsgrad D, starker Konsens]

\section{Kommentar}

Die allergische Sensibilisierung, orale Schleimhautexkoration und fibrosierende Kolonerkrankung können bei Kindern und Jugendlichen unter oraler Pankreasenzymsubstitution auftreten. Es existieren hierzu jedoch nur einzelne Fallberichte, aus denen keine Angaben zur Häufigkeit abgeleitet werden können. Eine Sensibilisierung im Prick-Test ist bei Patienten mit zystischer Fibrose nicht häufiger als bei gesunden Kontrollen zu beobachten [482-484]. Eine fibrosierende Kolonerkrankung oder orale Schleimhautexkoration wurde bisher nur bei Patienten mit zystischer Fibrose beschrieben.

\section{Statement 12-7-2}

Bei Kindern und Jugendlichen mit chronischer Pankreatitis sollte bei ungenügender körperlicher Entwicklung eine inadäquate Pankreasenzymsubstitution ausgeschlossen werden. [Evidenzgrad 5, Empfehlungsgrad B, starker Konsens] 


\section{Kommentar}

Häufige volumenreiche Stühle, fettige Stühle, gesteigerte Flatulenz, exzessiver Appetit und eine reduzierte Wachstumsgeschwindigkeit weisen auf eine inadäquate PankreasenzymErsatztherapie hin und müssen deshalb im Kindes- und Jugendalter besonders beachtet werden. Die Substitution eines Pankreaslipase-Präparats mit retardierter Formulierung ist effektiv und stellt bei schlechter Compliance möglicherweise einen Vorteil dar [484].

\section{Statement 12-7-3}

Bei Kindern und Jugendlichen, die unter regelrechter oraler Substitution von Pankreasenzymen weiterhin Zeichen einer schweren Maldigestion haben, soll eine probatorische säuresuppressive Therapie mit Protonenpumpeninhibitoren durchgeführt werden.

[Evidenzgrad 1b, Empfehlungsgrad A, starker Konsens]

\section{Kommentar}

In verschiedenen Studien wurde gezeigt, dass Kinder und Jugendliche, die trotz regelrechter Substitution nicht verkapselter oder mikroverkapselter Pankreasenzyme Zeichen einer Maldigestion mit Steatorrhö haben, unter säuresuppressiver Therapie besser gedeihen [359, 484, 485].

\section{Appendix: Beteiligte Autoren ( 0 Tab. 6)}

$\nabla$

Tab. 6 Beteiligte Autoren.



\section{Tab. 6 (Fortsetzung)}

Prof. Dr. Jörg Kleeff, München

Prof. Dr. Wolfram Trudo Knoefel, Düsseldorf

Prof. Dr. Paul Georg Lankisch, Lüneburg

Prof. Dr. Peter Layer, Hamburg

Prof. Dr. Markus M. Lerch, Greifswald

Prof. Dr. Matthias Löhr, Stockholm

Prof. Dr. Christian Löser, Kassel

Prof. Dr. Jutta Lüttges, Hamburg

Prof. Dr. Peter Malfertheiner, Magdeburg

Prof. Dr. Julia Mayerle, Greifswald

Prof. Dr. Rémy Meier, Liestal

Prof. Dr. Joachim Mössner, Leipzig

Prof. Dr. Horst Neuhaus, Düsseldorf

Prof. Dr. Claus Niederau, Oberhausen

Prof. Dr. Johann Ockenga, Bremen

PD Dr. Roland Pfützer, Köln

Prof. Dr. Bettina Rau, Rostock

Prof. Dr. Jürgen Riemann, Ludwigshafen

Prof. Dr. Michael Rünzi, Essen

Prof. Dr. Roland Schmid, München

PD Dr. Alexander Schneider, Aschaffenburg

Prof. Dr. Michael Schoenberg, München

PD Dr. Andreas Schreyer, Regensburg

Prof. Dr. Hans-Joachim Schulz, Berlin

Prof. Dr. Dietrich von Schweinitz, München

Prof. Dr. Hans Seifert, Oldenburg

Dr. Peter Simon, Greifswald

Prof. Dr. Tim Strate, Reinbek

PD Dr. Niels Teich, Leipzig

Dr. Matthias Treiber, München

Prof. Dr. Barbara Tribl, Wien

Prof. Dr. Jens Werner, Heidelberg

Prof. Dr. Uwe Will, Gera

Prof. Dr. Heiko Witt, München

Prof. Dr. Christian Wittekind, Leipzig

Prof. Dr. Helmut Witzigmann, Dresden

Prof. Dr. Emre F. Yekebas, Darmstadt

\section{Institute}

Klinik und Poliklinik für Gastroenterologie und Rheumatologie,

Universitätsklinikum Leipzig

Klinik für Innere Medizin A, Universitätsmedizin der Ernst-Moritz-Arndt Universität, Greifswald

Klinik für Gastroenterologie und Hepatologie Universitätsspital Basel, Schweiz

${ }^{4}$ Klinik für Allgemeine, Viszerale und Transplantationschirurgie, Universitätsklinikum Heidelberg, Ruprecht-Karls-Universität, Heidelberg

Dr. von Haunersches Kinderspital, Ludwig Maximilian Universität München

Deutsche Gesellschaft für Verdauungs- und Stoffwechselerkrankungen (DGVS), Berlin

Klinik für Allgemeine Innere Medizin, Christian-Albrechts-Universität zu Kiel

8 Chirurgische Klinik und Poliklinik am Klinikum Rechts der Isar, Technische Universität München

${ }^{9}$ Klinik und Poliklinik für Allgemein-, Visceral- und Thoraxchirurgie am Universitätsklinikum Hamburg-Eppendorf

${ }^{10}$ Klinik für Innere Medizin Schwerpunkt Gastroenterologie, Hämatologie und Onkologie, Nephrologie DRK Kliniken Berlin-Köpenick

11 Allgemeine Chirurgie, Thorax-, Gefäß- und Transplantationschirurgie, Universität Rostock

12 Medizinische Klinik, Israelitisches Krankenhaus Hamburg

13 Klinik für Allgemein-, Viszeral- und Kinderchirurgie, Universitätsklinikum Düsseldorf der Heinrich-Heine-Universität

14 Surgical Gastroenterology, Gastrocentrum, Karolinska University Hospital Huddinge

15 Abteilung für Gastroenterologie, Kantonsspital Liestal, Medizinische Universitätsklinik

${ }^{16}$ Medizinische Klinik C am Klinikum der Stadt Ludwigshafen/Rhein gGmbH

17 Klinik für Gastroenterologie u. Stoffwechselerkrankungen, Kliniken Essen Süd 
18 Medizinische Klinik 2 am Klinikum Rechts der Isar, Technische Universität München

19 Institut für Röntgendiagnostik am Universitätsklinikum Regensburg

20 Innere Medizin IV, Abt. f. Gastroenterologie und Hepatologie, Universitätsklinik Wien

21 Klinik und Poliklinik für Kinder- und Jugendmedizin, Kinderklinik München Schwabing, Technische Universität München

\section{Literatur}

1 Dufour MC, Adamson MD. The epidemiology of alcohol-induced pancreatitis. Pancreas 2003; 27: 286-290

2 Ammann RW, Akovbiantz A, Largiader $F$ et al. Course and outcome of chronic pancreatitis. Longitudinal study of a mixed medical-surgical series of 245 patients. Gastroenterology 1984; 86: 820-828

3 Miyake H, Harada H, Kunichika K et al. Clinical course and prognosis of chronic pancreatitis. Pancreas 1987; 2: $378-385$

4 Lankisch PG, Lohr-Happe A, Otto J et al. Natural course in chronic pancreatitis. Pain, exocrine and endocrine pancreatic insufficiency and prognosis of the disease. Digestion 1993; 54: 148-155

5 Gastard J, Joubaud F, Farbos T et al. Etiology and course of primary chronic pancreatitis in Western France. Digestion 1973; 9: 416-428

6 Lowenfels AB, Maisonneuve P, Cavallini G et al. Prognosis of chronic pancreatitis: an international multicenter study. International Pancreatitis Study Group. Am J Gastroenterol 1994; 89: 1467-1471

7 Maisonneuve P, Lowenfels AB, Mullhaupt B et al. Cigarette smoking accelerates progression of alcoholic chronic pancreatitis. Gut 2005; 54 : $510-514$

8 van Geenen EJ, Smits MM, Schreuder TC et al. Smoking is related to pancreatic fibrosis in humans. Am J Gastroenterol 2011; 106: 1161 - 1166; quiz 1167

9 Mossner J, Keim V, Niederau C et al. [Guidelines for therapy of chronic pancreatitis. Consensus Conference of the German Society of Digestive and Metabolic Diseases. Halle 21-23 November 1996]. Z Gastroenterol 1998; 36: 359-367

10 Durbec JP, Sarles H. Multicenter survey of the etiology of pancreatic diseases. Relationship between the relative risk of developing chronic pancreaitis and alcohol, protein and lipid consumption. Digestion 1978; 18 : $337-350$

11 Johnson $C D$, Hosking $S$. National statistics for diet, alcohol consumption, and chronic pancreatitis in England and Wales, 1960-88. Gut 1991; 32 $1401-1405$

12 Lin Y, Tamakoshi A, Hayakawa T et al. Associations of alcohol drinking and nutrient intake with chronic pancreatitis: findings from a casecontrol study in Japan. Am J Gastroenterol 2001; 96: 2622 - 2627

13 Maruyama K, Otsuki M. Incidence of alcoholic pancreatitis in Japanese alcoholics: survey of male sobriety association members in Japan. Pancreas 2007; 34: $63-65$

14 Sarles $H$, Cros RC, Bidart JM. A multicenter inquiry into the etiology of pancreatic diseases. Digestion 1979; 19: 110-125

15 Stigendal L, Olsson R. Alcohol consumption pattern and serum lipids in alcoholic cirrhosis and pancreatitis. A comparative study. Scand J Gastroenterol 1984; 19: $582-587$

16 Talamini G, Bassi C, Falconi $M$ et al. Alcohol and smoking as risk factors in chronic pancreatitis and pancreatic cancer. Dig Dis Sci 1999; 44: $1303-1311$

17 Levy $P$, Mathurin $P$, Roqueplo A et al. A multidimensional case-control study of dietary, alcohol, and tobacco habits in alcoholic men with chronic pancreatitis. Pancreas 1995; 10: 231 - 238

18 Suda K, Shiotsu H, Nakamura T et al. Pancreatic fibrosis in patients with chronic alcohol abuse: correlation with alcoholic pancreatitis. Am J Gastroenterol 1994; 89: 2060-2062

19 UK guidelines for the management of acute pancreatitis. Gut 2005; 54 (Suppl 3): iii1 - iii9

20 Bakker OJ, van Santvoort HC, Hagenaars JC et al. Timing of cholecystectomy after mild biliary pancreatitis. Br J Surg 2011; 98: 1446 - 1454

21 Yan MX, Li YQ. Gall stones and chronic pancreatitis: the black box in between. Postgrad Med J 2006; 82: 254-258

22 Garg PK, Tandon RK. Survey on chronic pancreatitis in the Asia-Pacific region. J Gastroenterol Hepatol 2004; 19: 998 - 1004

23 Jacob JJ, John M, Thomas $N$ et al. Does hyperparathyroidism cause pancreatitis? A South Indian experience and a review of published work. ANZ J Surg 2006; 76: 740-744
24 Carnaille B, Oudar C, Pattou F et al. Pancreatitis and primary hyperparathyroidism: forty cases. Aust N Z J Surg 1998; 68: 117-119

25 Talamini G, Falconi M, Bassi C et al. Previous cholecystectomy, gastrectomy, and diabetes mellitus are not crucial risk factors for pancreatic cancer in patients with chronic pancreatitis. Pancreas 2001; 23: $364-367$

26 Burtin P, Person B, Charneau J et al. Pancreas divisum and pancreatitis: a coincidental association? Endoscopy 1991; 23: 55-58

27 Kamisawa $T, T u$ Y, Egawa $N$ et al. Clinical implications of incomplete pancreas divisum. JOP 2006; 7: 625-630

$28 \mathrm{Kim} \mathrm{MH,} \mathrm{Lee} \mathrm{SS,} \mathrm{Kim} \mathrm{CD} \mathrm{et} \mathrm{al.} \mathrm{Incomplete} \mathrm{pancreas} \mathrm{divisum:} \mathrm{is} \mathrm{it} \mathrm{merely}$ a normal anatomic variant without clinical implications? Endoscopy 2001; 33: $778-785$

29 SpicakJ, Poulova P, Plucnarova J et al. Pancreas divisum does not modify the natural course of chronic pancreatitis. J Gastroenterol 2007; 42: $135-139$

$30 \mathrm{Su}$ WJ, Chen HL, Lai HS et al. Pancreaticobiliary anomalies is the leading cause of childhood recurrent pancreatitis. J Formos Med Assoc 2007; 106: $119-125$

31 Yatto RP, Siegel JH. The role of pancreatobiliary duct anatomy in the etiology of alcoholic pancreatitis. J Clin Gastroenterol 1984; 6: 419423

32 Agha FP, Williams KD. Pancreas divisum: incidence, detection, and clinical significance. Am J Gastroenterol 1987; 82: 315-320

33 Dhar A, Goenka MK, Kochhar $R$ et al. Pancrease divisum: five years' experience in a teaching hospital. Indian J Gastroenterol 1996; 15: 7-9

34 Quest L, Lombard M. Pancreas divisum: opinio divisa. Gut 2000; 47: 317-319

35 Buhler H, Seefeld U, Deyhle P et al. [Clinical significance of pancreas divisum]. Schweiz Med Wochenschr 1983; 113: 320-324

36 Akatsu T, Aiura K, Takahashi S et al. Recurrent pancreatitis caused by ampullary carcinoma and minor papilla adenoma in familial polyposis: report of a case. Surg Today 2008; 38: 440 - 444

37 Maisonneuve P, Frulloni L, Mullhaupt B et al. Impact of smoking on patients with idiopathic chronic pancreatitis. Pancreas 2006; 33: $163-$ 168

38 Yadav D, Hawes RH, Brand RE et al. Alcohol consumption, cigarette smoking, and the risk of recurrent acute and chronic pancreatitis. Arch Intern Med 2009; 169: 1035 - 1045

39 Ammann RW, Knoblauch M, Mohr P et al. High incidence of extrapancreatic carcinoma in chronic pancreatitis. Scand J Gastroenterol 1980; 15: $395-399$

40 Ammann $R W$, Muellhaupt $B$. The natural history of pain in alcoholic chronic pancreatitis. Gastroenterology 1999; 116: $1132-1140$

41 Cavallini G, Talamini G, Vaona B et al. Effect of alcohol and smoking on pancreatic lithogenesis in the course of chronic pancreatitis. Pancreas 1994; 9: 42-46

42 Talamini G, Bassi C, Falconi $M$ et al. Pain relapses in the first 10 years of chronic pancreatitis. Am J Surg 1996; 171: 565-569

43 Whitcomb DC, Gorry MC, Preston RA et al. Hereditary pancreatitis is caused by a mutation in the cationic trypsinogen gene. Nat Genet 1996: 14: $141-145$

44 Whitcomb DC, Preston RA, Aston CE et al. A gene for hereditary pancreatitis maps to chromosome 7q35. Gastroenterology 1996; 110: 19751980

45 Howes N, Lerch MM, Greenhalf W et al. Clinical and genetic characteristics of hereditary pancreatitis in Europe. Clin Gastroenterol Hepatol 2004; $2: 252-261$

46 Applebaum-Shapiro SE, Finch R, Pfutzer RH et al. Hereditary pancreatitis in North America: the Pittsburgh-Midwest Multi-Center Pancreatic Study Group Study. Pancreatology 2001; 1: 439-443

47 Simon $P$, Weiss FU, Sahin-Toth $M$ et al. Hereditary pancreatitis caused by a novel PRSS1 mutation (Arg-122 - Cys) that alters autoactivation and autodegradation of cationic trypsinogen. J Biol Chem 2002; 277: $5404-5410$

48 Rebours V, Boutron-Ruault MC, Jooste $V$ et al. Mortality rate and risk factors in patients with hereditary pancreatitis: uni- and multidimensional analyses. Am J Gastroenterol 2009; 104: 2312 - 2317

49 Rebours V, Boutron-Ruault MC, Schnee $M$ et al. The natural history of hereditary pancreatitis: a national series. Gut 2009; 58: 97-103

50 Elitsur $Y$, Chertow $B C$, Jewell RD et al. Identification of a hereditary pancreatitis mutation in four West Virginia families. Pediatr Res 1998; 44: 927-930 
51 Le Bodic L, Bignon JD, Raguenes 0 et al. The hereditary pancreatitis gene maps to long arm of chromosome 7. Hum Mol Genet 1996; 5: 549 554

52 Le Bodic L, Schnee M, Georgelin T et al. An exceptional genealogy for hereditary chronic pancreatitis. Dig Dis Sci 1996; 41: 1504-1510

53 Aoun E, Chang CC, Greer JB et al. Pathways to injury in chronic pancreatitis: decoding the role of the high-risk SPINK1 N34S haplotype using meta-analysis. PLoS One 2008; 3: e2003

54 Witt H, Luck W, Hennies HC et al. Mutations in the gene encoding the serine protease inhibitor, Kazal type 1 are associated with chronic pancreatitis. Nat Genet 2000; 25: 213-216

55 Durno C, Corey M, Zielenski J et al. Genotype and phenotype correlations in patients with cystic fibrosis and pancreatitis. Gastroenterology 2002; 123: 1857 - 1864

56 Cohn JA, Neoptolemos JP, Feng J et al. Increased risk of idiopathic chronic pancreatitis in cystic fibrosis carriers. Hum Mutat 2005; 26: $303-307$

57 Choudari CP, Imperiale TF, Sherman $S$ et al. Risk of pancreatitis with mutation of the cystic fibrosis gene. Am J Gastroenterol 2004; 99: $1358-1363$

58 Sharer N, Schwarz M, Malone G et al. Mutations of the cystic fibrosis gene in patients with chronic pancreatitis. N Engl J Med 1998; 339: $645-652$

59 Weiss FU, Simon P, Bogdanova $N$ et al. Complete cystic fibrosis transmembrane conductance regulator gene sequencing in patients with idiopathic chronic pancreatitis and controls. Gut 2005; 54: $1456-1460$

60 De Boeck K, Weren M, Proesmans $M$ et al. Pancreatitis among patients with cystic fibrosis: correlation with pancreatic status and genotype. Pediatrics 2005; 115: e463-469

61 Rosendahl J, Witt H, Szmola R et al. Chymotrypsin C (CTRC) variants that diminish activity or secretion are associated with chronic pancreatitis. Nat Genet 2008; 40: 78-82

62 Masson E, Chen JM, Scotet $V$ et al. Association of rare chymotrypsinogen $\mathrm{C}(\mathrm{CTRC})$ gene variations in patients with idiopathic chronic pancreatitis. Hum Genet 2008; 123: 83-91

63 Masson E, Le Marechal C, Delcenserie $R$ et al. Hereditary pancreatitis caused by a double gain-of-function trypsinogen mutation. Hum Genet 2008; 123 : $521-529$

64 Chang MC, Chang YT, Wei SC et al. Association of novel chymotrypsin C gene variations and haplotypes in patients with chronic pancreatitis in Chinese in Taiwan. Pancreatology 2009; 9: 287-292

65 Sarles H, Sarles JC, Muratore R et al. Chronic inflammatory sclerosis of the pancreas - an autonomous pancreatic disease? Am J Dig Dis 1961; 6: $688-698$

66 Yoshida K, Toki F, Takeuchi T et al. Chronic pancreatitis caused by an autoimmune abnormality. Proposal of the concept of autoimmune pancreatitis. Dig Dis Sci 1995; 40: 1561 - 1568

67 Kamisawa T, Chari ST, Giday SA et al. Clinical profile of autoimmune pancreatitis and its histological subtypes: an international multicenter survey. Pancreas 40: 809-814

68 Chari ST, Smyrk TC, Levy MJ et al. Diagnosis of autoimmune pancreatitis: the Mayo Clinic experience. Clin Gastroenterol Hepatol 2006; 4: 1010-1016; quiz 1934

69 Kamisawa T, Egawa N, Nakajima $\mathrm{H}$ et al. Clinical difficulties in the differentiation of autoimmune pancreatitis and pancreatic carcinoma. Am J Gastroenterol 2003; 98: 2694-2699

70 Chari ST, Kloeppel G, Zhang L et al. Histopathologic and clinical subtypes of autoimmune pancreatitis: the Honolulu consensus document. Pancreas 39: 549-554

71 Frulloni L, Gabbrielli A, Pezzilli R et al. Chronic pancreatitis: report from a multicenter Italian survey (PanCroInfAISP) on 893 patients. Dig Liver Dis 2009; 41: $311-317$

72 Lankisch PG, Assmus C, Maisonneuve Pet al. Epidemiology of pancreatic diseases in Luneburg County. A study in a defined german population. Pancreatology 2002; 2: 469-477

73 Levy P, Barthet M, Mollard BR et al. Estimation of the prevalence and incidence of chronic pancreatitis and its complications. Gastroenterol Clin Biol 2006; 30: 838-844

74 Kloppel G, Sipos B, Zamboni $G$ et al. Autoimmune pancreatitis: histoand immunopathological features. J Gastroenterol 2007; 42 (Suppl 18): $28-31$

75 Church NI, Pereira SP, Deheragoda MG et al. Autoimmune pancreatitis: clinical and radiological features and objective response to steroid therapy in a UK series. Am J Gastroenterol 2007; 102: 2417-2425

76 Deheragoda MG, Church NI, Rodriguez-Justo $M$ et al. The use of immunoglobulin g4 immunostaining in diagnosing pancreatic and extra- pancreatic involvement in autoimmune pancreatitis. Clin Gastroenterol Hepatol 2007; 5: 1229-1234

77 Okazaki K, Kawa S, Kamisawa T et al. Japanese clinical guidelines for autoimmune pancreatitis. Pancreas 2009; 38: 849-866

78 Kamisawa T, Shimosegawa T, Okazaki K et al. Standard steroid treatment for autoimmune pancreatitis. Gut 2009; 58: 1504-1507

79 Comfort MW, Steinberg AG. Pedigree of a family with hereditary chronic relapsing pancreatitis. Gastroenterology 1952; 21: 54-63

80 Lowenfels $A B$, Maisonneuve $P$, Whitcomb DC et al. Cigarette smoking as a risk factor for pancreatic cancer in patients with hereditary pancreatitis. JAMA 2001; 286: 169-170

81 Ellis I, Lerch MM, Whitcomb DC. Genetic testing for hereditary pancreatitis: guidelines for indications, counselling, consent and privacy issues. Pancreatology 2001; 1: 405 - 415

82 Rebours V, Boutron-Ruault MC, Schnee $M$ et al. Risk of pancreatic adenocarcinoma in patients with hereditary pancreatitis: a national exhaustive series. Am J Gastroenterol 2008; 103: 111 -119

83 Löhr J. Exokrine Pankreasinsuffizienz. 3rd ed. Bremen: UNI-MED Verlag; 2010

84 Layer $P$, Holtmann $G$. Pancreatic enzymes in chronic pancreatitis. Int J Pancreatol 1994; 15: 1-11

85 DiMagno EP, Go VL, Summerskill WH. Relations between pancreatic enzyme ouputs and malabsorption in severe pancreatic insufficiency. N Engl J Med 1973; 288: 813-815

86 DiMagno EP, Malagelada JR, Go VL et al. Fate of orally ingested enzymes in pancreatic insufficiency. Comparison of two dosage schedules. N Engl J Med 1977; 296: 1318 - 1322

87 Lankisch PG, Seidensticker F, Otto J et al. Secretin-pancreozymin test (SPT) and endoscopic retrograde cholangiopancreatography (ERCP): both are necessary for diagnosing or excluding chronic pancreatitis. Pancreas 1996; 12: 149-152

88 Lankisch PG, Droge M, Hofses S et al. Steatorrhoea: you cannot trust your eyes when it comes to diagnosis. Lancet 1996; 347: 1620-1621

89 Dumasy V, Delhaye $M$, Cotton F et al. Fat malabsorption screening in chronic pancreatitis. Am J Gastroenterol 2004; 99: 1350-1354

90 Meier R, Ockenga J, Pertkiewicz $M$ et al. ESPEN Guidelines on Enteral Nutrition: Pancreas. Clin Nutr 2006; 25: 275 - 284

91 Haaber $A B$, Rosenfalck $A M$, Hansen $B$ et al. Bone mineral metabolism, bone mineral density, and body composition in patients with chronic pancreatitis and pancreatic exocrine insufficiency. Int J Pancreatol 2000: 27: $21-27$

92 Kalvaria I, Labadarios D, Shephard GS et al. Biochemical vitamin E deficiency in chronic pancreatitis. Int J Pancreatol 1986; 1: 119-128

93 Mann ST, Stracke H, Lange $U$ et al. Vitamin D3 in patients with various grades of chronic pancreatitis, according to morphological and functional criteria of the pancreas. Dig Dis Sci 2003; 48: 533 - 538

94 Mann ST, Mann V, Stracke H et al. Fecal elastase 1 and vitamin D3 in patients with osteoporotic bone fractures. Eur J Med Res 2008; 13: 68 - 72

95 Bozkurt T, Braun U, Leferink S et al. Comparison of pancreatic morphology and exocrine functional impairment in patients with chronic pancreatitis. Gut 1994; 35: $1132-1136$

96 Chowdhury RS, Forsmark CE. Review article: Pancreatic function testing. Aliment Pharmacol Ther 2003; 17: 733-750

97 Chowdhury R, Bhutani MS, Mishra G et al. Comparative analysis of direct pancreatic function testing versus morphological assessment by endoscopic ultrasonography for the evaluation of chronic unexplained abdominal pain of presumed pancreatic origin. Pancreas 2005; 31: $63-68$

98 Stevens T, Lopez R, Adler DG et al. Multicenter comparison of the interobserver agreement of standard EUS scoring and Rosemont classification scoring for diagnosis of chronic pancreatitis. Gastrointest Endosc 71: $519-526$

99 Conwell DL, Zuccaro G, Purich E et al. Comparison of endoscopic ultrasound chronic pancreatitis criteria to the endoscopic secretin-stimulated pancreatic function test. Dig Dis Sci 2007; 52: 1206-1210. DOI: $10.1007 /$ s10620-006-9469-6

100 Conwell DL, Zuccaro G, Purich E et al. Comparison of endoscopic ultrasound chronic pancreatitis criteria to the endoscopic secretin-stimulated pancreatic function test. Dig Dis Sci 2007; 52: 1206-1210

101 Conwell DL, Zuccaro G Jr, Vargo JJ et al. Comparison of the secretin stimulated endoscopic pancreatic function test to retrograde pancreatogram. Dig Dis Sci 2007; 52: 1076-1081

102 Albashir S, Bronner MP, Parsi MA et al. Endoscopic ultrasound, secretin endoscopic pancreatic function test, and histology: correlation in chronic pancreatitis. Am J Gastroenterol 105: 2498-2503 
103 Bali MA, Sztantics A, Metens T et al. Quantification of pancreatic exocrine function with secretin-enhanced magnetic resonance cholangiopancreatography: normal values and short-term effects of pancreatic duct drainage procedures in chronic pancreatitis. Initial results. Eur Radiol 2005; 15: 2110-2121

104 Bali MA, Golstein P, Deviere J et al. Evaluation of somatostatin inhibitory effect on pancreatic exocrine function using secretin-enhanced dynamic magnetic resonance cholangiopancreatography: a crossover, randomized, double blind, placebo-controlled study. Pancreas 2006; 32: 346-350

105 Donati F, Boraschi P, Gigoni R et al. Secretin-stimulated MR cholangiopancreatography in the evaluation of asymptomatic patients with non-specific pancreatic hyperenzymemia. Eur J Radiol 75: e38 - 44

106 Siegmund E, Lohr JM, Schuff-Werner P. [The diagnostic validity of noninvasive pancreatic function tests - a meta-analysis]. Z Gastroenterol 2004; 42: 1117-1128

107 Rathmann W, Haastert B, Icks A et al. High prevalence of undiagnosed diabetes mellitus in Southern Germany: target populations for efficient screening. The KORA survey 2000. Diabetologia 2003; 46: $182-189$

108 Hardt PD, Hauenschild A, Jaeger C et al. High prevalence of steatorrhea in 101 diabetic patients likely to suffer from exocrine pancreatic insufficiency according to low fecal elastase 1 concentrations: a prospective multicenter study. Dig Dis Sci 2003; 48: 1688-1692

109 Hardt PD, Hauenschild A, Nalop J et al. The commercially available ELISA for pancreatic elastase 1 based on polyclonal antibodies does measure an as yet unknown antigen different from purified elastase 1. Binding studies and clinical use in patients with exocrine pancreatic insufficiency. Z Gastroenterol 2003; 41: 903-906

110 Ewald N, Bretzel RG, Fantus IG et al. Pancreatin therapy in patients with insulin-treated diabetes mellitus and exocrine pancreatic insufficiency according to low fecal elastase 1 concentrations. Results of a prospective multi-centre trial. Diabetes Metab Res Rev 2007; 23: 386 - 391

111 Creutzfeldt W, Arnold R. Somatostatin and the stomach: exocrine and endocrine aspects. Metabolism 1978; 27: 1309-1315

112 Lohr M, Kloppel G. [Pathology of the pancreas in chronic type 1 diabetes mellitus: B-cell content, exocrine atrophy and angiopathy]. Verh Dtsch Ges Pathol 1987; 71: 114-119

113 Catalano MF, Sahai A, Levy $M$ et al. EUS-based criteria for the diagnosis of chronic pancreatitis: the Rosemont classification. Gastrointest Endosc 2009; 69: 1251 - 1261

114 Catalano MF, Lahoti S, Geenen JE et al. Prospective evaluation of endoscopic ultrasonography, endoscopic retrograde pancreatography, and secretin test in the diagnosis of chronic pancreatitis. Gastrointest Endosc 1998; 48: $11-17$

115 Catalano MF, Geenen JE. Diagnosis of chronic pancreatitis by endoscopic ultrasonography. Endoscopy 1998; 30 (Suppl 1): A111 -A115

116 Chong AK, Hawes RH, Hoffman BJ et al. Diagnostic performance of EUS for chronic pancreatitis: a comparison with histopathology. Gastrointest Endosc 2007; 65: 808-814

117 Nattermann C, Goldschmidt AJ, Dancygier H. [Endosonography in chronic pancreatitis. A comparative study of endoscopic retrograde pancreatography and endoscopic sonography]. Ultraschall in Med 1992; 13: $263-270$

118 Nattermann C, Goldschmidt AJ, Dancygier H. Endosonography in chronic pancreatitis - a comparison between endoscopic retrograde pancreatography and endoscopic ultrasonography. Endoscopy 1993; 25: 565-570. DOI: 10.1055/s-2007-1010406

119 Pungpapong S, Wallace MB, Woodward TA et al. Accuracy of endoscopic ultrasonography and magnetic resonance cholangiopancreatography for the diagnosis of chronic pancreatitis: a prospective comparison study. J Clin Gastroenterol 2007; 41: 88-93

120 Wiersema MJ, Hawes RH, Lehman GA et al. Prospective evaluation of endoscopic ultrasonography and endoscopic retrograde cholangiopancreatography in patients with chronic abdominal pain of suspected pancreatic origin. Endoscopy 1993; 25: 555-564

121 Tamura R, Ishibashi T, Takahashi S. Chronic pancreatitis: MRCP versus ERCP for quantitative caliber measurement and qualitative evaluation. Radiology 2006; 238: 920-928

122 Testoni PA, Mariani A, Curioni S et al. MRCP-secretin test-guided management of idiopathic recurrent pancreatitis: long-term outcomes. Gastrointest Endosc 2008; 67: 1028 - 1034

123 Adamek HE, Albert J, Breer $H$ et al. Pancreatic cancer detection with magnetic resonance cholangiopancreatography and endoscopic retrograde cholangiopancreatography: a prospective controlled study. Lancet 2000; 356: 190-193

124 Buscail L, Escourrou J, Moreau J et al. Endoscopic ultrasonography in chronic pancreatitis: a comparative prospective study with conventional ultrasonography, computed tomography, and ERCP. Pancreas 1995; 10: $251-257$

125 Stevens T, Conwell DL, Zuccaro G Jr et al. A prospective crossover study comparing secretin-stimulated endoscopic and Dreiling tube pancreatic function testing in patients evaluated for chronic pancreatitis. Gastrointest Endosc 2008; 67: 458-466

126 Stevens T, Conwell DL, Zuccaro G Jr et al. Comparison of endoscopic ultrasound and endoscopic retrograde pancreatography for the prediction of pancreatic exocrine insufficiency. Dig Dis Sci 2008; 53: 11461151

127 Stevens T, Zuccaro G Jr, Dumot JA et al. Prospective comparison of radial and linear endoscopic ultrasound for diagnosis of chronic pancreatitis. Endoscopy 2009; 41: 836 - 841

128 Glasbrenner B, Kahl S, Malfertheiner P. Modern diagnostics of chronic pancreatitis. Eur J Gastroenterol Hepatol 2002; 14: 935 - 941

129 Hollerbach S, Ruser J, Ochs A et al. [Current status of abdominal pancreatic ultrasound. A retrospective analysis of 585 pancreatic ultrasound examinations]. Med Klin (Munich) 1994; 89: 7-13

$130 \mathrm{Kahl} \mathrm{S,} \mathrm{Glasbrenner} \mathrm{B,} \mathrm{Leodolter} \mathrm{A} \mathrm{et} \mathrm{al.} \mathrm{EUS} \mathrm{in} \mathrm{the} \mathrm{diagnosis} \mathrm{of} \mathrm{early}$ chronic pancreatitis: a prospective follow-up study. Gastrointest Endosc 2002; 55: 507 - 511

$131 \mathrm{Kahl}$ S, Glasbrenner B, Zimmermann S et al. Endoscopic ultrasound in pancreatic diseases. Dig Dis 2002; 20: 120-126

132 Sahai AV, Zimmerman M, Aabakken L et al. Prospective assessment of the ability of endoscopic ultrasound to diagnose, exclude, or establish the severity of chronic pancreatitis found by endoscopic retrograde cholangiopancreatography. Gastrointest Endosc 1998; 48: 18-25

133 Gebel M, Stiehl M, Freise J. [Value of sonographic imaging of the pancreatic duct for the diagnosis of chronic pancreatitis and pancreatic cancer compared to ERCP]. Ultraschall in Med 1985; 6: 127-130

$134 \mathrm{Kahl} \mathrm{S,} \mathrm{Glasbrenner} \mathrm{B,} \mathrm{Leodolter} \mathrm{A} \mathrm{et} \mathrm{al.} \mathrm{EUS} \mathrm{in} \mathrm{the} \mathrm{diagnosis} \mathrm{of} \mathrm{early}$ chronic pancreatitis: a prospective follow-up study. Gastrointest Endosc 2002; 55: $507-511$

135 Sarner M, Cotton PB. Classification of pancreatitis. Gut 1984; 25 $756-759$

136 Sai JK, Suyama M, Kubokawa Y et al. Diagnosis of mild chronic pancreatitis (Cambridge classification): comparative study using secretin injection-magnetic resonance cholangiopancreatography and endoscopic retrograde pancreatography. World J Gastroenterol 2008; 14: $1218-1221$

137 Catalano MF, Lahoti S, Geenen JE et al. Prospective evaluation of endoscopic ultrasonography, endoscopic retrograde pancreatography, and secretin test in the diagnosis of chronic pancreatitis. Gastrointest Endosc 1998; 48: 11-17

138 Janssen J, Schlorer E, Greiner L. EUS elastography of the pancreas: feasibility and pattern description of the normal pancreas, chronic pancreatitis, and focal pancreatic lesions. Gastrointest Endosc 2007; 65: 971 978

139 Saftoiu A, Vilmann P, Gorunescu F et al. Neural network analysis of dynamic sequences of EUS elastography used for the differential diagnosis of chronic pancreatitis and pancreatic cancer. Gastrointest Endosc 2008; 68: 1086-1094

140 Iglesias-Garcia J, Larino-Noia J, Abdulkader I et al. Quantitative endoscopic ultrasound elastography: an accurate method for the differentiation of solid pancreatic masses. Gastroenterology 139: 1172 - 1180

141 Dietrich CF, Hirche TO, Ott M et al. Real-time tissue elastography in the diagnosis of autoimmune pancreatitis. Endoscopy 2009; 41: 718 720

142 Bagul A, Siriwardena AK. Evaluation of the Manchester classification system for chronic pancreatitis. JOP 2006; 7: 390-396

143 Buchler MW, Martignoni ME, Friess $H$ et al. A proposal for a new clinical classification of chronic pancreatitis. BMC Gastroenterol 2009; 9: 93

144 Ramesh $\mathrm{H}$. Proposal for a new grading system for chronic pancreatitis: the ABC system. J Clin Gastroenterol 2002; 35: 67-70

145 Schneider A, Lohr JM, Singer MV. The M-ANNHEIM classification of chronic pancreatitis: introduction of a unifying classification system based on a review of previous classifications of the disease. J Gastroenterol 2007; 42: 101 - 119

146 Balthazar EJ, Robinson DL, Megibow AJ et al. Acute pancreatitis: value of CT in establishing prognosis. Radiology 1990; 174: 331 -336 
147 Balthazar EJ, Freeny PC, vanSonnenberg E. Imaging and intervention in acute pancreatitis. Radiology 1994; 193: 297-306

148 Arvanitakis M, Delhaye M, De Maertelaere V et al. Computed tomography and magnetic resonance imaging in the assessment of acute pancreatitis. Gastroenterology 2004; 126: 715-723

149 Rickes S, Uhle C, Kahl S et al. Echo enhanced ultrasound: a new valid initial imaging approach for severe acute pancreatitis. Gut 2006; 55 : $74-78$

150 Brugge WR. Role of endoscopic ultrasound in the diagnosis of cystic lesions of the pancreas. Pancreatology 2001; 1: 637-640

151 Lerch MM, Stier A, Wahnschaffe U et al. Pancreatic pseudocysts: observation, endoscopic drainage, or resection? Dtsch Arztebl Int 2009; 106: 614-621

152 Will U, Mueller A, Topalidis T et al. Value of endoscopic ultrasonography-guided fine needle aspiration (FNA) in the diagnosis of neoplastic tumor(-like) pancreatic lesions in daily clinical practice. Ultraschall in Med 31: 169-174

153 Fritscher-Ravens A, Brand L, Knofel WT et al. Comparison of endoscopic ultrasound-guided fine needle aspiration for focal pancreatic lesions in patients with normal parenchyma and chronic pancreatitis. Am J Gastroenterol 2002; 97: 2768 - 2775

154 Adler G, Seufferlein T. [ZfG 2007: A successful interim result]. Z Gastroenterol 2007; 45: 943

$155 \mathrm{Kim} J K$, Altun E, Elias J Jr et al. Focal pancreatic mass: distinction of pancreatic cancer from chronic pancreatitis using gadolinium-enhanced 3D-gradient-echo MRI. J Magn Reson Imaging 2007; 26 : 313 - 322. DOI: 10.1002/jmri.21010

156 Hocke M, Schmidt C, Zimmer B et al. [Contrast enhanced endosonography for improving differential diagnosis between chronic pancreatitis and pancreatic cancer]. Dtsch Med Wochenschr 2008; 133: 1888 1892. DOI: $10.1055 / \mathrm{s}-0028-1085571$

157 Krishna NB, Mehra M, Reddy AV et al. EUS/EUS-FNA for suspected pancreatic cancer: influence of chronic pancreatitis and clinical presentation with or without obstructive jaundice on performance characteristics. Gastrointest Endosc 2009; 70: 70-79

158 Saftoiu A, Popescu C, Cazacu S et al. Power Doppler endoscopic ultrasonography for the differential diagnosis between pancreatic cancer and pseudotumoral chronic pancreatitis. J Ultrasound Med 2006; 25 : $363-372$

159 Napoleon B, Alvarez-Sanchez MV, Gincoul R et al. Contrast-enhanced harmonic endoscopic ultrasound in solid lesions of the pancreas: results of a pilot study. Endoscopy 42: 564-570

160 Ardengh JC, Paulo GA, Nakao FS et al. Endoscopic ultrasound guided fine-needle aspiration core biopsy: comparison between an automatic biopsy device and two conventional needle systems. Acta Gastroenterol Latinoam 2008; 38: 105 - 115

161 Horwhat JD, Paulson EK, McGrath Ket al. A randomized comparison of EUS-guided FNA versus CT or US-guided FNA for the evaluation of pancreatic mass lesions. Gastrointest Endosc 2006; 63: 966 - 975

162 Chari ST. Diagnosis of autoimmune pancreatitis using its five cardinal features: introducing the Mayo Clinic's HISORt criteria. J Gastroenterol 2007; 42 (Suppl 18): 39-41

163 Choi EK, Kim MH, Kim JC et al. The Japanese diagnostic criteria for autoimmune chronic pancreatitis: is it completely satisfactory? Pancreas 2006 ; 33 : $13-19$

164 Lerch MM, Mayerle J. The benefits of diagnostic ERCP in autoimmune pancreatitis. Gut 60: 565-566

165 Sugumar A, Levy MJ, Kamisawa T et al. Endoscopic retrograde pancreatography criteria to diagnose autoimmune pancreatitis: an international multicentre study. Gut 60: 666-670

166 Hirota M, Takada T, Kawarada Y et al. JPN Guidelines for the management of acute pancreatitis: severity assessment of acute pancreatitis. J Hepatobiliary Pancreat Surg 2006; 13: 33-41

167 Hirota $M$, Takada T, Kitamura $N$ et al. Fundamental and intensive care of acute pancreatitis. J Hepatobiliary Pancreat Sci 17: 45-52

168 Gardner TB, Vege SS, Chari ST et al. Faster rate of initial fluid resuscitation in severe acute pancreatitis diminishes in-hospital mortality. Pancreatology 2009; 9: 770 - 776

$169 \mathrm{Wu} B U$, Johannes RS, Conwell DL et al. Early hemoconcentration predicts increased mortality only among transferred patients with acute pancreatitis. Pancreatology 2009; 9: 639-643

$170 \mathrm{Wu} B U$, Johannes RS, Sun X et al. Early changes in blood urea nitrogen predict mortality in acute pancreatitis. Gastroenterology 2009; 137 : $129-135$
171 Brunkhorst FM, Engel C, Bloos F et al. Intensive insulin therapy and pentastarch resuscitation in severe sepsis. N Engl J Med 2008; 358: $125-139$

172 Lankisch PG, Mahlke R, Blum T et al. Hemoconcentration: an early marker of severe and/or necrotizing pancreatitis? A critical appraisal. Am J Gastroenterol 2001; 96: 2081 -2085

173 Banks PA, Freeman ML. Practice guidelines in acute pancreatitis. Am J Gastroenterol 2006; 101: 2379-2400

174 Field BE, Hepner GW, Shabot MM et al. Nasogastric suction in alcoholic pancreatitis. Dig Dis Sci 1979; 24: 339 - 344

175 Fuller RK, Loveland JP, Frankel MH. An evaluation of the efficacy of nasogastric suction treatment in alcoholic pancreatitis. Am J Gastroenterol 1981; 75: 349 - 353

176 Naeije $R$, Salingret $E$, Clumeck $N$ et al. Is nasogastric suction necessary in acute pancreatitis? Br Med J 1978; 2: 659-660

177 Sarr MG, Sanfey H, Cameron JL. Prospective, randomized trial of nasogastric suction in patients with acute pancreatitis. Surgery 1986; 100: $500-504$

178 Jakobs R, Adamek MU, von Bubnoff AC et al. Buprenorphine or procaine for pain relief in acute pancreatitis. A prospective randomized study. Scand J Gastroenterol 2000; 35: 1319-1323

179 Staritz M. Pharmacology of the sphincter of Oddi. Endoscopy 1988; 20 (Suppl 1): $171-174$

180 Niesel HC, Klimpel L, Kaiser $H$ et al. [Epidural blockade for analgesia and treatment of acute pancreatitis]. Reg Anaesth 1991; 14: 97-100

181 Bernhardt A, Kortgen A, Niesel $H$ et al. [Using epidural anesthesia in patients with acute pancreatitis - prospective study of 121 patients]. Anaesthesiol Reanim 2002; 27: 16-22

182 Thompson DR. Narcotic analgesic effects on the sphincter of Oddi: a review of the data and therapeutic implications in treating pancreatitis. Am J Gastroenterol 2001; 96: 1266-1272

183 Niederau $C$, Niederau $M$, Luthen $R$ et al. Pancreatic exocrine secretion in acute experimental pancreatitis. Gastroenterology 1990; 99: $1120-1127$

184 Eatock FC, Brombacher GD, Steven A et al. Nasogastric feeding in severe acute pancreatitis may be practical and safe. Int J Pancreatol 2000; 28: $23-29$

185 McClave SA, Greene LM, Snider HL et al. Comparison of the safety of early enteral vs parenteral nutrition in mild acute pancreatitis. JPEN J Parenter Enteral Nutr 1997; 21: 14-20

186 Olah A, Belagyi T, Issekutz A et al. Randomized clinical trial of specific lactobacillus and fibre supplement to early enteral nutrition in patients with acute pancreatitis. Br J Surg 2002; 89: 1103-1107

187 Powell JJ, Murchison JT, Fearon KC et al. Randomized controlled trial of the effect of early enteral nutrition on markers of the inflammatory response in predicted severe acute pancreatitis. Br J Surg 2000; 87: $1375-1381$

188 Pupelis G, Selga G, Austrums E et al. Jejunal feeding, even when instituted late, improves outcomes in patients with severe pancreatitis and peritonitis. Nutrition 2001; 17: 91 -94

189 Sax HC, Warner BW, Talamini MA et al. Early total parenteral nutrition in acute pancreatitis: lack of beneficial effects. Am J Surg 1987; 153: $117-124$

190 Windsor AC, Kanwar S, Li AG et al. Compared with parenteral nutrition, enteral feeding attenuates the acute phase response and improves disease severity in acute pancreatitis. Gut 1998; 42: 431 - 435

191 Karamitsios N, Saltzman JR. Enteral nutrition in acute pancreatitis. Nutr Rev 1997; 55: 279-282

192 Petrov MS, Kukosh MV, Emelyanov NV. A randomized controlled trial of enteral versus parenteral feeding in patients with predicted severe acute pancreatitis shows a significant reduction in mortality and in infected pancreatic complications with total enteral nutrition. Dig Surg 2006; 23: 336-344; discussion 344-335

193 Eckerwall GE, Axelsson JB, Andersson RG. Early nasogastric feeding in predicted severe acute pancreatitis: A clinical, randomized study. Ann Surg 2006; 244: 959-965; discussion 965-957

194 Eatock FC, Chong P, Menezes N et al. A randomized study of early nasogastric versus nasojejunal feeding in severe acute pancreatitis. Am J Gastroenterol 2005; 100: 432 - 439

195 Imrie CW, Carter CR, McKay CJ. Enteral and parenteral nutrition in acute pancreatitis. Best Pract Res Clin Gastroenterol 2002; 16: 391 - 397

196 Kumar A, Singh N, Prakash S et al. Early enteral nutrition in severe acute pancreatitis: a prospective randomized controlled trial comparing nasojejunal and nasogastric routes. J Clin Gastroenterol 2006; 40: $431-434$ 
197 Lecleire S, Antonietti M, Ben-Soussan E et al. Nasojejunal feeding in patients with severe acute pancreatitis: comparison of endoscopic and self-migration tube placement. Pancreas 2007; 35: 376 - 378

198 Huber W, Umgelter A, Reindl W et al. Volume assessment in patients with necrotizing pancreatitis: a comparison of intrathoracic blood volume index, central venous pressure, and hematocrit, and their correlation to cardiac index and extravascular lung water index. Crit Care Med 2008; 36: 2348-2354

199 Levy $P$, Heresbach $D$, Pariente EA et al. Frequency and risk factors of recurrent pain during refeeding in patients with acute pancreatitis: a multivariate multicentre prospective study of 116 patients. Gut 1997; 40: $262-266$

200 Petrov MS, van Santvoort HC, Besselink MG et al. Oral refeeding after onset of acute pancreatitis: a review of literature. Am J Gastroenterol 2007; 102: 2079 - 2084; quiz 2085

201 Eckerwall GE, Tingstedt BB, Bergenzaun PE et al. Immediate oral feeding in patients with mild acute pancreatitis is safe and may accelerate recovery - a randomized clinical study. Clin Nutr 2007; 26: $758-763$

202 Teich N, Aghdassi A, Fischer J et al. Optimal timing of oral refeeding in mild acute pancreatitis: results of an open randomized multicenter trial. Pancreas 39: 1088 - 1092

203 Weimann A, Braunert M, Muller T et al. Feasibility and safety of needle catheter jejunostomy for enteral nutrition in surgically treated severe acute pancreatitis. JPEN J Parenter Enteral Nutr 2004; 28: 324 - 327

204 Zhihui T, Wenkui Y, Weiqin L et al. A randomised clinical trial of transnasal endoscopy versus fluoroscopy for the placement of nasojejunal feeding tubes in patients with severe acute pancreatitis. Postgrad Med J 2009; 85: 59-63

205 Sahin H, Mercanligil SM, Inanc $N$ et al. Effects of glutamine-enriched total parenteral nutrition on acute pancreatitis. Eur J Clin Nutr 2007; 61: $1429-1434$

206 Fuentes-Orozco C, Cervantes-Guevara G, Mucino-Hernandez I et al. Lalanyl-L-glutamine-supplemented parenteral nutrition decreases infectious morbidity rate in patients with severe acute pancreatitis. JPEN J Parenter Enteral Nutr 2008; 32: 403 - 411

207 Wang X, Li W, Zhang F et al. Fish oil-supplemented parenteral nutrition in severe acute pancreatitis patients and effects on immune function and infectious risk: a randomized controlled trial. Inflammation 2009; 32: $304-309$

208 Petrov MS, Loveday BP, Pylypchuk RD et al. Systematic review and meta-analysis of enteral nutrition formulations in acute pancreatitis. Br J Surg 2009; 96: 1243 - 1252

209 Dellinger EP, Tellado JM, Soto NE et al. Early antibiotic treatment for severe acute necrotizing pancreatitis: a randomized, double-blind, placebo-controlled study. Ann Surg 2007; 245: 674-683

210 Xu T, Cai Q. Prophylactic antibiotic treatment in acute necrotizing pancreatitis: results from a meta-analysis. Scand J Gastroenterol 2008; 43: $1249-1258$

211 Villatoro E, Mulla M, Larvin M. Antibiotic therapy for prophylaxis against infection of pancreatic necrosis in acute pancreatitis. Cochrane Database Syst Rev CD002941

212 Hart PA, Bechtold ML, Marshall JB et al. Prophylactic antibiotics in necrotizing pancreatitis: a meta-analysis. South Med J 2008; 101: $1126-1131$

213 Xue P, Deng LH, Zhang ZD et al. Effect of antibiotic prophylaxis on acute necrotizing pancreatitis: results of a randomized controlled trial. J Gastroenterol Hepatol 2009; 24: 736-742

214 Isenmann $R$, Runzi M, Kron $M$ et al. Prophylactic antibiotic treatment in patients with predicted severe acute pancreatitis: a placebo-controlled, double-blind trial. Gastroenterology 2004; 126: 997-1004

215 Rokke O, Harbitz TB, Liljedal J et al. Early treatment of severe pancreatitis with imipenem: a prospective randomized clinical trial. Scand J Gastroenterol 2007; 42: 771 - 776

216 de Vries AC, Besselink MG, Buskens E et al. Randomized controlled trials of antibiotic prophylaxis in severe acute pancreatitis: relationship between methodological quality and outcome. Pancreatology 2007; 7: $531-538$

217 Olah A, Belagyi T, Issekutz A et al. [Combination of early nasojejunal feeding with modern synbiotic therapy in the treatment of severe acute pancreatitis (prospective, randomized, double-blind study)] Magy Seb 2005; 58: $173-178$

218 Besselink MG, van Santvoort HC, Buskens E et al. Probiotic prophylaxis in predicted severe acute pancreatitis: a randomised, double-blind, placebo-controlled trial. Lancet 2008; 371: 651 -659
219 Sand J, Nordback I. Probiotics in severe acute pancreatitis. Lancet 2008; 371: 634-635

220 Zhang MM, Cheng JQ Lu YR et al. Use of pre-, pro- and synbiotics in patients with acute pancreatitis: a meta-analysis. World J Gastroenterol 16: 3970 - 3978

221 Besselink MG, van Santvoort HC, Boermeester MA et al. Timing and impact of infections in acute pancreatitis. Br J Surg 2009; 96: 267 - 273

222 Sharma M, Banerjee D, Garg PK. Characterization of newer subgroups of fulminant and subfulminant pancreatitis associated with a high early mortality. Am J Gastroenterol 2007; 102: 2688-2695

223 Nieuwenhuijs VB, Besselink MG, van Minnen LP et al. Surgical management of acute necrotizing pancreatitis: a 13-year experience and a systematic review. Scand J Gastroenterol Suppl 2003; 239: 111 - 116

224 Connor S, Alexakis N, Raraty MG et al. Early and late complications after pancreatic necrosectomy. Surgery 2005; 137: 499-505

225 Mier J, Leon EL, Castillo A et al. Early versus late necrosectomy in severe necrotizing pancreatitis. Am J Surg 1997; 173: 71 - 75

226 Runzi M, Niebel W, Goebell $H$ et al. Severe acute pancreatitis: nonsurgical treatment of infected necroses. Pancreas 2005; 30: 195-199

227 Shankar S, vanSonnenberg E, Silverman SG et al. Imaging and percutaneous management of acute complicated pancreatitis. Cardiovasc Intervent Radiol 2004; 27: $567-580$

228 Werner J, Feuerbach S, Uhl W et al. Management of acute pancreatitis: from surgery to interventional intensive care. Gut 2005; 54: 426 436

229 van Santvoort HC, Besselink MG, Bakker OJ et al. A step-up approach or open necrosectomy for necrotizing pancreatitis. N Engl J Med 362: $1491-1502$

230 Raczynski S, Teich N, Borte G et al. Percutaneous transgastric irrigation drainage in combination with endoscopic necrosectomy in necrotizing pancreatitis (with videos). Gastrointest Endosc 2006; 64: 420-424

231 Seewald S, Groth S, Omar S et al. Aggressive endoscopic therapy for pancreatic necrosis and pancreatic abscess: a new safe and effective treatment algorithm (videos). Gastrointest Endosc 2005; 62: 92 - 100

232 Seifert H, Wehrmann T, Schmitt T et al. Retroperitoneal endoscopic debridement for infected peripancreatic necrosis. Lancet 2000; 356: $653-655$

233 Hocke $M$, Will $U$, Gottschalk $P$ et al. Transgastral retroperitoneal endoscopy in septic patients with pancreatic necrosis or infected pancreatic pseudocysts. Z Gastroenterol 2008; 46: 1363 -1368

234 Niederau C, Hippenstiel J. Conservative management of acute pancreatitis: complications and outcome in a community-based hospital. Pancreas 2006; 32: $67-79$

235 Ramesh H, Prakash K, Lekha V et al. Are some cases of infected pancreatic necrosis treatable without intervention? Dig Surg 2003; 20: 296-299; discussion 300

236 Besselink MG, van Santvoort HC, Nieuwenhuijs VB et al. Minimally invasive 'step-up approach' versus maximal necrosectomy in patients with acute necrotising pancreatitis (PANTER trial): design and rationale of a randomised controlled multicenter trial [ISRCTN38327949]. BMC Surg 2006; 6: 6

237 Besselink MG, van Santvoort HC, Schaapherder AF et al. Feasibility of minimally invasive approaches in patients with infected necrotizing pancreatitis. Br J Surg 2007; 94: 604-608

238 Besselink MG, van Santvoort HC, Witteman BJ et al. Management of severe acute pancreatitis: it's all about timing. Curr Opin Crit Care 2007; 13: $200-206$

239 van Santvoort HC, Besselink MG, Bollen TL et al. Case-matched comparison of the retroperitoneal approach with laparotomy for necrotizing pancreatitis. World J Surg 2007; 31: 1635-1642

240 van Santvoort HC, Besselink MG, Horvath KD et al. Videoscopic assisted retroperitoneal debridement in infected necrotizing pancreatitis. HPB (Oxford) 2007; 9: 156-159

241 Seifert H, Biermer M, Schmitt W et al. Transluminal endoscopic necrosectomy after acute pancreatitis: a multicentre study with long-term follow-up (the GEPARD Study). Gut 2009; 58: 1260-1266

242 Chauhan S, Forsmark CE. Pain management in chronic pancreatitis: A treatment algorithm. Best Pract Res Clin Gastroenterol 24: 323 - 335

243 Dite $P$, Ruzicka M, Zboril V et al. A prospective, randomized trial comparing endoscopic and surgical therapy for chronic pancreatitis. Endoscopy 2003; 35: $553-558$

244 Cahen DL, Gouma DJ, Nio Y et al. Endoscopic versus surgical drainage of the pancreatic duct in chronic pancreatitis. N Engl J Med 2007; 356: $676-684$ 
245 Neoptolemos JP, Stocken DD, Bassi C et al. Adjuvant chemotherapy with fluorouracil plus folinic acid vs gemcitabine following pancreatic cancer resection: a randomized controlled trial. JAMA 304: 1073 1081

246 Burris HA 3rd, Moore MJ, Andersen J et al. Improvements in survival and clinical benefit with gemcitabine as first-line therapy for patients with advanced pancreas cancer: a randomized trial. J Clin Oncol 1997; 15: $2403-2413$

247 Izbicki JR, Yekebas EF, Strate T et al. Extrahepatic portal hypertension in chronic pancreatitis: an old problem revisited. Ann Surg 2002; 236: $82-89$

248 Beger HG, Schlosser W, Friess HM et al. Duodenum-preserving head resection in chronic pancreatitis changes the natural course of the disease: a single-center 26-year experience. Ann Surg 1999; 230: 512 - 519; discussion 519-523

249 Vijungco JD, Prinz RA. Management of biliary and duodenal complications of chronic pancreatitis. World J Surg 2003; 27: 1258 - 1270

250 Cahen DL, van Berkel AM, Oskam D et al. Long-term results of endoscopic drainage of common bile duct strictures in chronic pancreatitis. Eur J Gastroenterol Hepatol 2005; 17: 103 -108

251 Kahl S, Zimmermann S, Genz I et al. Risk factors for failure of endoscopic stenting of biliary strictures in chronic pancreatitis: a prospective follow-up study. Am J Gastroenterol 2003; 98: 2448 - 2453

252 Smith MT, Sherman S, Ikenberry SO et al. Alterations in pancreatic ductal morphology following polyethylene pancreatic stent therapy. Gastrointest Endosc 1996; 44: 268-275

253 Kozarek RA. Pancreatic stents can induce ductal changes consistent with chronic pancreatitis. Gastrointest Endosc 1990; 36: 93 - 95

254 Nguyen-Tang T, Dumonceau JM. Endoscopic treatment in chronic pancreatitis, timing, duration and type of intervention. Best Pract Res Clin Gastroenterol 24: 281 - 298

255 Barthet M, Bugallo M, Moreira LS et al. Management of cysts and pseudocysts complicating chronic pancreatitis. A retrospective study of 143 patients. Gastroenterol Clin Biol 1993; 17: 270-276

256 Andren-Sandberg A, Dervenis C. Surgical treatment of pancreatic pseudocysts in the 2000's - laparoscopic approach. Acta Chir Iugosl 2003: 50: $21-26$

257 Traverso LW, Tompkins RK, Urrea PT et al. Surgical treatment of chronic pancreatitis. Twenty-two years' experience. Ann Surg 1979; 190: $312-319$

258 Usatoff $V$, Brancatisano $R$, Williamson $R C$. Operative treatment of pseudocysts in patients with chronic pancreatitis. Br J Surg 2000; 87: $1494-1499$

259 Nealon WH, Walser E. Duct drainage alone is sufficient in the operative management of pancreatic pseudocyst in patients with chronic pancreatitis. Ann Surg 2003; 237: 614-620; discussion 620-612

260 Cheruvu CV, Clarke MG, Prentice M et al. Conservative treatment as an option in the management of pancreatic pseudocyst. Ann R Coll Surg Engl 2003; 85: $313-316$

261 Bartoli E, Delcenserie R, Yzet T et al. Endoscopic treatment of chronic pancreatitis. Gastroenterol Clin Biol 2005; 29: 515 - 521

262 Johnson MD, Walsh RM, Henderson JM et al. Surgical versus nonsurgical management of pancreatic pseudocysts. J Clin Gastroenterol 2009; 43: $586-590$

263 Aghdassi A, Mayerle J, Kraft $M$ et al. Diagnosis and treatment of pancreatic pseudocysts in chronic pancreatitis. Pancreas 2008; 36: 105 112

264 NIH state-of-the-science statement on endoscopic retrograde cholangiopancreatography (ERCP) for diagnosis and therapy. NIH Consens State Sci Statements 2002; 19: 1 -26

265 Barthet M, Lamblin G, Gasmi M et al. Clinical usefulness of a treatment algorithm for pancreatic pseudocysts. Gastrointest Endosc 2008; 67: $245-252$

266 Gouyon B, Levy P, Ruszniewski P et al. Predictive factors in the outcome of pseudocysts complicating alcoholic chronic pancreatitis. Gut 1997; 41: 821 - 825

267 Bradley EL, Clements JL Jr, Gonzalez AC. The natural history of pancreatic pseudocysts: a unified concept of management. Am J Surg 1979; 137: $135-141$

268 Varadarajulu S, Christein JD, Tamhane A et al. Prospective randomized trial comparing EUS and EGD for transmural drainage of pancreatic pseudocysts (with videos). Gastrointest Endosc 2008; 68: 1102 1111

269 Tanaka $M$, Chari S, Adsay $V$ et al. International consensus guidelines for management of intraductal papillary mucinous neoplasms and mucinous cystic neoplasms of the pancreas. Pancreatology 2006; 6: $17-32$

270 Brugge WR, Lewandrowski K, Lee-Lewandrowski E et al. Diagnosis of pancreatic cystic neoplasms: a report of the cooperative pancreatic cyst study. Gastroenterology 2004; 126: 1330-1336

271 Spinelli KS, Fromwiller TE, Daniel RA et al. Cystic pancreatic neoplasms: observe or operate. Ann Surg 2004; 239: 651 -657; discussion 657-659

272 Grutzmann $R$, Niedergethmann $M$, Pilarsky $C$ et al. Intraductal papillary mucinous tumors of the pancreas: biology, diagnosis, and treatment. Oncologist 15: $1294-1309$

273 Megibow AJ, Baker ME, Gore RM et al. The incidental pancreatic cyst. Radiol Clin North Am 49: 349 - 359

274 Werner J, Bartosch HRA, Andersson R. Cystic pancreatic lesions: Current evidence for diagnosis and treatment. Scand J Gastroenterol 2011; 46: $773-788$

275 Barthet M, Sahel J, Bodiou-Bertei C et al. Endoscopic transpapillary drainage of pancreatic pseudocysts. Gastrointest Endosc 1995; 42: $208-213$

276 Udd M, Leppaniemi AK, Bidel S et al. Treatment of bleeding pseudoaneurysms in patients with chronic pancreatitis. World J Surg 2007; 31: $504-510$

277 Widdison AL, Alvarez C, Karanjia ND et al. Experimental evidence of beneficial effects of ductal decompression in chronic pancreatitis. Endoscopy $1991 ; 23: 151-154$

278 Treacy PJ, Worthley CS. Pancreatic stents in the management of chronic pancreatitis. Aust N Z J Surg 1996; 66: 210-213

279 Rosch T, Daniel S, Scholz M et al. Endoscopic treatment of chronic pancreatitis: a multicenter study of 1000 patients with long-term followup. Endoscopy 2002; 34: 765-771

280 Cremer M, Deviere J, Delhaye $M$ et al. Stenting in severe chronic pancreatitis: results of medium-term follow-up in seventy-six patients. Endoscopy 1991; 23: 171 - 176

281 McCarthy J, Geenen JE, Hogan WJ. Preliminary experience with endoscopic stent placement in benign pancreatic diseases. Gastrointest Endosc 1988; 34: 16-18

282 Binmoeller KF, Jue P, Seifert H et al. Endoscopic pancreatic stent drainage in chronic pancreatitis and a dominant stricture: long-term results. Endoscopy 1995; 27: 638-644

283 Huibregtse K, Schneider B, Vrij AA et al. Endoscopic pancreatic drainage in chronic pancreatitis. Gastrointest Endosc 1988; 34: 9-15

284 Kozarek RA. Endoscopic treatment of chronic pancreatitis. Indian J Gastroenterol 2002; 21: 67-73

285 Kozarek RA, Ball TJ, Patterson DJ et al. Endoscopic transpapillary therapy for disrupted pancreatic duct and peripancreatic fluid collections. Gastroenterology 1991; 100: 1362-1370

286 Kozarek RA, Patterson DJ, Ball TJ et al. Endoscopic placement of pancreatic stents and drains in the management of pancreatitis. Ann Surg 1989; 209: 261 - 266

287 Kozarek RA, Traverso LW. Endotherapy for chronic pancreatitis. Int J Pancreatol 1996; 19: 93-102

288 Ponchon T, Bory RM, Hedelius F et al. Endoscopic stenting for pain relief in chronic pancreatitis: results of a standardized protocol. Gastrointest Endosc 1995; 42: 452-456

289 Smits ME, Rauws EA, van Gulik TM et al. Long-term results of endoscopic stenting and surgical drainage for biliary stricture due to chronic pancreatitis. Br J Surg 1996; 83: $764-768$

290 Boerma D, van Gulik TM, Rauws EA et al. Outcome of pancreaticojejunostomy after previous endoscopic stenting in patients with chronic pancreatitis. Eur J Surg 2002; 168: 223 -228

291 Sauer B, Talreja J, Ellen K et al. Temporary placement of a fully covered self-expandable metal stent in the pancreatic duct for management of symptomatic refractory chronic pancreatitis: preliminary data (with videos). Gastrointest Endosc 2008; 68: 1173-1178

292 Kahl S, Zimmermann S, Glasbrenner B et al. Treatment of benign biliary strictures in chronic pancreatitis by self-expandable metal stents. Dig Dis 2002; 20: 199-203

293 Guda NM, Partington S, Freeman ML. Extracorporeal shock wave lithotripsy in the management of chronic calcific pancreatitis: a meta-analysis. JOP 2005; 6: 6-12

294 Schneider HT, May A, Benninger J et al. Piezoelectric shock wave lithotripsy of pancreatic duct stones. Am J Gastroenterol 1994; 89: 2042 2048

295 Dumonceau JM, Costamagna G, Tringali A et al. Treatment for painful calcified chronic pancreatitis: extracorporeal shock wave lithotripsy 
versus endoscopic treatment: a randomised controlled trial. Gut 2007; 56: $545-552$

296 Adamek HE, Jakobs R, Buttmann A et al. Long term follow up of patients with chronic pancreatitis and pancreatic stones treated with extracorporeal shock wave lithotripsy. Gut 1999; 45: 402 - 405

297 Brand B, Kahl M, Sidhu S et al. Prospective evaluation of morphology, function, and quality of life after extracorporeal shockwave lithotripsy and endoscopic treatment of chronic calcific pancreatitis. Am J Gastroenterol 2000; 95: 3428-3438

298 Barrioz T, Ingrand P, Besson I et al. Randomised trial of prevention of biliary stent occlusion by ursodeoxycholic acid plus norfloxacin. Lancet $1994 ; 344: 581-582$

299 Ghosh S, Palmer KR. Prevention of biliary stent occlusion using cyclical antibiotics and ursodeoxycholic acid. Gut 1994; 35: 1757-1759

300 Ghosh S, Palmer KR. Preventing biliary stent occlusion. Lancet 1994; 344: 1087 -1088; author reply 1088-1089

301 Groen AK, Out T, Huibregtse Ket al. Characterization of the content of occluded biliary endoprostheses. Endoscopy 1987; 19: 57-59

302 Smit JM, Out MM, Groen AK et al. A placebo-controlled study on the efficacy of aspirin and doxycycline in preventing clogging of biliary endoprostheses. Gastrointest Endosc 1989; 35: 485 - 489

303 Mayerle J, Stier A, Lerch MM et al. [Chronic pancreatitis. Diagnosis and treatment]. Chirurg 2004; 75: 731 - 747; quiz 748

304 Catalano MF, Linder JD, George S et al. Treatment of symptomatic distal common bile duct stenosis secondary to chronic pancreatitis: comparison of single vs. multiple simultaneous stents. Gastrointest Endosc 2004; 60: 945 - 952

305 van Boeckel PG, Vleggaar FP, Siersema PD. Plastic or metal stents for benign extrahepatic biliary strictures: a systematic review. BMC Gastroenterol 2009; 9: 96

306 Behm B, Brock A, Clarke BW et al. Partially covered self-expandable metallic stents for benign biliary strictures due to chronic pancreatitis. Endoscopy 2009; 41: 547 - 551

307 Wilcox CM, Varadarajulu S. Endoscopic therapy for chronic pancreatitis: an evidence-based review. Curr Gastroenterol Rep 2006; 8: 104 110

308 Smits ME, Rauws EA, Tytgat GN et al. Endoscopic treatment of pancreatic stones in patients with chronic pancreatitis. Gastrointest Endosc 1996: $43: 556-560$

309 Cahen D, Rauws E, Fockens $P$ et al. Endoscopic drainage of pancreatic pseudocysts: long-term outcome and procedural factors associated with safe and successful treatment. Endoscopy 2005; 37: 977 - 983

310 Farnbacher MJ, Rabenstein T, Ell C et al. Is endoscopic drainage of common bile duct stenoses in chronic pancreatitis up-to-date? Am J Gastroenterol 2000; 95: 1466-1471

311 Lawrence C, Romagnuolo J, Payne KM et al. Low symptomatic premature stent occlusion of multiple plastic stents for benign biliary strictures: comparing standard and prolonged stent change intervals. Gastrointest Endosc 72: 558-563

312 McClaine RJ, Lowy AM, Matthews JB et al. A comparison of pancreaticoduodenectomy and duodenum-preserving head resection for the treatment of chronic pancreatitis. HPB (Oxford) 2009; 11: 677-683

313 Muller MW, Friess H, Martin DJ et al. Long-term follow-up of a randomized clinical trial comparing Beger with pylorus-preserving Whipple procedure for chronic pancreatitis. Br J Surg 2008; 95: $350-356$

314 Riediger $H$, Adam U, Fischer $E$ et al. Long-term outcome after resection for chronic pancreatitis in 224 patients. J Gastrointest Surg 2007; 11 : 949-959; discussion 959-960

315 van der Gaag NA, Rauws EA, van Eijck $\mathrm{CH}$ et al. Preoperative biliary drainage for cancer of the head of the pancreas. N Engl J Med 2010; 362: $129-137$

316 Mullady DK, Yadav D, Amann ST et al. Type of pain, pain-associated complications, quality of life, disability and resource utilisation in chronic pancreatitis: a prospective cohort study. Gut 60: 77-84

317 Bloechle C, Izbicki JR, Knoefel WT et al. Quality of life in chronic pancreatitis - results after duodenum-preserving resection of the head of the pancreas. Pancreas 1995; 11: $77-85$

318 Pezzilli R, Fantini L, Calculli L et al. The quality of life in chronic pancreatitis: the clinical point of view. JOP 2006; 7: 113-116

319 Delcore R, Rodriguez FJ, Thomas JH et al. The role of pancreatojejunostomy in patients without dilated pancreatic ducts. Am J Surg 1994; 168: 598-601; discussion 601-592
320 Malfertheiner P, Mayer D, Buchler M et al. Treatment of pain in chronic pancreatitis by inhibition of pancreatic secretion with octreotide. Gut 1995; 36 : $450-454$

321 Lieb JG 2nd, Shuster JJ, Theriaque D et al. A pilot study of Octreotide LAR vs. octreotide tid for pain and quality of life in chronic pancreatitis. JOP 2009; 10: $518-522$

322 Shafiq N, Rana S, Bhasin D et al. Pancreatic enzymes for chronic pancreatitis. Cochrane Database Syst Rev 2009,:CD006302

323 Whitcomb DC, Lehman GA, Vasileva G et al. Pancrelipase delayed-release capsules (CREON) for exocrine pancreatic insufficiency due to chronic pancreatitis or pancreatic surgery: A double-blind randomized trial. Am J Gastroenterol 2010; 105: 2276-2286

324 Uden S, Bilton D, Nathan L et al. Antioxidant therapy for recurrent pancreatitis: placebo-controlled trial. Aliment Pharmacol Ther 1990; 4: $357-371$

325 Kirk GR, White JS, McKie L et al. Combined antioxidant therapy reduces pain and improves quality of life in chronic pancreatitis. J Gastrointest Surg 2006; 10: 499 - 503

326 Bhardwaj P, Garg PK, Maulik SK et al. A randomized controlled trial of antioxidant supplementation for pain relief in patients with chronic pancreatitis. Gastroenterology 2009; 136: 149 - 159, e142

327 Omenn GS, Goodman GE, Thornquist MD et al. Effects of a combination of beta carotene and vitamin A on lung cancer and cardiovascular disease. N Engl J Med 1996; 334: 1150-1155

328 The effect of vitamin $\mathrm{E}$ and beta carotene on the incidence of lung cancer and other cancers in male smokers. The Alpha-Tocopherol Beta Carotene Cancer Prevention Study Group. N Engl J Med 1994; 330: 1029-1035

329 Ballegaard S, Christophersen SJ, Dawids SG et al. Acupuncture and transcutaneous electric nerve stimulation in the treatment of pain associated with chronic pancreatitis. A randomized study. Scand J Gastroenterol 1985; 20: 1249-1254

330 Cartmell MT, O'Reilly DA, Porter C et al. A double-blind placebo-controlled trial of a leukotriene receptor antagonist in chronic pancreatitis in humans. J Hepatobiliary Pancreat Surg 2004; 11: 255 - 259

331 Guarner L, Navalpotro B, Molero X et al. Management of painful chronic pancreatitis with single-dose radiotherapy. Am J Gastroenterol 2009; 104: 349-355

332 Kaufman M, Singh G, Das $S$ et al. Efficacy of endoscopic ultrasoundguided celiac plexus block and celiac plexus neurolysis for managing abdominal pain associated with chronic pancreatitis and pancreatic cancer. J Clin Gastroenterol 2010; 44: 127-134

333 Puli SR, Reddy JB, Bechtold ML et al. EUS-guided celiac plexus neurolysis for pain due to chronic pancreatitis or pancreatic cancer pain: a meta-analysis and systematic review. Dig Dis Sci 2009; 54: 2330 2337

334 Howard TJ, Swofford JB, Wagner DL et al. Quality of life after bilateral thoracoscopic splanchnicectomy: long-term evaluation in patients with chronic pancreatitis. J Gastrointest Surg 2002; 6: 845-852; discussion 853-844

335 Stefaniak T, Vingerhoets A, Makarewicz W et al. Opioid use determines success of videothoracoscopic splanchnicectomy in chronic pancreatic pain patients. Langenbecks Arch Surg 2008; 393: 213 - 218

336 Gress F, Schmitt C, Sherman S et al. A prospective randomized comparison of endoscopic ultrasound- and computed tomography-guided celiac plexus block for managing chronic pancreatitis pain. Am J Gastroenterol 1999; 94: 900 -905

337 LeBlanc JK, DeWitt J, Johnson C et al. A prospective randomized trial of 1 versus 2 injections during EUS-guided celiac plexus block for chronic pancreatitis pain. Gastrointest Endosc 2009; 69: 835-842

338 Madsen P, Hansen E. Coeliac plexus block versus pancreaticogastrostomy for pain in chronic pancreatitis. A controlled randomized trial. Scand J Gastroenterol 1985; 20: 1217-1220

339 Santosh D, Lakhtakia S, Gupta R et al. Clinical trial: a randomized trial comparing fluoroscopy guided percutaneous technique vs. endoscopic ultrasound guided technique of coeliac plexus block for treatment of pain in chronic pancreatitis. Aliment Pharmacol Ther 2009; 29: 979-984

340 Sahai AV, Lemelin V, Lam E et al. Central vs. bilateral endoscopic ultrasound-guided celiac plexus block or neurolysis: a comparative study of short-term effectiveness. Am J Gastroenterol 2009; 104: 326 - 329

341 Deviere J, Bell RH Jr, Beger HG et al. Treatment of chronic pancreatitis with endotherapy or surgery: critical review of randomized control trials. J Gastrointest Surg 2008; 12: 640-644 
342 Regan PT, Malagelada JR, DiMagno EP et al. Comparative effects of antacids, cimetidine and enteric coating on the therapeutic response to oral enzymes in severe pancreatic insufficiency. N Engl J Med 1977; 297: $854-858$

343 Layer P, von der Ohe MR, Holst JJ et al. Altered postprandial motility in chronic pancreatitis: role of malabsorption. Gastroenterology 1997; 112: $1624-1634$

344 Wooldridge JL, Heubi JE, Amaro-Galvez R et al. EUR-1008 pancreatic enzyme replacement is safe and effective in patients with cystic fibrosis and pancreatic insufficiency. J Cyst Fibros 2009; 8: 405-417

345 Layer P, Yamamoto $H$, Kalthoff $L$ et al. The different courses of earlyand late-onset idiopathic and alcoholic chronic pancreatitis. Gastroenterology 1994; 107: 1481 - 1487

346 Czako L, Takacs T, Hegyi P et al. Quality of life assessment after pancreatic enzyme replacement therapy in chronic pancreatitis. Can J Gastroenterol 2003; 17: 597-603

347 Dominguez-Munoz JE, Iglesias-Garcia J, Vilarino-Insua M et al. 13Cmixed triglyceride breath test to assess oral enzyme substitution therapy in patients with chronic pancreatitis. Clin Gastroenterol Hepatol 2007; 5: 484-488

348 Dominguez-Munoz JE, Iglesias-Garcia J. Oral pancreatic enzyme substitution therapy in chronic pancreatitis: is clinical response an appropriate marker for evaluation of therapeutic efficacy? JOP 2010; 11: $158-162$

349 Ritz MA, Fraser RJ, Di Matteo AC et al. Evaluation of the 13C-triolein breath test for fat malabsorption in adult patients with cystic fibrosis. J Gastroenterol Hepatol 2004; 19: 448-453

350 Dominguez-Munoz JE, Iglesias-Garcia J, Iglesias-Rey $M$ et al. Effect of the administration schedule on the therapeutic efficacy of oral pancreatic enzyme supplements in patients with exocrine pancreatic insufficiency: a randomized, three-way crossover study. Aliment Pharmacol Ther 2005; 21: $993-1000$

351 Heizer WD, Cleaveland CR, Iber FL. Gastric Inactivation of Pancreatic Supplements. Bull Johns Hopkins Hosp 1965; 116: 261 - 270

352 Delchier JC, Vidon N, Saint-Marc Girardin MF et al. Fate of orally ingested enzymes in pancreatic insufficiency: comparison of two pancreatic enzyme preparations. Aliment Pharmacol Ther 1991; 5: 365378

353 Meyer JH, Elashoff J, Porter-Fink $V$ et al. Human postprandial gastric emptying of 1-3-millimeter spheres. Gastroenterology 1988; 94: $1315-1325$

354 Borowitz D, Goss CH, Limauro S et al. Study of a novel pancreatic enzyme replacement therapy in pancreatic insufficient subjects with cystic fibrosis. J Pediatr 2006; 149: 658 - 662

355 Bruno MJ, Rauws EA, Hoek FJ et al. Comparative effects of adjuvant cimetidine and omeprazole during pancreatic enzyme replacement therapy. Dig Dis Sci 1994; 39: 988-992

356 Bruno MJ, Borm JJ, Hoek FJ et al. Comparative effects of enteric-coated pancreatin microsphere therapy after conventional and pylorus-preserving pancreatoduodenectomy. Br J Surg 1997; 84: 952-956

357 Durie PR, Bell L, Linton W et al. Effect of cimetidine and sodium bicarbonate on pancreatic replacement therapy in cystic fibrosis. Gut 1980; $21: 778-786$

358 Lankisch PG, Lembcke B, Kirchhoff S et al. [Therapy of pancreatogenic steatorrhea. Comparison of 2 acid-protected enzyme preparations]. Dtsch Med Wochenschr 1988; 113: 15-17

359 Carroccio A, Pardo F, Montalto G et al. Use of famotidine in severe exocrine pancreatic insufficiency with persistent maldigestion on enzymatic replacement therapy. A long-term study in cystic fibrosis. Dig Dis Sci 1992; 37: 1441 - 1446

360 Keller J, Layer P. Human pancreatic exocrine response to nutrients in health and disease. Gut 2005; 54 (Suppl 6): vi1 - vi28

361 Casellas F, Guarner L, Vaquero E et al. Hydrogen breath test with glucose in exocrine pancreatic insufficiency. Pancreas 1998; 16: 481 486

362 Smyth RL, Ashby D, O'Hea $U$ et al. Fibrosing colonopathy in cystic fibrosis: results of a case-control study. Lancet 1995; 346: 1247-1251

363 Serban DE, Florescu P, Miu N. Fibrosing colonopathy revealing cystic fibrosis in a neonate before any pancreatic enzyme supplementation. J Pediatr Gastroenterol Nutr 2002; 35: 356 - 359

364 Taylor CJ. Fibrosing colonopathy unrelated to pancreatic enzyme supplementation. J Pediatr Gastroenterol Nutr 2002; 35: 268 - 269

365 Waters BL. Cystic fibrosis with fibrosing colonopathy in the absence of pancreatic enzymes. Pediatr Dev Pathol 1998; 1: 74-78
366 Connett GJ, Lucas JS, Atchley JT et al. Colonic wall thickening is related to age and not dose of high strength pancreatin microspheres in children with cystic fibrosis. Eur J Gastroenterol Hepatol 1999; 11: 181 183

367 O'Keefe SJ, Cariem AK, Levy M. The exacerbation of pancreatic endocrine dysfunction by potent pancreatic exocrine supplements in patients with chronic. pancreatitis. J Clin Gastroenterol 2001; 32: $319-323$

368 Nojgaard C. Prognosis of acute and chronic pancreatitis - a 30-year follow-up of a Danish cohort. Dan Med Bull 2010; 57: B4228

369 Hebuterne X, Hastier P, Peroux JL et al. Resting energy expenditure in patients with alcoholic chronic pancreatitis. Dig Dis Sci 1996; 41: $533-539$

370 Suzuki A, Mizumoto A, Sarr MG et al. Bacterial lipase and high-fat diets in canine exocrine pancreatic insufficiency: a new therapy of steatorrhea? Gastroenterology 1997; 112: 2048-2055

371 Caliari S, Benini L, Sembenini C et al. Medium-chain triglyceride absorption in patients with pancreatic insufficiency. Scand J Gastroenterol 1996; 31: 90 - 94

372 Gullo L, Barbara L, Labo G. Effect of cessation of alcohol use on the course of pancreatic dysfunction in alcoholic pancreatitis. Gastroenterology 1988; 95: 1063-1068

373 Marotta F, Labadarios D, Frazer L et al. Fat-soluble vitamin concentration in chronic alcohol-induced pancreatitis. Relationship with steatorrhea. Dig Dis Sci 1994; 39: 993 - 998

374 American Gastroenterological Association Medical Position Statement: treatment of pain in chronic pancreatitis. Gastroenterology 1998; 115: $763-764$

375 Birkmeyer JD, Siewers AE, Finlayson EV et al. Hospital volume and surgical mortality in the United States. N Engl J Med 2002; 346: 1128 1137

376 Fong $Y$, Gonen M, Rubin D et al. Long-term survival is superior after resection for cancer in high-volume centers. Ann Surg 2005; 242: 540-544; discussion 544-547

377 Belina F, Fronek J, Ryska M. Duodenopancreatectomy versus duodenum-preserving pancreatic head excision for chronic pancreatitis. Pancreatology 2005; 5: 547-552

378 Witzigmann H, Max D, Uhlmann D et al. Quality of life in chronic pancreatitis: a prospective trial comparing classical whipple procedure and duodenum-preserving pancreatic head resection. J Gastrointest Surg 2002; 6: 173 - 179; discussion 179-180

379 Hartwig $W$, Hackert T, Hinz $U$ et al. Pancreatic cancer surgery in the new millennium: better prediction of outcome. Ann Surg 2011; 254: $311-319$

380 Strobel O, Buchler MW, Werner J. [Duodenum-preserving pancreatic head resection: technique according to Beger, technique according to Frey and Berne modifications]. Chirurg 2009; 80: $22-27$

381 Witzigmann H, Max D, Uhlmann D et al. Outcome after duodenumpreserving pancreatic head resection is improved compared with classic Whipple procedure in the treatment of chronic pancreatitis. Surgery 2003; 134: 53-62

382 Mobius C, Max D, Uhlmann D et al. Five-year follow-up of a prospective non-randomised study comparing duodenum-preserving pancreatic head resection with classic Whipple procedure in the treatment of chronic pancreatitis. Langenbecks Arch Surg 2007; 392: 359-364

383 Izbicki JR, Bloechle C, Knoefel WT et al. [Drainage versus resection in surgical therapy of chronic pancreatitis of the head of the pancreas: a randomized study]. Chirurg 1997; 68: 369-377

384 Diener MK, Bruckner T, Contin P et al. ChroPac-trial: duodenum-preserving pancreatic head resection versus pancreatoduodenectomy for chronic pancreatitis. Trial protocol of a randomised controlled multicentre trial. Trials 11: 47

385 Diener MK, Knaebel HP, Witte ST et al. DISPACT trial: a randomized controlled trial to compare two different surgical techniques of DIStal PAnCreaTectomy - study rationale and design. Clin Trials 2008; 5 : 534-545

386 Diener MK, Rahbari NN, Fischer L et al. Duodenum-preserving pancreatic head resection versus pancreatoduodenectomy for surgical treatment of chronic pancreatitis: a systematic review and meta-analysis. Ann Surg 2008; 247: 950-961

387 Izbicki JR, Bloechle C, Broering DC et al. Extended drainage versus resection in surgery for chronic pancreatitis: a prospective randomized trial comparing the longitudinal pancreaticojejunostomy combined with local pancreatic head excision with the pylorus-preserving pancreatoduodenectomy. Ann Surg 1998; 228: 771 - 779 
388 Izbicki JR, Bloechle C, Broering DC et al. Longitudinal V-shaped excision of the ventral pancreas for small duct disease in severe chronic pancreatitis: prospective evaluation of a new surgical procedure. Ann Surg 1998; 227: 213 - 219

389 Koninger J, Seiler CM, Sauerland S et al. Duodenum-preserving pancreatic head resection - a randomized controlled trial comparing the original Beger procedure with the Berne modification (ISRCTN No. 50638764). Surgery 2008; 143: $490-498$

390 Muller MW, Friess H, Leitzbach S et al. Perioperative and follow-up results after central pancreatic head resection (Berne technique) in a consecutive series of patients with chronic pancreatitis. Am J Surg 2008; 196: $364-372$

391 Strate T, Bachmann K, Busch P et al. Resection vs drainage in treatment of chronic pancreatitis: long-term results of a randomized trial. Gastroenterology 2008; 134: 1406 - 1411

392 Gloor B, Friess $H$, Uhl W et al. A modified technique of the Beger and Frey procedure in patients with chronic pancreatitis. Dig Surg 2001; 18: $21-25$

393 Buchler MW, Friess H, Muller MW et al. Randomized trial of duodenum-preserving pancreatic head resection versus pylorus-preserving Whipple in chronic pancreatitis. Am J Surg 1995; 169: 65-69; discussion 69-70

394 Strate T, Taherpour Z, Bloechle C et al. Long-term follow-up of a randomized trial comparing the beger and frey procedures for patients suffering from chronic pancreatitis. Ann Surg 2005; 241: 591 - 598

395 Duval MK Jr. Caudal pancreaticojejunostomy for chronic pancreatitis; operative criteria and technique. Surg Clin North Am 1956, Aug.: $831-839$

396 Partington PF. Chronic pancreatitis treated by Roux type jejunal anastomosis to the biliary tract. AMA Arch Surg 1952; 65: $532-542$

397 Jimenez RE, Fernandez-Del Castillo C, Rattner DW et al. Pylorus-preserving pancreaticoduodenectomy in the treatment of chronic pancreatitis. World J Surg 2003; 27: 1211 - 1216

398 Buchler MW, Warshaw AL. Resection versus drainage in treatment of chronic pancreatitis. Gastroenterology 2008; 134: 1605-1607

399 Beger HG, Witte C, Krautzberger $W$ et al. [Experiences with duodenum-sparing pancreas head resection in chronic pancreatitis]. Chirurg 1980; 51: $303-307$

400 Bloechle C, Busch $C$, Tesch $C$ et al. Prospective randomized study of drainage and resection on non-occlusive segmental portal hypertension in chronic pancreatitis. Br J Surg 1997; 84: 477-482

401 Frey CF, Amikura K. Local resection of the head of the pancreas combined with longitudinal pancreaticojejunostomy in the management of patients with chronic pancreatitis. Ann Surg 1994; 220: 492 - 504 discussion 504-497

402 Frey CF, Smith GJ. Description and rationale of a new operation for chronic pancreatitis. Pancreas 1987; 2: 701 - 707

403 Yekebas EF, Bogoevski D, Honarpisheh $H$ et al. Long-term follow-up in small duct chronic pancreatitis: A plea for extended drainage by „Vshaped excision“ of the anterior aspect of the pancreas. Ann Surg 2006; 244: 940 -946; discussion 946-948

404 Bockhorn M, Gebauer F, Bogoevski D et al. Chronic pancreatitis complicated by cavernous transformation of the portal vein: contraindication to surgery? Surgery 2011; 149: $321-328$

405 Shrikhande SV, Kleeff J, Friess $H$ et al. Management of pain in small duct chronic pancreatitis. J Gastrointest Surg 2006; 10: 227-233

406 Whipple AO, Parsons WB, Mullins CR. Treatment of Carcinoma of the Ampulla of Vater. Ann Surg 1935; 102: 763 - 779

407 Yeo CJ, Cameron JL, Sohn TA et al. Pancreaticoduodenectomy with or without extended retroperitoneal lymphadenectomy for periampullary adenocarcinoma: comparison of morbidity and mortality and short-term outcome. Ann Surg 1999; 229: 613-622; discussion 622-614

408 Warshaw AL, Thayer SP. Pancreaticoduodenectomy. J Gastrointest Surg 2004; 8: 733-741

409 Cameron JL, Riall TS, Coleman J et al. One thousand consecutive pancreaticoduodenectomies. Ann Surg 2006; 244: 10-15

410 Beger HG, Kunz R, Poch B. The Beger procedure - duodenum-preserving pancreatic head resection. J Gastrointest Surg 2004; 8: 1090 1097

411 Izbicki JR, Bloechle C, Knoefel WT et al. Duodenum-preserving resection of the head of the pancreas in chronic pancreatitis. A prospective, randomized trial. Ann Surg 1995; 221: 350 - 358

412 Cataldegirmen G, Schneider CG, Bogoevski D et al. Extended central pancreatic resection as an alternative for extended left or extended right resection for appropriate pancreatic neoplasms. Surgery 2010 ; 147: $331-338$

413 Asanuma Y, Koyama K, Saito K et al. An appraisal of segmental pancreatectomy for benign tumors of the pancreatic body: a report of two cases. Surg Today 1993; 23: 733 - 736

414 Christein JD, Kim AW, Golshan MA et al. Central pancreatectomy for the resection of benign or low malignant potential neoplasms. World J Surg 2003; 27: 595-598

415 Iacono C, Bortolasi $L$, Serio $G$. Is there a place for central pancreatectomy in pancreatic surgery? J Gastrointest Surg 1998; 2: 509-516; discussion 516-507

416 Ikeda S, Matsumoto S, Maeshiro K et al. Segmental pancreatectomy for the diagnosis and treatment of small lesions in the neck or body of the pancreas. Hepatogastroenterology 1995; 42: $730-733$

417 Rotman N, Sastre B, Fagniez PL. Medial pancreatectomy for tumors of the neck of the pancreas. Surgery 1993; 113: $532-535$

418 Sperti C, Pasquali C, Ferronato A et al. Median pancreatectomy for tumors of the neck and body of the pancreas. J Am Coll Surg 2000; 190: $711-716$

419 Warshaw AL, Rattner DW, Fernandez-del Castillo $C$ et al. Middle segment pancreatectomy: a novel technique for conserving pancreatic tissue. Arch Surg 1998; 133: 327 - 331

420 Muller MW, Friess $H$, Kleeff J et al. Middle segmental pancreatic resection: An option to treat benign pancreatic body lesions. Ann Surg 2006; 244: 909-918; discussion 918-920

421 Sauvanet A, Partensky C, Sastre B et al. Medial pancreatectomy: a multi-institutional retrospective study of 53 patients by the French Pancreas Club. Surgery 2002; 132: 836-843

422 Partelli S, Boninsegna L, Salvia $R$ et al. Middle-preserving pancreatectomy for multicentric body-sparing lesions of the pancreas. Am J Surg 2009; 198: e49-53

423 Braasch JW, Vito L, Nugent FW. Total pancreatectomy of end-stage chronic pancreatitis. Ann Surg 1978; 188: 317- 322

424 Rossi RL, Rothschild J, Braasch JW et al. Pancreatoduodenectomy in the management of chronic pancreatitis. Arch Surg 1987; 122: 416-420

425 Balcom JHt, Rattner DW, Warshaw AL et al. Ten-year experience with 733 pancreatic resections: changing indications, older patients, and decreasing length of hospitalization. Arch Surg 2001; 136: 391 - 398

426 Buchler MW, Wagner M, Schmied BM et al. Changes in morbidity after pancreatic resection: toward the end of completion pancreatectomy. Arch Surg 2003; 138: 1310-1314; discussion 1315

427 Pratt WB, Maithel SK, Vanounou T et al. Clinical and economic validation of the International Study Group of Pancreatic Fistula (ISGPF) classification scheme. Ann Surg 2007; 245: 443 - 451

428 Reid-Lombardo KM, Farnell MB, Crippa S et al. Pancreatic anastomotic leakage after pancreaticoduodenectomy in 1,507 patients: a report from the Pancreatic Anastomotic Leak Study Group. J Gastrointest Surg 2007; 11: 1451 -1458; discussion 1459

429 Reid-Lombardo KM, Ramos-De la Medina A, Thomsen K et al. Longterm anastomotic complications after pancreaticoduodenectomy for benign diseases. J Gastrointest Surg 2007; 11: 1704-1711

430 Bassi C, Dervenis C, Butturini G et al. Postoperative pancreatic fistula: an international study group (ISGPF) definition. Surgery 2005; 138 $8-13$

431 Welsch T, Borm M, Degrate L et al. Evaluation of the International Study Group of Pancreatic Surgery definition of delayed gastric emptying after pancreatoduodenectomy in a high-volume centre. Br J Surg 2010; 97: 1043 - 1050

432 Welsch T, Frommhold K, Hinz U et al. Persisting elevation of C-reactive protein after pancreatic resections can indicate developing inflammatory complications. Surgery 2008; 143: $20-28$

433 Molinari E, Bassi C, Salvia $R$ et al. Amylase value in drains after pancreatic resection as predictive factor of postoperative pancreatic fistula: results of a prospective study in 137 patients. Ann Surg 2007; 246: $281-287$

434 Seelig $M H$, Chromik AM, Weyhe D et al. Pancreatic redo procedures: to do or not to do - this is the question. J Gastrointest Surg 2007; 11: $1175-1182$

435 Cruciani RA, Jain S. Pancreatic pain: a mini review. Pancreatology 2008; $8: 230-235$

436 Laubenthal H, Becker M, Neugebauer E. [Guideline: „Treatment of acute perioperative and posttraumatic pain“. Updating from the S2- to the S3-level: a preliminary report]. Anasthesiol Intensivmed Notfallmed Schmerzther 2006; 41:470-472 
437 Gueroult S, Parc Y, Duron F et al. Completion pancreatectomy for postoperative peritonitis after pancreaticoduodenectomy: early and late outcome. Arch Surg 2004; 139: 16-19

438 de Castro SM, Busch OR, van Gulik TM et al. Incidence and management of pancreatic leakage after pancreatoduodenectomy. Br J Surg 2005; 92: 1117 - 1123

439 Lowenfels $A B$, Maisonneuve P, Cavallini $G$ et al. Prognosis of chronic pancreatitis: an international multicenter study. International Pancreatitis Study Group. Am J Gastroenterol 1994; 89: 1467 - 1471

440 Lowenfels $A B$, Sullivan T, Fiorianti J et al. The epidemiology and impact of pancreatic diseases in the United States. Curr Gastroenterol Rep 2005; 7: $90-95$

441 Levy P, Milan C, Pignon JP et al. Mortality factors associated with chronic pancreatitis. Unidimensional and multidimensional analysis of a medical-surgical series of 240 patients. Gastroenterology 1989; 96: $1165-1172$

442 Seicean A, Tantau M, Grigorescu M et al. Mortality risk factors in chronic pancreatitis. J Gastrointestin Liver Dis 2006; 15: 21 - 26

443 Gullo L, Parenti M, Monti L et al. Diabetic retinopathy in chronic pancreatitis. Gastroenterology 1990; 98: 1577-1581

444 Billings BJ, Christein JD, Harmsen WS et al. Quality-of-life after total pancreatectomy: is it really that bad on long-term follow-up? J Gastrointest Surg 2005; 9: 1059-1066; discussion 1066-1057

445 Nakamura T, Imamura K, Takebe K et al. Diabetic retinopathy in Japanese patients with long-standing pancreatic diabetes due to calcifying pancreatitis. Tohoku J Exp Med 1994; 174: 49-58

446 Rosa ESL, Troncon LE, Gallo L Jr et al. Factors associated with abnormal gastric emptying in alcohol-related chronic pancreatitis. J Clin Gastroenterol 2007; 41: 306-311

447 Tiengo A, Segato T, Briani G et al. The presence of retinopathy in patients with secondary diabetes following pancreatectomy or chronic pancreatitis. Diabetes Care 1983; 6: 570-574

448 Malka $D$, Levy $P$, Bernades $P$. Thrombotic thrombocytopenic purpura caused by acute pancreatitis in a woman with a pancreas divisum: a case report. Pancreas 1996; 12: 414-416

449 Parsaik AK, Murad MH, Sathananthan A et al. Metabolic and target organ outcomes after total pancreatectomy: Mayo Clinic experience and meta-analysis of the literature. Clin Endocrinol (Oxf) 73: 723-731

450 Moran CE, Sosa EG, Martinez SM et al. Bone mineral density in patients with pancreatic insufficiency and steatorrhea. Am J Gastroenterol 1997; $92: 867-871$

451 Teichmann J, Mann ST, Stracke H et al. Alterations of vitamin D3 metabolism in young women with various grades of chronic pancreatitis. Eur J Med Res 2007; 12: 347 - 350

452 Lowenfels $A B$. Chronic pancreatitis, pancreatic cancer, alcohol, and smoking. Gastroenterology 1984; 87: 744-745

453 Ammann RW, Heitz PU, Kloppel G. The „two-hit“ pathogenetic concept of chronic pancreatitis. Int J Pancreatol 1999; 25: 251

454 Talamini G, Bassi C, Falconi $M$ et al. Early detection of pancreatic cancer following the diagnosis of chronic pancreatitis. Digestion 1999; 60: $554-561$

455 Mohan V, Premalatha G, Padma A et al. Fibrocalculous pancreatic diabetes. Long-term survival analysis. Diabetes Care 1996; 19: 1274 1278

456 Rosch T, Schusdziarra V, Born P et al. Modern imaging methods versus clinical assessment in the evaluation of hospital in-patients with suspected pancreatic disease. Am J Gastroenterol 2000; 95: 2261 - 2270

457 Adler G, Seufferlein T, Bischoff SC et al. [S3-Guidelines „Exocrine pancreatic cancer“ 2007]. Z Gastroenterol 2007; 45: 487-523

458 Tuyns AJ, Pequignot G, Jensen OM. [Esophageal cancer in Ille-et-Vilaine in relation to levels of alcohol and tobacco consumption. Risks are multiplying]. Bull Cancer 1977; 64: 45-60

459 Salaspuro MP. Alcohol consumption and cancer of the gastrointestinal tract. Best Pract Res Clin Gastroenterol 2003; 17: 679-694

460 Menge BA, Schrader H, Breuer TG et al. Metabolic consequences of a 50\% partial pancreatectomy in humans. Diabetologia 2009; 52: 306-317

461 Ozturk E, Can MF, Yagci G et al. Management and mid- to long-term results of early referred bile duct injuries during laparoscopic cholecystectomy. Hepatogastroenterology 2009; 56: 17 - 25
462 Muller MW, Friess H, Kleeff J et al. Is there still a role for total pancreatectomy? Ann Surg 2007; 246: 966 - 974; discussion 974-965

463 Linehan IP, Lambert MA, Brown DC et al. Total pancreatectomy for chronic pancreatitis. Gut 1988; 29: $358-365$

464 Cooperman AM, Herter FP, Marboe CA et al. Pancreatoduodenal resection and total pnacreatectomy - an institutional review. Surgery 1981; 90: 707-712

465 Benifla $M$, Weizman $Z$. Acute pancreatitis in childhood: analysis of literature data. J Clin Gastroenterol 2003; 37: 169-172

466 Tomomasa T, Tabata M, Miyashita $M$ et al. Acute pancreatitis in Japanese and Western children: etiologic comparisons. J Pediatr Gastroenterol Nutr 1994; 19: 109-110

467 Darge K, Anupindi S. Pancreatitis and the role of US, MRCP and ERCP. Pediatr Radiol 2009; 39 (Suppl 2): S153-157

468 Varadarajulu S, Tamhane A, Eloubeidi MA. Yield of EUS-guided FNA of pancreatic masses in the presence or the absence of chronic pancreatitis. Gastrointest Endosc 2005; 62: 728 - 736; quiz 751, 753

469 Varadarajulu S, Wilcox CM, Eloubeidi MA. Impact of EUS in the evaluation of pancreaticobiliary disorders in children. Gastrointest Endosc 2005; 62: $239-244$

470 Attila T, Adler DG, Hilden K et al. EUS in pediatric patients. Gastrointest Endosc 2009; 70: 892-898

471 Manfredi R, Lucidi V, Gui B et al. Idiopathic chronic pancreatitis in children: MR cholangiopancreatography after secretin administration. Radiology 2002; 224: 675 - 682

472 Hsu RK, Draganov P, Leung JW et al. Therapeutic ERCP in the management of pancreatitis in children. Gastrointest Endosc 2000; 51: 396 400

473 Siegel MJ, Martin KW, Worthington JL. Normal and abnormal pancreas in children: US studies. Radiology 1987; 165: 15-18

474 Kugathasan S, Halabi I, Telega G et al. Pancreatitis as a presenting manifestation of pediatric Crohn's disease: a report of three cases. J Pediatr Gastroenterol Nutr 2002; 35: 96-98

475 Ludvigsson JF, Montgomery SM, Ekbom A. Risk of pancreatitis in 14,000 individuals with celiac disease. Clin Gastroenterol Hepatol 2007; 5 : $1347-1353$

476 Witt H, Kage A, Luck W et al. Alpha1-antitrypsin genotypes in patients with chronic pancreatitis. Scand J Gastroenterol 2002; 37: 356-359

477 Gerstner T, Bell N, Konig S. Oral valproic acid for epilepsy - long-term experience in therapy and side effects. Expert Opin Pharmacother 2008; 9: 285 - 292

$478 \mathrm{Earl} M$. Incidence and management of asparaginase-associated adverse events in patients with acute lymphoblastic leukemia. Clin Adv $\mathrm{He}-$ matol Oncol 2009; 7: 600-606

479 Noone PG, Zhou Z, Silverman LM et al. Cystic fibrosis gene mutations and pancreatitis risk: relation to epithelial ion transport and trypsin inhibitor gene mutations. Gastroenterology 2001; 121: 1310-1319

480 Audrezet MP, Chen JM, Le Marechal C et al. Determination of the relative contribution of three genes-the cystic fibrosis transmembrane conductance regulator gene, the cationic trypsinogen gene, and the pancreatic secretory trypsin inhibitor gene-to the etiology of idiopathic chronic pancreatitis. Eur J Hum Genet 2002; 10: 100-106

481 Iqbal CW, Baron TH, Moir CR et al. Post-ERCP pancreatitis in pediatric patients. J Pediatr Gastroenterol Nutr 2009; 49: 430 - 434

482 Griese M, Dokupil K, Latzin P. Skin prick test reactivity to supplemental enzymes in cystic fibrosis and pancreatic insufficiency. J Pediatr Gastroenterol Nutr 2005; 40: $194-198$

483 Stallings VA, Stark LJ, Robinson KA et al. Evidence-based practice recommendations for nutrition-related management of children and adults with cystic fibrosis and pancreatic insufficiency: results of a systematic review. J Am Diet Assoc 2008; 108: 832 -839

484 Graff GR, Maguiness K, McNamara J et al. Efficacy and tolerability of a new formulation of pancrelipase delayed-release capsules in children aged 7 to 11 years with exocrine pancreatic insufficiency and cystic fibrosis: a multicenter, randomized, double-blind, placebo-controlled, two-period crossover, superiority study. Clin Ther 2010; 32: 89-103

485 DiMagno EP. Gastric acid suppression and treatment of severe exocrine pancreatic insufficiency. Best Pract Res Clin Gastroenterol 2001; 15: $477-486$ 